In cooperation with the University of Wisconsin-Madison Discovery Farms program and the University of Wisconsin-Platteville Pioneer Farm program

Methods of Data Collection, Sample Processing, and Data Analysis for Edge-of-Field, Streamgaging, Subsurface-Tile, and Meteorological Stations at Discovery Farms and Pioneer Farm in Wisconsin, 2001-7
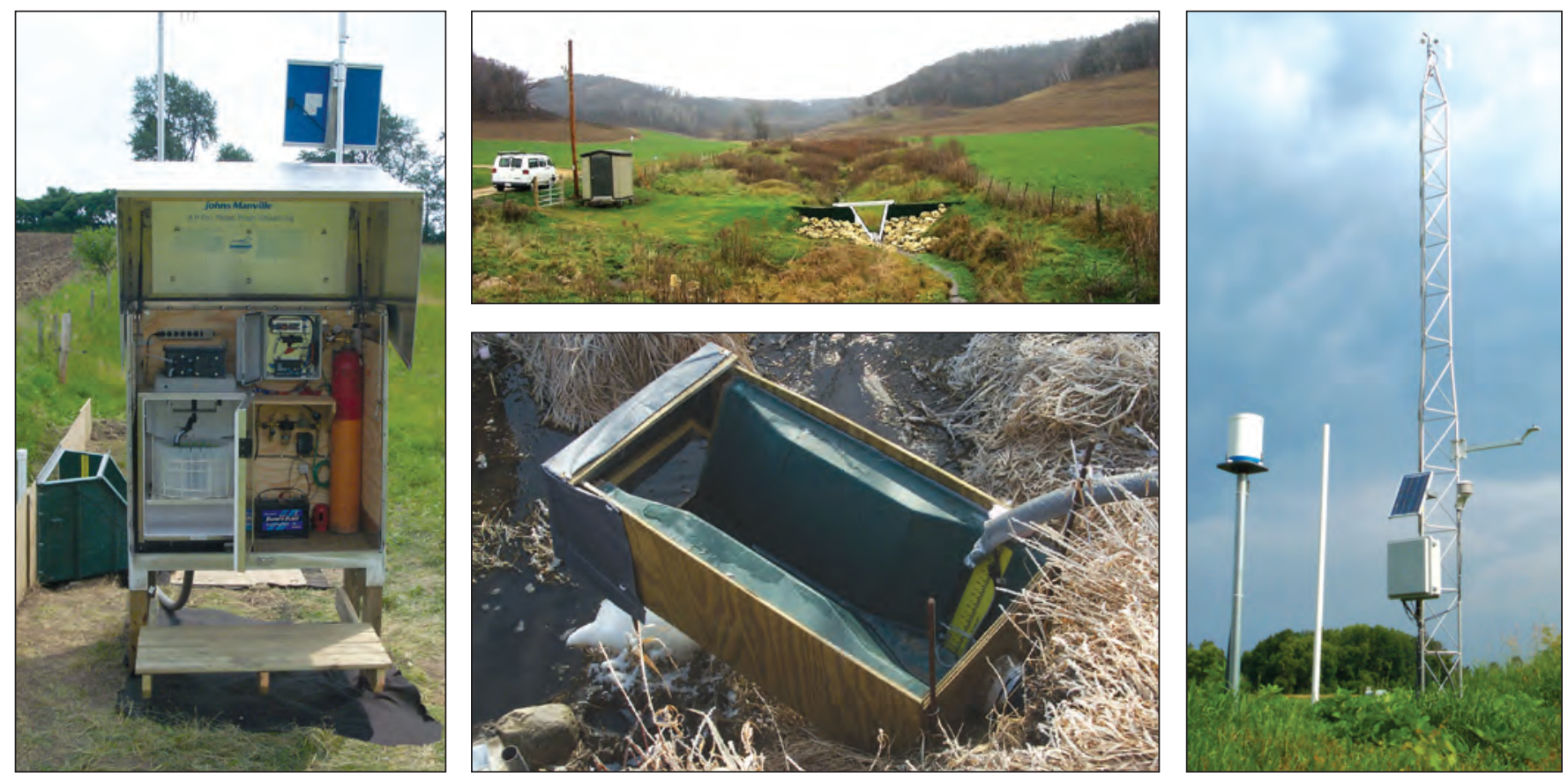

Open-File Report 2008-1015

U.S. Department of the Interior

U.S. Geological Survey 



\section{Methods of Data Collection, Sample Processing, and Data Analysis for Edge-of-Field, Streamgaging, Subsurface-Tile, and Meteorological Stations at Discovery Farms and Pioneer Farm in Wisconsin, 2001-7}

By Todd D. Stuntebeck, Matthew J. Komiskey, David W. Owens, and David W. Hall

In cooperation with the University of Wisconsin-Madison Discovery Farms

program and the University of Wisconsin-Platteville Pioneer Farm program

Open-File Report 2008-1015 


\section{U.S. Department of the Interior DIRK KEMPTHORNE, Secretary}

\section{U.S. Geological Survey \\ Mark D. Myers, Director}

\section{U.S. Geological Survey, Reston, Virginia: 2008}

For product and ordering information:

World Wide Web: http://www.usgs.gov/pubprod

Telephone: 1-888-ASK-USGS

For more information on the USGS — the Federal source for science about the Earth, its natural and living resources, natural hazards, and the environment:

World Wide Web: http://www.usgs.gov

Telephone: 1-888-ASK-USGS

Any use of trade, product, or firm names is for descriptive purposes only and does not imply endorsement by the U.S. Government.

Although this report is in the public domain, permission must be secured from the individual copyright owners to reproduce any copyrighted materials contained within this report.

Suggested citation:

Stuntebeck, T.D., Komiskey, M.J., Owens, D.W., and Hall, D.W., 2008, Methods of data collection, sample processing, and data analysis for edge-of-field, streamgaging, subsurface-tile, and meteorological stations at Discovery Farms and Pioneer Farm in Wisconsin, 2001-7: U.S. Geological Survey Open-File Report 2008-1015, $51 \mathrm{p}$.

Cover photos (clockwise from left): edge-of-field station, streamgaging station, meteorological station, and subsurface-tile station. 


\section{Contents}

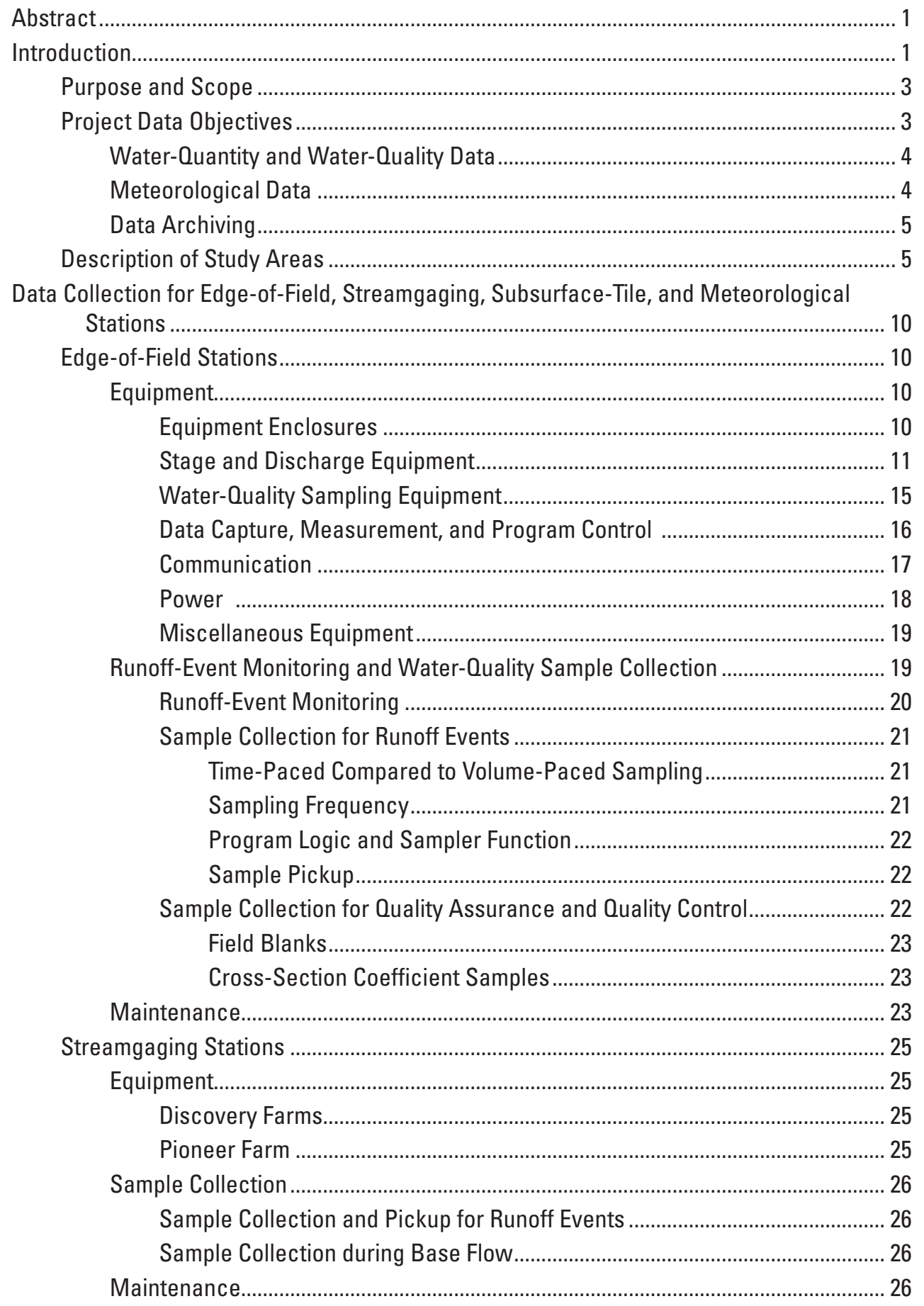




\section{Contents (cont.)}

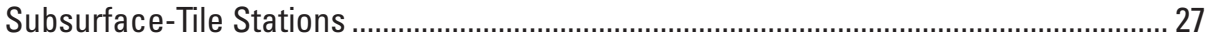

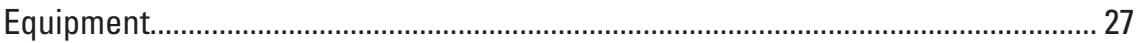

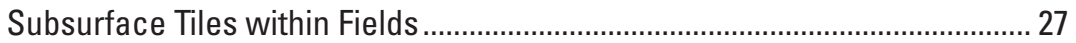

Subsurface Tiles at Outlets ........................................................................... 28

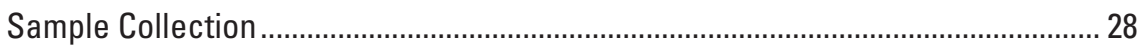

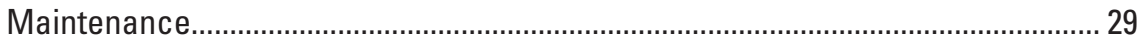

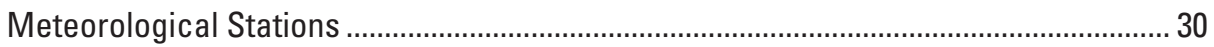

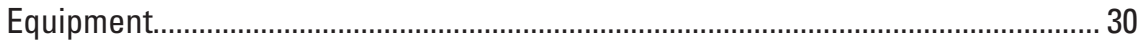

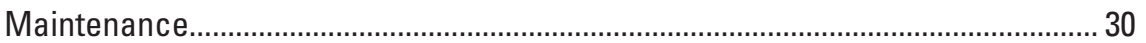

Sample Processing for Edge-of-Field, Streamgaging, and Subsurface-Tile Stations ............ 32

Sample Processing for Samples Sent to the Water and Environmental Analysis

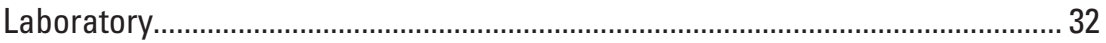

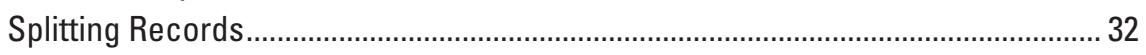

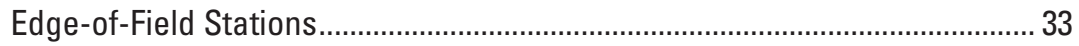

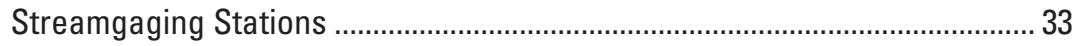

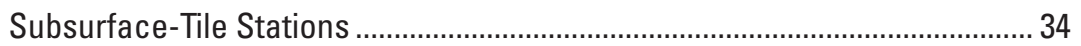

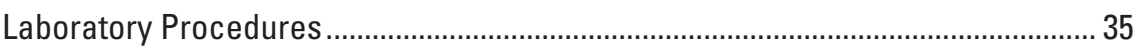

Splitting Procedures.............................................................................. 35

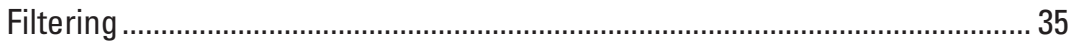

Sample Processing for Samples Sent to the Wisconsin State Laboratory of Hygiene . 36

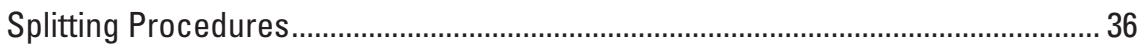

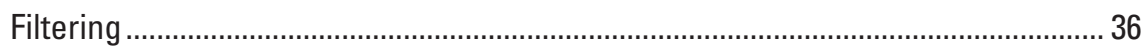

Laboratory Quality Assurance and Quality Control...................................................... 37

Data Analysis for Edge-of-Field, Streamgaging, Subsurface-Tile, and Meteorological

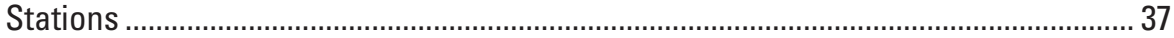

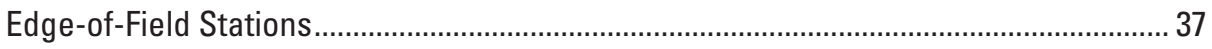

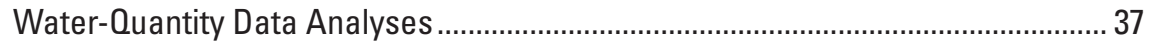

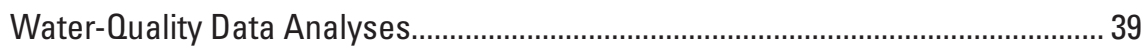

Estimating Constituent Concentrations for Unsampled Runoff Events.................... 39

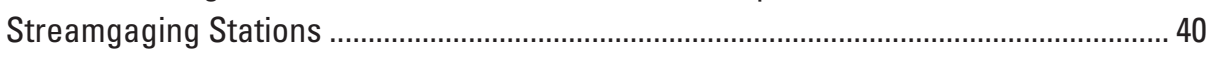

Water-Quantity Data Analyses ............................................................................. 40

Water-Quality Data Analyses.................................................................................. 40

Estimating Constituent Concentrations for Significant Unsampled

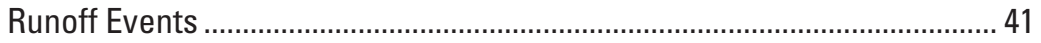

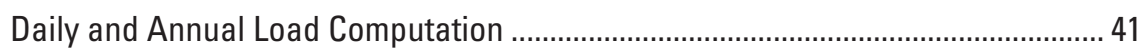

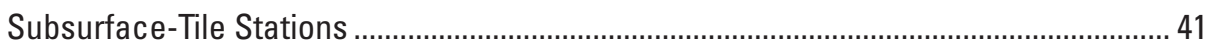

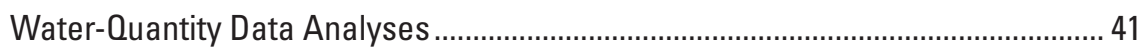

Water-Quality Data Analyses................................................................................. 42

Estimating Constituent Concentrations for Significant Unsampled

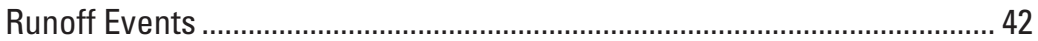

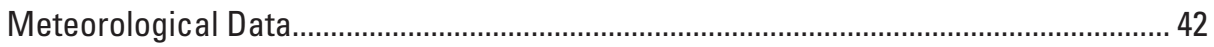

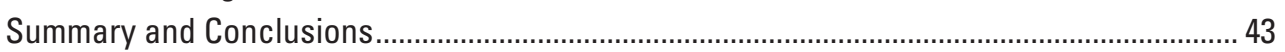

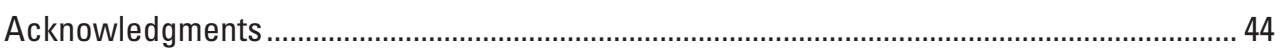

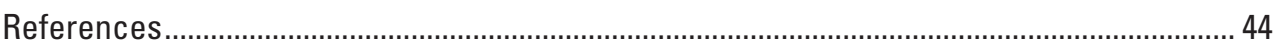

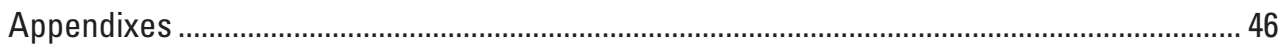




\section{Figures}

1. Screen capture showing an example of data that can be viewed on NWISWeb, the U.S. Geological Survey National Water Information System public web interface ..................................................................................... 5

2. Map showing the locations of farms in the Discovery Farms and Pioneer Farm programs in Wisconsin

3-10. Photographs showing:

3. A typical station for the Discovery Farms and Pioneer Farm programs, including an aluminum, clam-style enclosure to protect weather-sensitive instrumentation.

4. Staff gage, bubble tubing, sample-intake line, and heat tape of an $\mathrm{H}$ flume (2.5 feet in height) used to measure discharge

5. Plywood wingwalls used at most edge-of-field stations to provide a flumemounting surface and to direct all surface-water runoff through the flume ... 12

6. Concrete wingwalls used at edge-of-field stations where soils were typically saturated most of the year

7. Measurements of the cork line on the crest-stage gages made after a surface-water runoff event.

8. Ice removed from $\mathrm{H}$ flumes before runoff events 15

9. Automated, refrigerated samplers were used to collect samples of runoff water

10. A Campbell Scientific, Inc., CR10X datalogger, an RF400 spreadspectrum radio/modem, and a battery typically used for all edge-offield, streamgaging, subsurface-tile, and meteorological stations.

11. Screen capture showing Campbell Scientific, Inc., PC208W datalogger communication software used to communicate with stations

12-13. Photographs showing:

12. Remote-start generators used to provide AC power at some stations 18

13. Streamgaging station with power provided by solar panels for sample refrigeration and wintertime deicing

14. Screen capture showing Real Time Data Monitoring Software data display which allowed rapid assessment of many datalogger variables over time ..... 20

15-22. Photographs showing:

15. Snow cleared downstream from the flume to prevent backwater conditions ... 24

16. Sheet piling and earthen berms used as wingwalls for the streamgaging stations at Discovery Farms

17. U.S. Geological Survey field technician making a discharge measurement at a streamgaging station at Pioneer Farm

18. A 5-foot-diameter culvert installed to allow access to in-field subsurface tiles.

19. Extra-large,60-degree, v-throat, trapezoidal flumes installed inline with subsurface tiles within fields to compute discharge.

20. Extra-large, 60-degree, v-throat, trapezoidal flumes used to compute discharge at the outlets of subsurface tiles

21. Meteorological station equipment typically measured precipitation, wind speed and direction, air and soil temperature, relative humidity, solar radiation, and soil moisture

22. Soil-temperature probes ready for installation. 


\section{Figures (cont.)}

23. Screen capture showing an example of a splitting record summary showing which samples to combine and the proper aliquot sizes to create a discharge-weighted composite sample.

24. Graph showing an example hydrograph showing the method used for determining the start and end of a runoff event at a streamgaging station.

25-26. Photographs showing:

25. A set of water-quality sample bottles prior to compositing

26. Churn splitters and Wisconsin State Laboratory of Hygiene sample bottles used for preparing samples from the Buffalo County

Discovery Farm .

27-28. Graphs showing:

27. An example of corrections made to discharge data using HYDRA during periods that ice formed in the flume during a runoff event.

28. An example of corrections made to discharge data due to surcharge conditions in a subsurface tile. 


\section{Tables}

1. Data type and collection frequency for Discovery Farms and Pioneer Farm............ 3

2. Constituent and physical-property analysis list for Discovery Farms and Pioneer Farm

3. Edge-of-field, streamgaging, subsurface-tile, and meteorological stations

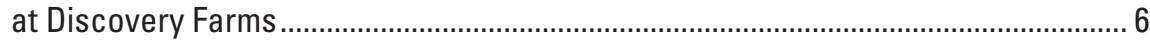

4. Edge-of-field, streamgaging, subsurface-tile, and meteorological stations

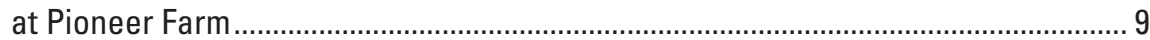

5. Equipment used for collection of water-quantity, hydrologic, and water-

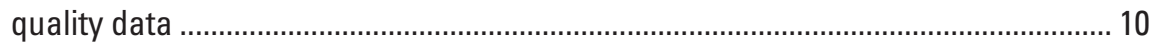

6. Equipment used for collection of meteorological data .......................................... 30

\section{Appendixes}

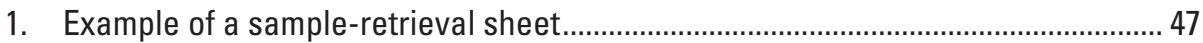

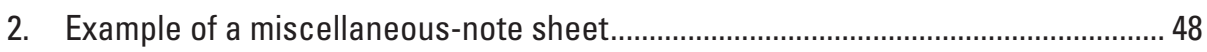

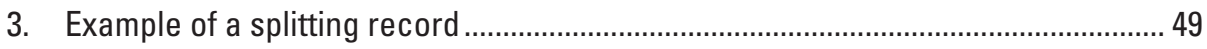

4. Example portion of a data-summary spreadsheet..................................................... 50 


\section{Conversion Factors and Abbreviated Units of Measurement}

\begin{tabular}{lcl}
\hline \multicolumn{1}{c}{ Multiply } & By & \multicolumn{1}{c}{ To obtain } \\
\hline inch (in.) & Length & \\
centimeter $(\mathrm{cm})$ & 2.54 & centimeter $(\mathrm{cm})$ \\
millimeter $(\mathrm{mm})$ & 0.3937 & inch $($ in. $)$ \\
micrometer $(\mu \mathrm{m})$ & 0.03937 & inch $(\mathrm{in})$. \\
foot $(\mathrm{ft})$ & 0.001 & millimeter $(\mathrm{mm})$ \\
mile $(\mathrm{mi})$ & 0.3048 & meter $(\mathrm{m})$ \\
\hline & 1.609 & kilometer $(\mathrm{km})$ \\
\hline acre & Area & \\
acre & 4,047 & square meter $\left(\mathrm{m}^{2}\right)$ \\
acre & 0.4047 & hectare $($ ha) \\
square mile $\left(\mathrm{mi}^{2}\right)$ & 0.004047 & square kilometer $\left(\mathrm{km}^{2}\right)$ \\
square mile $\left(\mathrm{mi}^{2}\right)$ & 259.0 & hectare $(\mathrm{ha})$ \\
\hline & 2.590 & square kilometer $\left(\mathrm{km}^{2}\right)$ \\
\hline gallon $(\mathrm{gal})$ & Volume & \\
\hline & 3.785 & liter $(\mathrm{L})$ \\
\hline liter $(\mathrm{L})$ & Flow rate & \\
cubic foot per second $\left(\mathrm{ft}{ }^{3} / \mathrm{s}\right)$ & 0.2642 & gallon $(\mathrm{gal})$ \\
\hline & 0.02832 & cubic meter per second $\left(\mathrm{m}^{3} / \mathrm{s}\right)$ \\
\hline pounds per acre per year & Application rate & \\
\hline & & \\
\hline
\end{tabular}

Temperature in degrees Celsius $\left({ }^{\circ} \mathrm{C}\right)$ may be converted to degrees Fahrenheit $\left({ }^{\circ} \mathrm{F}\right)$ as follows:

${ }^{\circ} \mathrm{F}=\left(1.8 x^{\circ} \mathrm{C}\right)+32$ 


\title{
Methods of Data Collection, Sample Processing, and Data Analysis for Edge-of-Field, Streamgaging, Subsurface-Tile, and Meteorological Stations at Discovery Farms and Pioneer Farm in Wisconsin, 2001-7
}

\author{
By Todd D. Stuntebeck, Matthew J. Komiskey, David W. Owens, and David W. Hall
}

\begin{abstract}
The University of Wisconsin (UW)-Madison Discovery Farms (Discovery Farms) and UW-Platteville Pioneer Farm (Pioneer Farm) programs were created in 2000 to help Wisconsin farmers meet environmental and economic challenges. As a partner with each program, and in cooperation with the Wisconsin Department of Natural Resources and the Sand County Foundation, the U.S. Geological Survey (USGS) Wisconsin Water Science Center (WWSC) installed, maintained, and operated equipment to collect water-quantity and water-quality data from 25 edge-offield, 6 streamgaging, and 5 subsurface-tile stations at 7 Discovery Farms and Pioneer Farm. The farms are located in the southern half of Wisconsin and represent a variety of landscape settings and crop- and animal-production enterprises common to Wisconsin agriculture. Meteorological stations were established at most farms to measure precipitation, wind speed and direction, air and soil temperature (in profile), relative humidity, solar radiation, and soil moisture (in profile). Data collection began in September 2001 and is continuing through the present (2008).

This report describes methods used by USGS WWSC personnel to collect, process, and analyze water-quantity, water-quality, and meteorological data for edge-of-field, streamgaging, subsurface-tile, and meteorological stations at Discovery Farms and Pioneer Farm from September 2001 through October 2007. Information presented includes equipment used; event-monitoring and samplecollection procedures; station maintenance; sample handling and processing procedures; water-quantity, water-
\end{abstract}

quality, and precipitation data analyses; and procedures for determining estimated constituent concentrations for unsampled runoff events.

\section{Introduction}

The Wisconsin Agricultural Stewardship Initiative (WASI) was introduced by then Governor Tommy Thompson in May 2000 (Wisconsin Legislative Fiscal Bureau, 2001) to help Wisconsin farmers meet environmental and economic challenges. This legislation established the University of Wisconsin (UW)-Madison Discovery Farms program (Discovery Farms), the UW-Platteville Pioneer Farm program (Pioneer Farm), and the UW Component Research program. The Discovery Farms program (http:/7 www.uwdiscoveryfarms.org, last accessed February 8, 2008) was developed to conduct environmental systems research on privately owned farms across the state, representing a variety of farming enterprises and management systems, to demonstrate the adaptability and practicality of agricultural management practices in diverse landscape settings. The Pioneer Farm program (http://www. uwplatt. edu/pioneerfarm, last accessed February 8, 2008) was developed to conduct environmental systems research in a controlled setting on Pioneer Farm to test the adoptability and financial ramifications of a set of agricultural practices and technologies that may be impractical, both financially and environmentally, to implement on privately owned production farms. The UW Component Research program used existing UW Agricultural Research Stations 
and UW System Laboratories to develop knowledge and test the feasibility of new agricultural practices in highly controlled research settings.

U.S. Geological Survey (USGS) Wisconsin Water Science Center (WWSC) personnel worked cooperatively with the Discovery Farms and Pioneer Farm programs and with the Wisconsin Department of Natural Resources and Sand County Foundation to collect water-quantity and water-quality data from 25 edge-of-field, 6 streamgaging, and 5 subsurface-tile stations at 7 Discovery Farms and Pioneer Farm. The farms are located in the southern half of Wisconsin (fig. 2) and represent a variety of landscape settings and crop- and animal-production enterprises common to Wisconsin agriculture. Meteorological stations were established at most farms to measure precipitation, wind speed and direction, air and soil temperature (in profile), relative humidity, solar radiation and soil moisture (in profile). Data collection began in September 2001 and is continuing through the present (2008). Objectives of the study included (1) quantifying annual and event-by-event runoff volumes and losses of sediment, nutrients, and other selected constituents; (2) collecting meteorological data to help establish cause-and-effect relations between agricultural practices and water quantity and quality; (3) ensuring that selected data were accurate and published in USGS annual data reports; and (4) ensuring that all data were archived in USGS databases.

Many historical agricultural monitoring efforts have primarily focused on the major crop-growing season from spring through fall (generally April through October in Wisconsin). An incomplete record of water-quantity and water-quality data during the winter months (November through March) was acceptable given the difficulties and costs associated with monitoring during winter. Although collecting data from spring through fall was important for the Discovery Farms and Pioneer Farm programs, it was critical that monitoring take place year-round so that water, sediment, and nutrient losses from agricultural settings could be fully characterized. In recent years, the number and severity of winter fish kills have markedly increased, and incidents of well contamination associated with runoff from the winter spreading of animal manure on frozen ground have underscored the importance of collecting accurate data during winter http://dnr.wi.gov/org/water wm/watersummary/305b_2006/agriculturalrunoff.htm, last accessed February 8, 2008).
Wisconsin receives an average of 30-34 inches of precipitation annually. The average annual snowfall ranges from about 30 inches in southern Wisconsin to more than 160 inches in northern Wisconsin (Moran and Hopkins, 2002). Subfreezing and alternating freeze-thaw conditions can extend from November into early April. Snow, subfreezing temperatures, and repeated freeze-thaw cycles often cause problems with equipment used to collect water-quantity and water-quality data. Common problems include clogging of flumes with snow and ice, freezing of sampling equipment and sampling lines, and periods of runoff that vary greatly with weather conditions. These problems have the potential to impair equipment functionality and to overwhelm anticipated personnel commitment by monitoring networks, resulting in numerous periods with missing or incomplete records.

In response to the need for accurate data collection during winter conditions in agricultural settings, equipment was selected and systematic procedures used or developed by the USGS WWSC that provided high-quality, waterquantity and water-quality data during the full range of annual weather conditions. Advances in wireless telecommunication, software applications, and other technologies enabled researchers to exert substantially more control over equipment function, such as real-time adjustments to sample-collection frequency made from remote locations, than previously possible. As a result of this continual evolution and refinement of techniques, some of the methods currently used for data collection, sample processing, and data analysis used by USGS WWSC personnel to monitor the hydrology and water quality of farmland runoff have not previously been documented. 


\section{Purpose and Scope}

This report describes methods used by USGS WWSC personnel to collect, process, and analyze water-quantity, water-quality, and meteorological data for edge-of-field, streamgaging, subsurface-tile, and meteorological stations at Discovery Farms and Pioneer Farm from September 2001 through October 2007. Information presented in this report includes equipment used; event-monitoring and sample-collection procedures; station maintenance; sample handling and processing procedures; water-quantity, waterquality, and precipitation data analyses; and procedures for determining estimated constituent concentrations for unsampled runoff events.

\section{Project Data Objectives}

A principal objective of the Discovery Farms and Pioneer Farm programs was to develop an understanding of the effect of agriculture on the quantity and quality of runoff water from monitored farms, including edges of fields, streams, and subsurface tiles. To meet this principal program objective, objectives of this study included (1) quantifying annual and event-by-event runoff volumes and losses of sediment, nutrients, and other selected constituents; (2) collecting meteorological data to help establish cause-and-effect relations between agricultural practices and water quantity and quality; (3) ensuring that selected data were accurate and published in USGS annual data reports; and (4) ensuring that all data were archived in USGS databases. Data were collected at frequencies (table 1) designed to meet project objectives.

Table 1. Data type and collection frequency for Discovery Farms and Pioneer Farm.

[--, not published; USGS, U.S. Geological Survey]

\begin{tabular}{|c|c|c|}
\hline Data type & Data-collection frequency & $\begin{array}{c}\text { Published in } \\
\text { USGS annual Water-Data Report }{ }^{1,2}\end{array}$ \\
\hline Water quantity & $\begin{array}{l}\text { Every } 1 \text { or } 5 \text { minutes during runoff events; } \\
\text { every } 15 \text { or } 60 \text { minutes otherwise }\end{array}$ & $\begin{array}{l}\text { Runoff-event total, daily mean discharge, } \\
\text { daily sum discharge }\end{array}$ \\
\hline Water quality & $\begin{array}{l}\text { Variable during runoff events, monthly for base flow } \\
\text { ( } 2 \text { weeks for Pioneer Farm base flow) }\end{array}$ & Constituent concentrations \\
\hline Precipitation & 1 minute & Daily sum \\
\hline Wind speed & 15 minutes & -- \\
\hline Wind direction & 15 minutes & -- \\
\hline Solar radiation & 15 minutes & -- \\
\hline Air temperature & 15 minutes & -- \\
\hline Relative humidity & 15 minutes & -- \\
\hline Soil temperature & 15 minutes & -- \\
\hline Soil moisture & 15 minutes & -- \\
\hline
\end{tabular}




\section{Water-Quantity and Water-Quality Data}

Water-quantity and water-quality data were collected so that flow (discharge) data could be combined with water-quality data to calculate loads (methods described in Porterfield (1972)), yields, and trends, which could subsequently be related to agricultural practices. Discharge data were measured continuously at all edge-of-field, streamgaging, and subsurface-tile stations. Measurement of discharge followed USGS standard procedures (Garn, 2002). Water-quality data were determined by laboratory analyses of water samples collected from edge-of-field, subsurface-tile, and streamgaging stations for the constituents and physical properties listed in table 2 .

\section{Meteorological Data}

Precipitation and other meteorological data were collected so they could potentially be related to changes in water quantity, water quality, and farm-management practices. Precipitation gages were used to provide estimates of unfrozen precipitation at each farm. Additional meteorological measurements included wind speed, wind direction, air temperature, relative humidity, solar radiation, soil temperatures (at 2, 5, 10, 20, 40, and 80 centimeters depth), and soil moisture (30-centimeter average and/or at $10,20,30$, and 50 centimeters depth).

Table 2. Constituent and physical-property analysis list for Discovery Farms and Pioneer Farm.

\begin{tabular}{|c|c|c|c|c|}
\hline Constituent & $\begin{array}{c}\text { Discovery Farms } \\
\text { (Nov. 2003-Jan. 2005) }\end{array}$ & $\begin{array}{c}\text { Discovery Farms } \\
\text { (Jan. } 2005 \text { to current) }\end{array}$ & $\begin{array}{c}\text { Buffalo County } \\
\text { Discovery Farm } \\
\text { (Sept. } 2001 \text { to current) }\end{array}$ & $\begin{array}{c}\text { Pioneer Farm } \\
\text { (May } 2003 \text { to current) }\end{array}$ \\
\hline Total solids & $\mathrm{X}$ & & $\mathrm{X}$ & $\mathrm{X}$ \\
\hline Total suspended solids & $\mathrm{X}$ & & $\mathrm{X}$ & $\mathrm{X}$ \\
\hline Suspended sediment & $\mathrm{X}$ & $\mathrm{X}$ & $\mathrm{X}$ & $\mathrm{X}$ \\
\hline Total volatile suspended solids & $\mathrm{X}$ & & $X$ & $\mathrm{X}$ \\
\hline Chloride & $\mathrm{X}$ & $\mathrm{X}$ & $\mathrm{X}$ & $\mathrm{X}$ \\
\hline Nitrate plus nitrite-N & $X$ & $\mathrm{X}$ & $X$ & $X$ \\
\hline Ammonium-N & $X$ & $\mathrm{X}$ & $X$ & $\mathrm{X}$ \\
\hline Total Kjeldahl nitrogen (filtered) & $X$ & & $\mathrm{X}$ & $X$ \\
\hline Total Kjeldahl nitrogen (unfiltered) & $\mathrm{X}$ & $\mathrm{X}$ & $X$ & $X$ \\
\hline Dissolved reactive phosphorus & $X$ & $\mathrm{X}$ & & $X$ \\
\hline Total dissolved phosphorus & $X$ & & $\mathrm{X}$ & $\mathrm{X}$ \\
\hline Total phosphorus & $X$ & $\mathrm{X}$ & $\mathrm{X}$ & $X$ \\
\hline Total dissolved solids & & $\mathrm{X}$ & & \\
\hline $\mathrm{pH}$ & & & $\mathrm{X}$ & \\
\hline Alkalinity & & & $\mathrm{X}$ & \\
\hline Specific conductance & & & $\mathrm{X}$ & \\
\hline
\end{tabular}




\section{Data Archiving}

Project data were archived according to the USGS WWSC policies for data archiving (U.S. Geological Survey, 2000). Water-quantity and meteorological data were entered into the USGS National Water Information System (NWIS) (Mathey, 1998) database according to USGS procedures (Garn, 2002). Water-quality data were entered into the USGS QWDATA system, the water-quality component of the USGS NWIS system (U.S. Geological Survey, 2006a). Once in the database, selected parameters are available for use on NWISWeb, the USGS public web interface (http://water.usgs.gov/nwis) (U.S. Geological Survey, 2002). NWISWeb output options include graphs of real-time discharge, water levels, and water quality; tabular output in HTML and ASCII tab-delimited files; and summary lists for selected stations. An example of a graphical display of discharge is shown in figure 1 .

Surface-water documents and records were handled as specified in the WWSC Surface-Water Quality-Assurance Plan (Garn, 2002). Station visits were recorded on

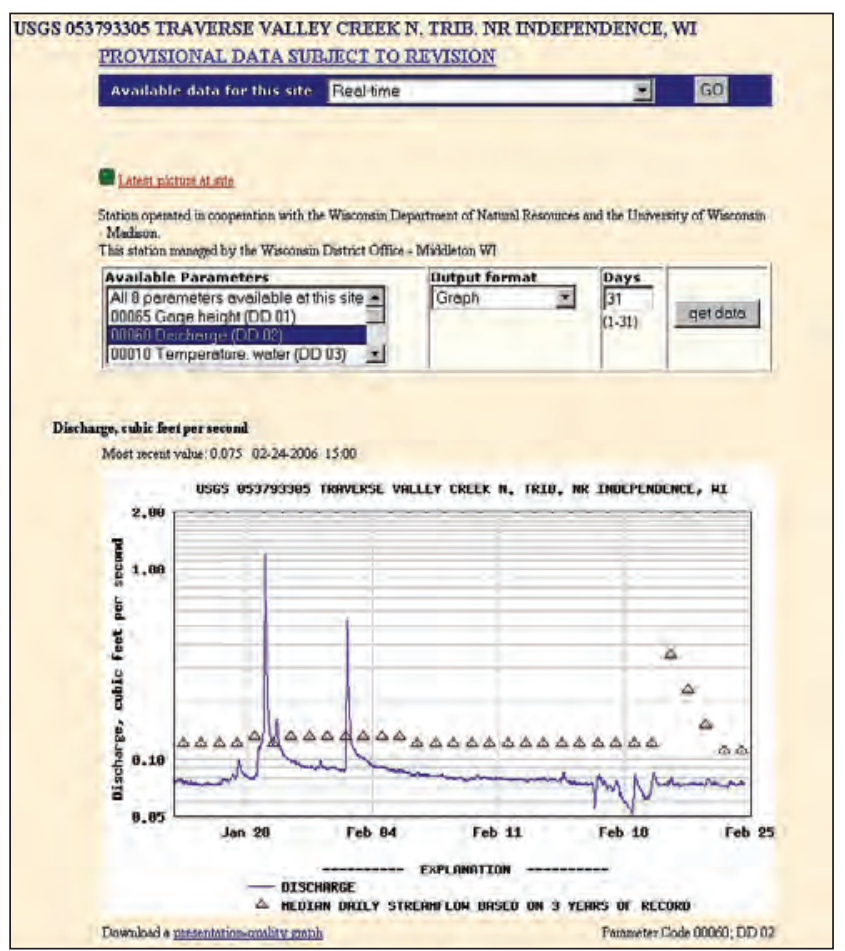

Figure 1. Example of data that can be viewed on NWISWeb, the U.S. Geological Survey National Water Information System (NWIS) public web interface (http://waterdata.usgs.gov/wit nwis). Data shown are for the USGS streamgaging station on the north tributary of Traverse Valley Creek near Independence, Wisconsin, for January 24 through February 24, 2006. field forms and/or on sample retrieval sheets. At the time of establishment of a station, and whenever changes at the station warranted, photos were taken.

\section{Description of Study Areas}

The seven farms in the Discovery Farms program were selected to include a variety of the different topography, soil types, and geology found in Wisconsin landscapes. The farms were also selected to represent a major portion of the diverse crop- and animal-production enterprises and management styles common to Wisconsin agriculture. A detailed description of the landscapes, production enterprises, and management styles for each farm is outside the scope of this report; however, the methods described are applicable to a wide range of landscape settings and farm types. An informational brochure describing each of the farms can be found on the Discovery Farms website (http://www.uwdiscoveryfarms.org/, last accessed February 8,2008$)$. Water-quantity, water-quality, and meteorological data were collected at 12 edge-of-field stations, 4 streamgaging stations, 5 subsurface-tile stations, 6 meteorological stations, and 2 precipitation-gage-only stations (fig. 2; table 3).

Water-quantity, water-quality, and meteorological data were collected on Pioneer Farm in southwest Wiscon$\sin$ (fig. 2; table 4). Data were collected at 11 edge-of-field stations, 2 streamgaging stations, 1 edge-of-field station upstream and 1 downstream from a small grass buffer collecting runoff from a 0.25 -acre heifer feedlot, and at 1 meteorological station. A description of the farm can be found on the Pioneer Farm website (http://www.uwplatt. edu/pioneerfarm/index.html, last accessed February 8, 2008). 


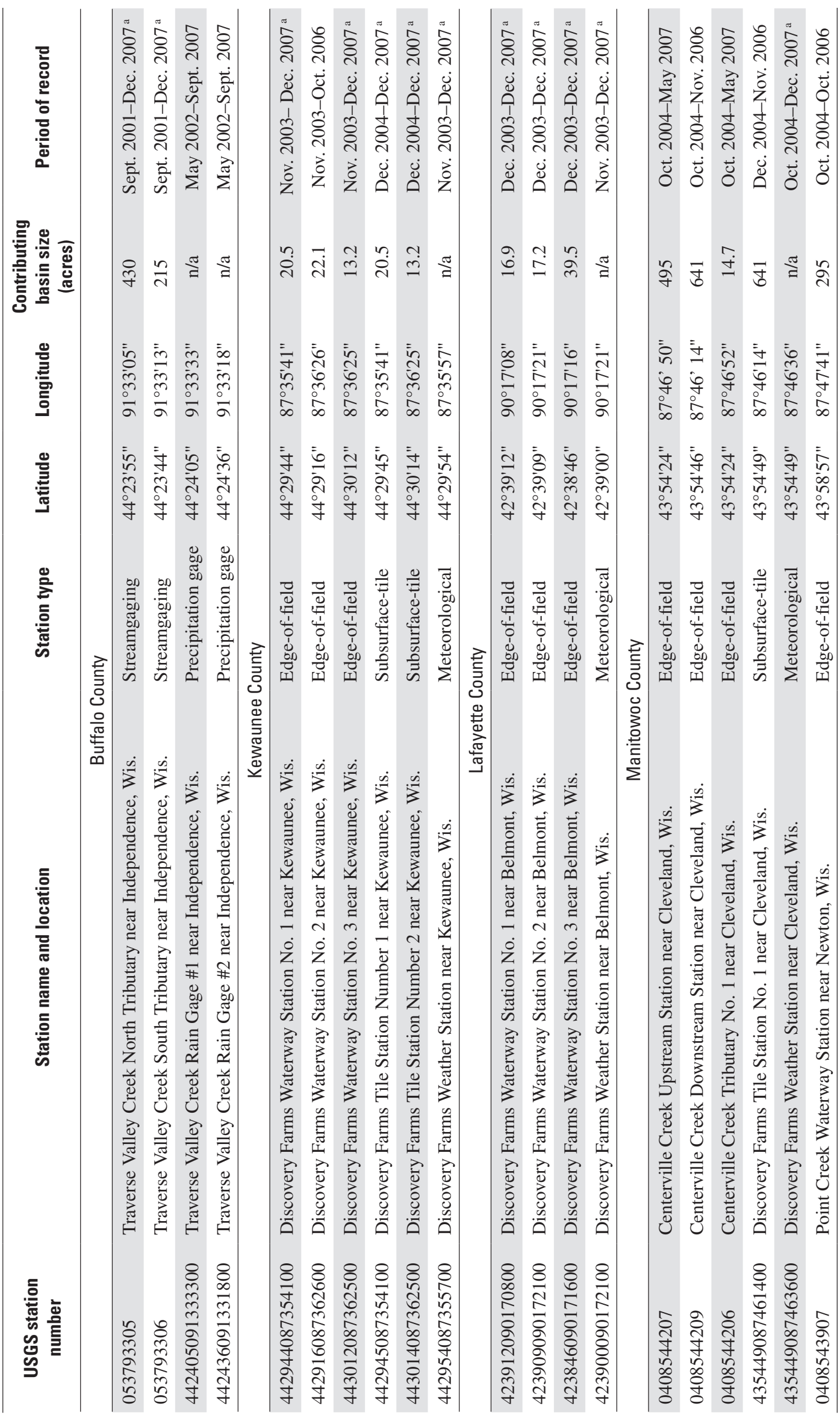




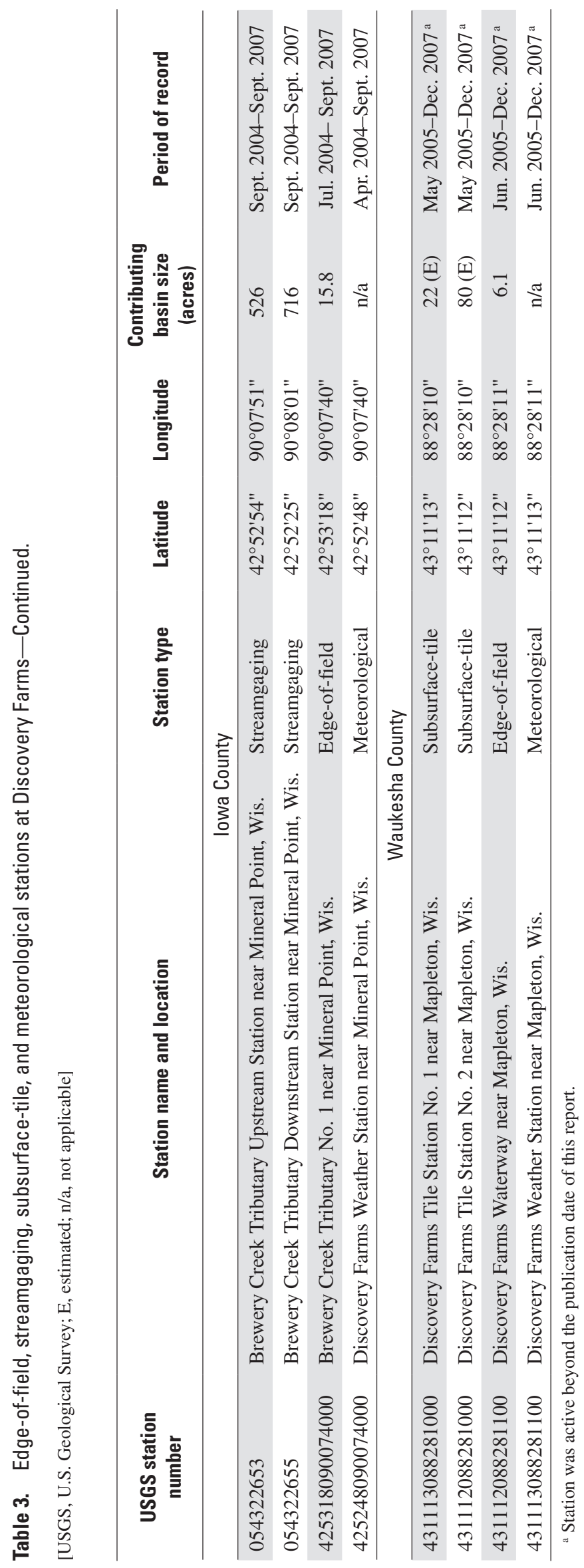




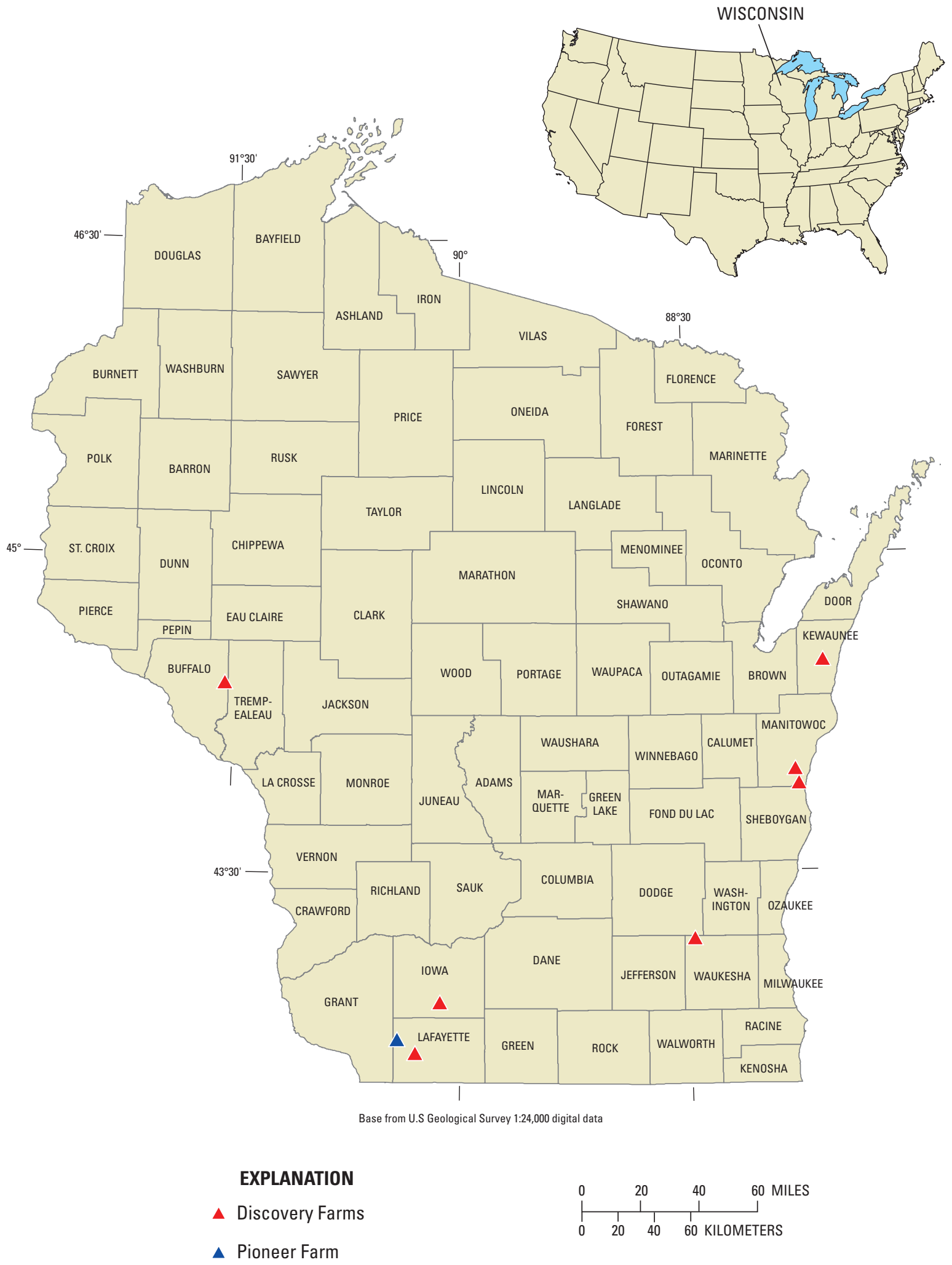

Figure 2. Locations of farms in the Discovery Farms and Pioneer Farm programs in Wisconsin. 


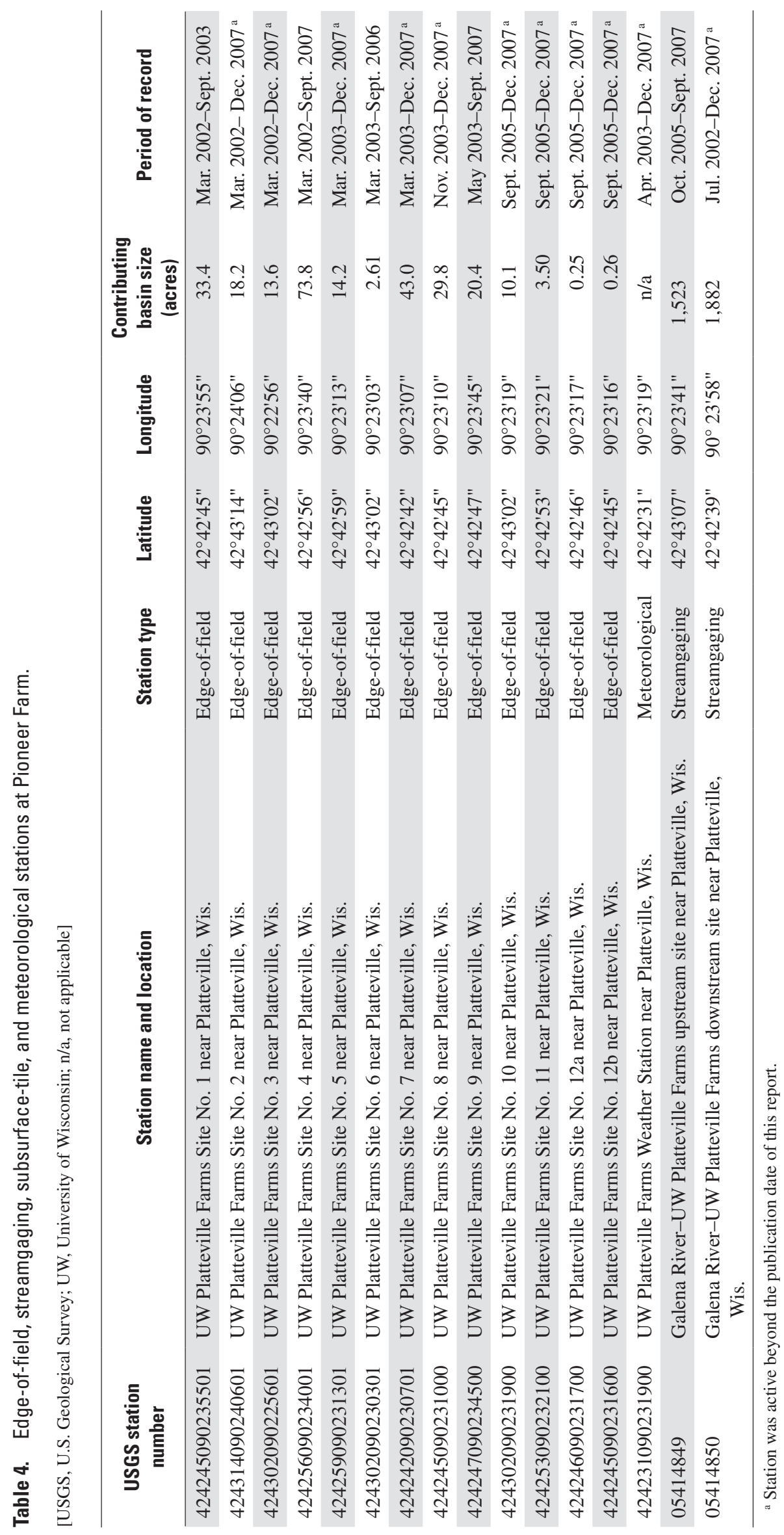




\section{Data Collection for Edge-of-Field, Streamgaging, Subsurface-Tile, and Meteorological Stations}

Edge-of-field stations were located in waterways or points of concentrated flow at the edges of agricultural fields or in intermittent streams in any location associated with field drainage. Streamgaging stations were generally located in small, headwater streams within a primarily agricultural setting. Subsurface-tile stations were located either in fields or at tile outlets, depending on topography. Each of these locations may not have been at or near a point of easy access and therefore could be difficult to service during wet or winter conditions. The collection of water-quality samples and data generally followed USGS WWSC procedures (Richards and others, 2006), except as otherwise described in this report.

\section{Edge-of-Field Stations \\ Equipment}

\section{Equipment Enclosures}

Similar equipment was used for edge-of-field stations at the Discovery Farms and Pioneer Farm. In most instances, a custom-made, aluminum, clam-style enclosure was used at each station to house equipment designed to measure stage (water level, used to compute discharge), collect water samples, and provide two-way telecommunication that enabled data acquisition and real-time programming (fig. 3, table 5). The aluminum enclosures were 4 feet wide by 2.5 feet deep by 5 feet tall when closed, and approximately 7 feet high when open. Hydraulic cylinders allowed the lid of the enclosure to easily open to allow equipment access but also to shelter the equipment from the elements during station visits. The enclosure design allowed it to be hand placed on four treated-wood posts or on wooden skids to keep it off the ground.

Table 5. Equipment used for collection of water-quantity, hydrologic, and water-quality data.

[Any use of trade, product, or firm names is for descriptive purposes only and does not imply endorsement by the U.S. Government.]

\begin{tabular}{lll}
\hline \multicolumn{1}{c}{ Equipment type } & \multicolumn{1}{c}{ Manufacturer } & \multicolumn{1}{c}{ Equipment name } \\
\hline Flume & \multicolumn{1}{c}{ Stage, discharge, and water-quality sampling } \\
Datalogger & Campbell Scientific, Inc. & H and Trapezoidal \\
Pressure transducer & Sutron Corporation & CR10 and CR10X \\
Gas bubbler system & Rickly Hydrological Company & Sutron Accubar Model 5600-0125 \\
Automatic sampler & Teledyne ISCO, Inc. & USGS Conoflow Sight Feed Assembly \\
\hline & \multicolumn{1}{c}{ Communication } & \\
\hline Cellular modem & AirLink Communications, Inc. & Raven CDMA Model C3211 \\
Spread-spectrum radio & Campbell Scientific, Inc. & RF400 900 MHz \\
Telephone modem & Campbell Scientific, Inc. & COM 210 \\
\hline & & \\
\hline Solar power inverter & Exceltech, Inc. & XP1100, 1100 Watt True Sine Wave \\
Solar power charge controller & Morningstar Corporation & SunGuard SG-4 and TS-45 TriStar 45 \\
Generator & Onan and Generac & Onan ${ }^{\circledR}$ Microlote 2800 and Generac Quietpact 40G \\
\hline
\end{tabular}




\section{Stage and Discharge Equipment}

Contributing basin sizes at edge-of-field stations were between 0.25 and 641 acres. For these edge-of-field stations, standard, prerated, fiberglass $\mathrm{H}$ flumes of various sizes were used (fig. 4) to measure stage over time, which was then used to compute a continuous record of discharge.

A maximum anticipated discharge was estimated for each edge-of-field station on the basis of basin area, topography, and soil characteristics. Using this discharge, an appropriately sized H flume was selected. Discovery Farms and Pioneer Farm edge-of-field stations used $\mathrm{H}$ flumes between 1.5 feet and 3.0 feet in height, with maximum discharge capacities between 5.4 and 30.7 cubic feet per second.

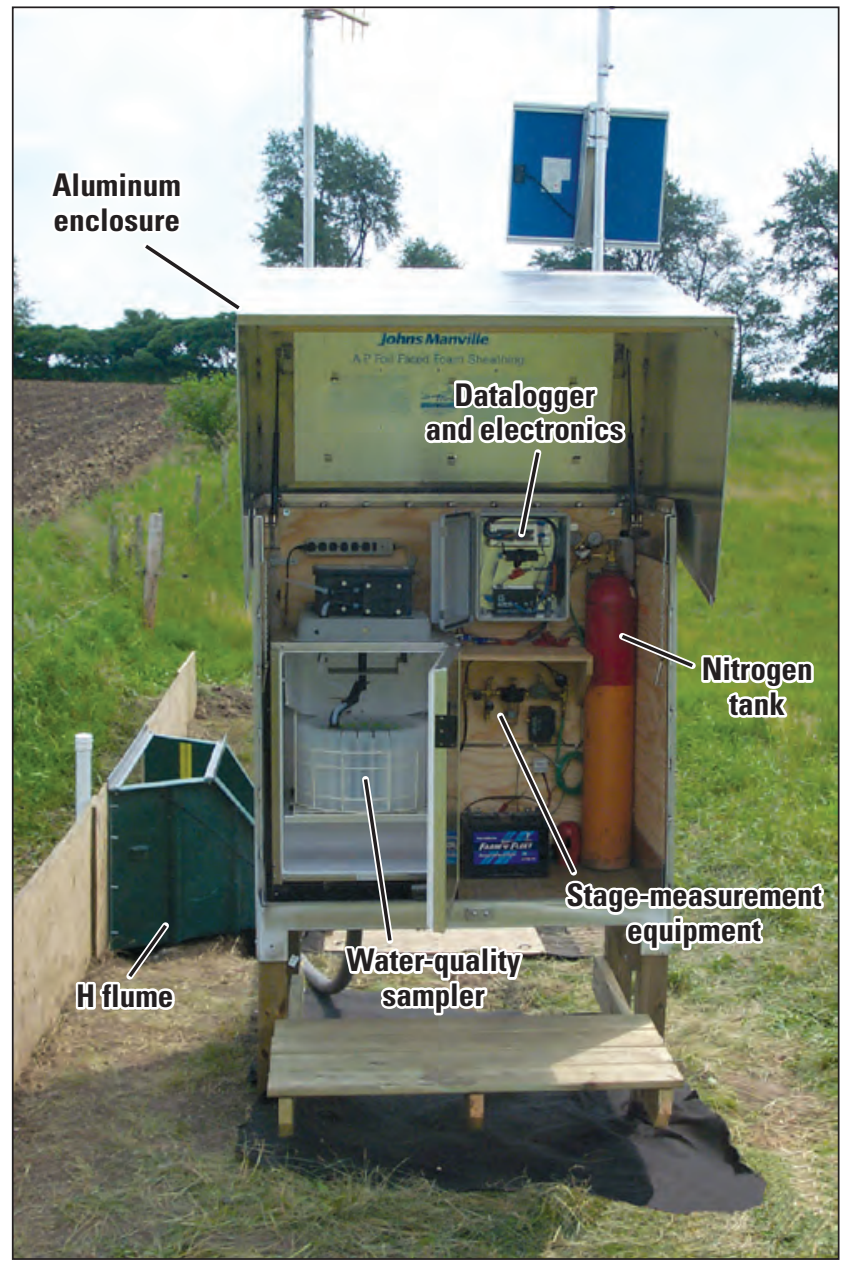

Figure 3. A typical station for the Discovery Farms and Pioneer Farm programs, including an aluminum, clam-style enclosure to protect weather-sensitive instrumentation.
An $\mathrm{H}$ flume was attached to a wingwall installed perpendicular to the direction of surface-water runoff. The wingwall provided a rigid location to mount the flume, and acted as a funnel to direct all surface-water runoff through the flume. The wingwall was made of either treated plywood or concrete, depending on the average soil moisture.

In locations with generally dry soils for a majority of the year, wooden wingwalls were constructed using 3 to 5 sheets of 3/4-inch-thick, treated plywood secured to each other with construction adhesive and screws. A 9-inch overlap was used to ensure a secure, watertight connection between the plywood sheets. A 4- to 6-inch-wide, 2-footdeep trench was excavated perpendicular to the flow path. The bottom of the plywood wingwall was cut so that, when placed in the trench, the top of the wingwall extended above the ground surface to the same height as the $\mathrm{H}$ flume (fig. 5). The excavated soil was placed back into the trench, carefully backfilled, and firmly tamped to prevent water from undercutting the wingwall. Earthen berms were created to secure the outside edges of the wingwall and to ensure that all discharge passed toward the $\mathrm{H}$ flume.

In locations where soils were saturated for most of the year (runoff was more prolonged), a concrete wingwall was used to prevent undercutting that could occur if plywood wingwalls were used. A trench was excavated and a concrete wall was poured on a concrete footer. The concrete wingwall was built to extend above the ground surface to the same height as the $\mathrm{H}$ flume (fig. 6).

The $\mathrm{H}$ flumes were leveled from side to side and from front to back before being secured to the downstream side of the wingwall. Support bracing was placed at the flume exit to minimize flume movement. Soil erosion at the exit of the $\mathrm{H}$ flume was prevented by placing rock riprap or treated wood on heavy-duty landscaping fabric.

$\mathrm{H}$ flumes are not accurate for measuring discharge under certain backwater conditions. Backwater occurs when the flow of water downstream from the flume becomes partially blocked or retarded, resulting in ponding and subsequent water backup such that an artificially high stage occurs in the flume relative to the volume of water discharged. Occasionally, downstream grades needed to be modified to ensure proper measurement conditions. $\mathrm{H}$ flumes have a prerated stage to discharge relation; that is, if the stage in the flume is measured, the discharge can be determined.

To accurately determine the discharge passing through an $\mathrm{H}$ flume, accurate stage readings are required. Accuracy requirements for stage measurements can be found in Garn (2002). Stages in the H flumes at Pioneer Farm were initially monitored by use of a shaft encoder 


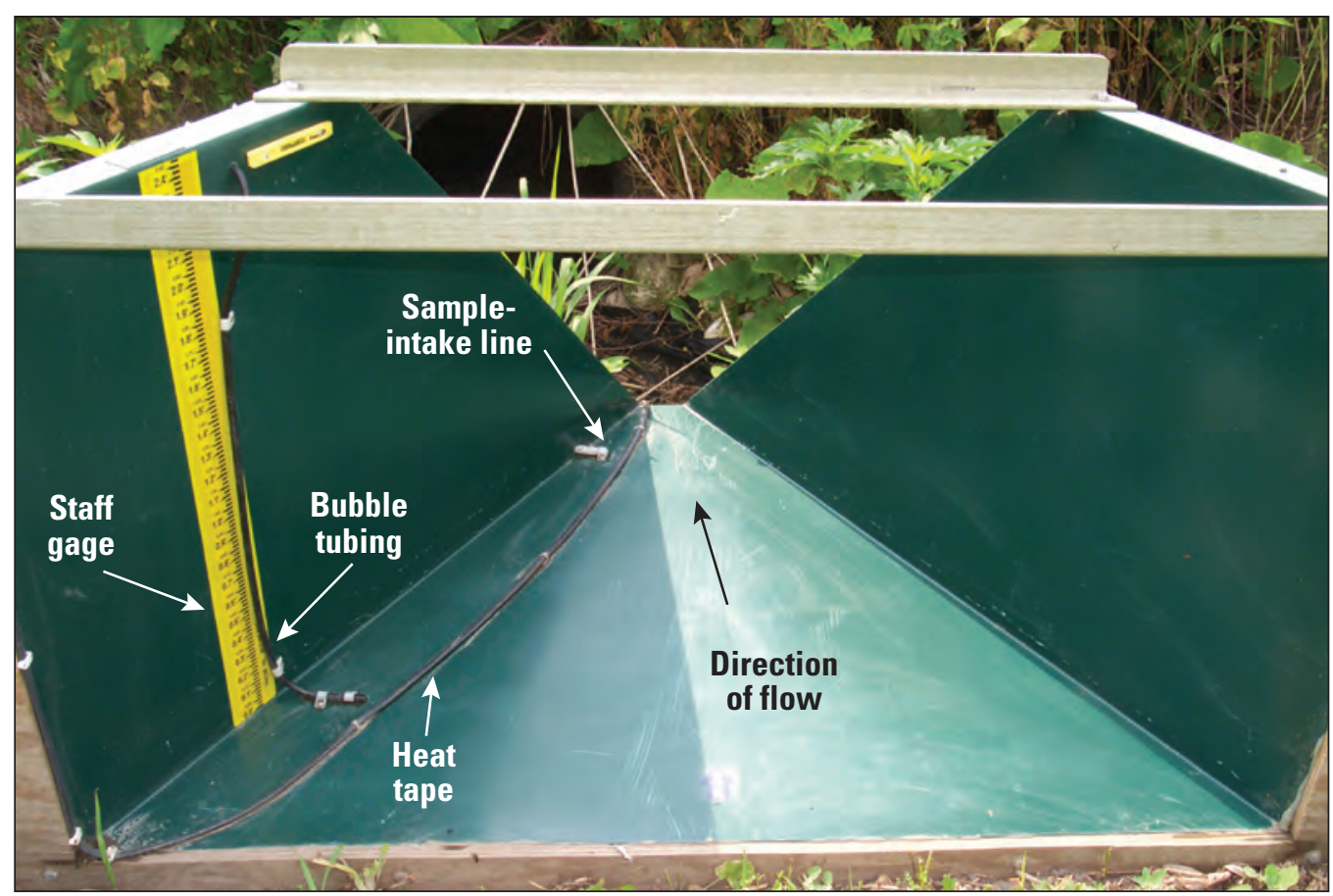

Figure 4. The staff gage, bubble tubing, sample-intake line, and heat tape are shown in this photograph of an $\mathrm{H}$ flume $(2.5$ feet in height) used to measure discharge.

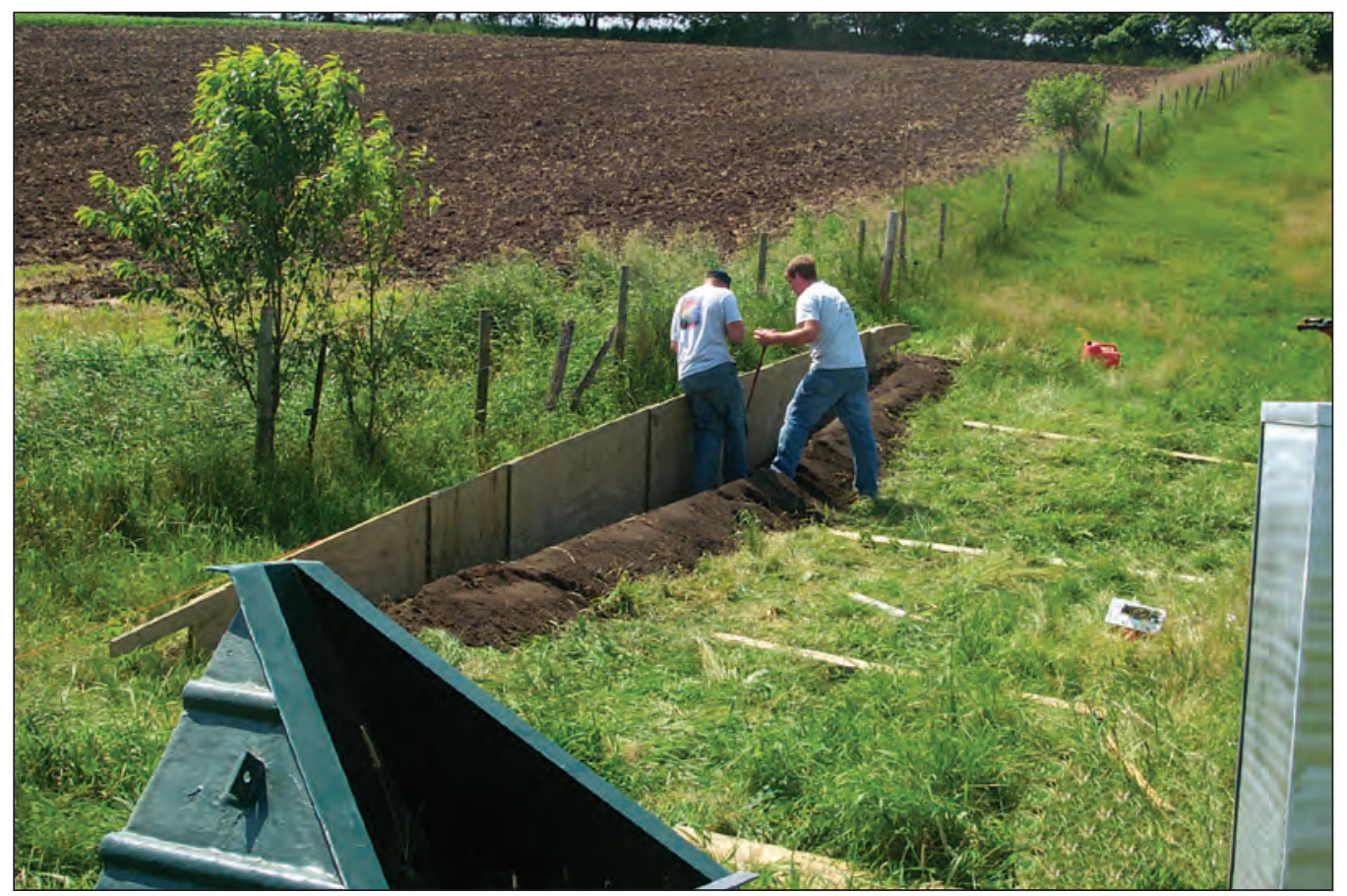

Figure 5. Plywood wingwalls were used at most edge-of-field stations to provide a flume-mounting surface and to direct all surface-water runoff through the flume. 


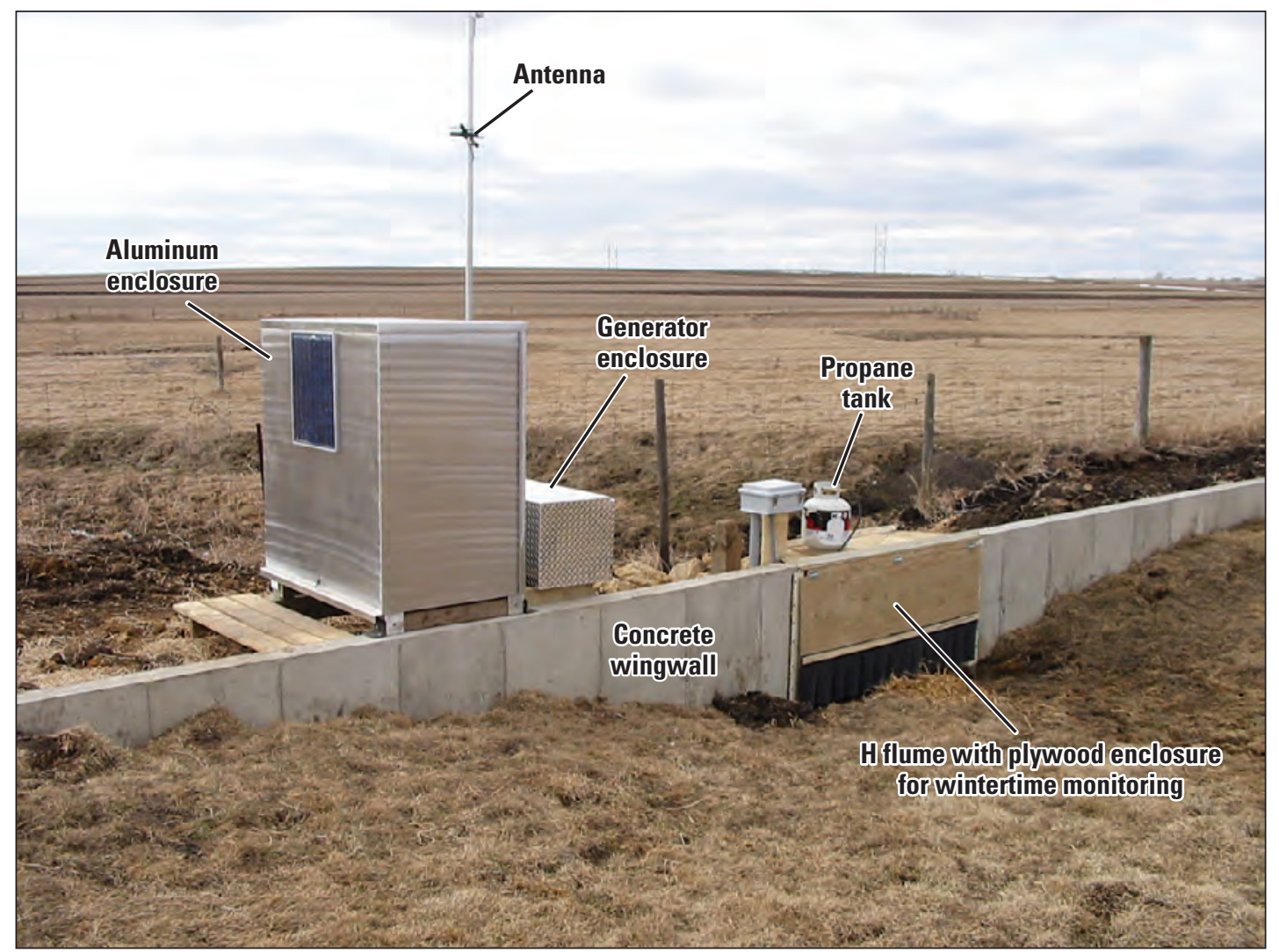

Figure 6. Concrete wingwalls were used at edge-of-field stations where soils were typically saturated most of the year.

and float system with a 6-inch stilling well. This method for monitoring stage was unsatisfactory during snowmelt events when nighttime temperatures fell below freezing because the float used for the shaft encoder became frozen within the stilling well and could not respond during runoff until it was thawed. The ice in the stilling well was difficult and time-consuming to thaw before the next precipitation or snowmelt event. Also, the float occasionally stuck or "hung" on the sides of the well during periods of rapid changes in stage during runoff events. For these reasons, use of the shaft encoder and float system was discontinued.

All Discovery Farms and Pioneer Farm stations eventually used nonsubmersible pressure transducers, coupled with nitrogen bubbler systems (Groetsch and Coleman, 2001), to monitor stage in the $\mathrm{H}$ flumes. These systems transmitted nitrogen gas at a known rate and pressure through 3/8-inch black polyethylene tubing (bubble tubing). The end of the bubble tubing, or orifice, was attached to the floor of each flume using plastic clips (fig. 4). Stages measured by the system were then recorded by a datalogger. Although water occasionally froze around the bubble tubing during wintertime runoff events (causing higher, incorrect stages), the nonsubmersible pressure transducer and nitrogen bubbler system was easier to maintain and provided more accurate and reliable data than the shaft encoder and float system. In addition, numerous comparisons of staff-gage (fig. 4) measurements to those recorded by the dataloggers showed that drawdown-a phenomenon where water velocities can cause stage-measurement devices to read lower than the actual stage-was insignificant in $\mathrm{H}$ flumes where the bubble tubing was attached to the flume floor, even for high discharges.

A crest-stage gage (CSG) was mounted to the upstream side of the wingwall at most edge-of-field stations to confirm that the event-maximum stage measured by the pressure transducer was accurate (Garn, 2002, figs. 8 and 15). The CSG was a 3-foot-long piece of wood with a small sheet metal cup at the bottom to hold shredded cork. The wood was placed in a 2-inch-diameter pipe that was capped on both ends. The bottom cap of the pipe was fixed and had holes to allow water to move in and out of the pipe. The top cap was removable and had a hole in the side to prevent pressure from limiting water movement. After a runoff event, the maximum stage was determined 


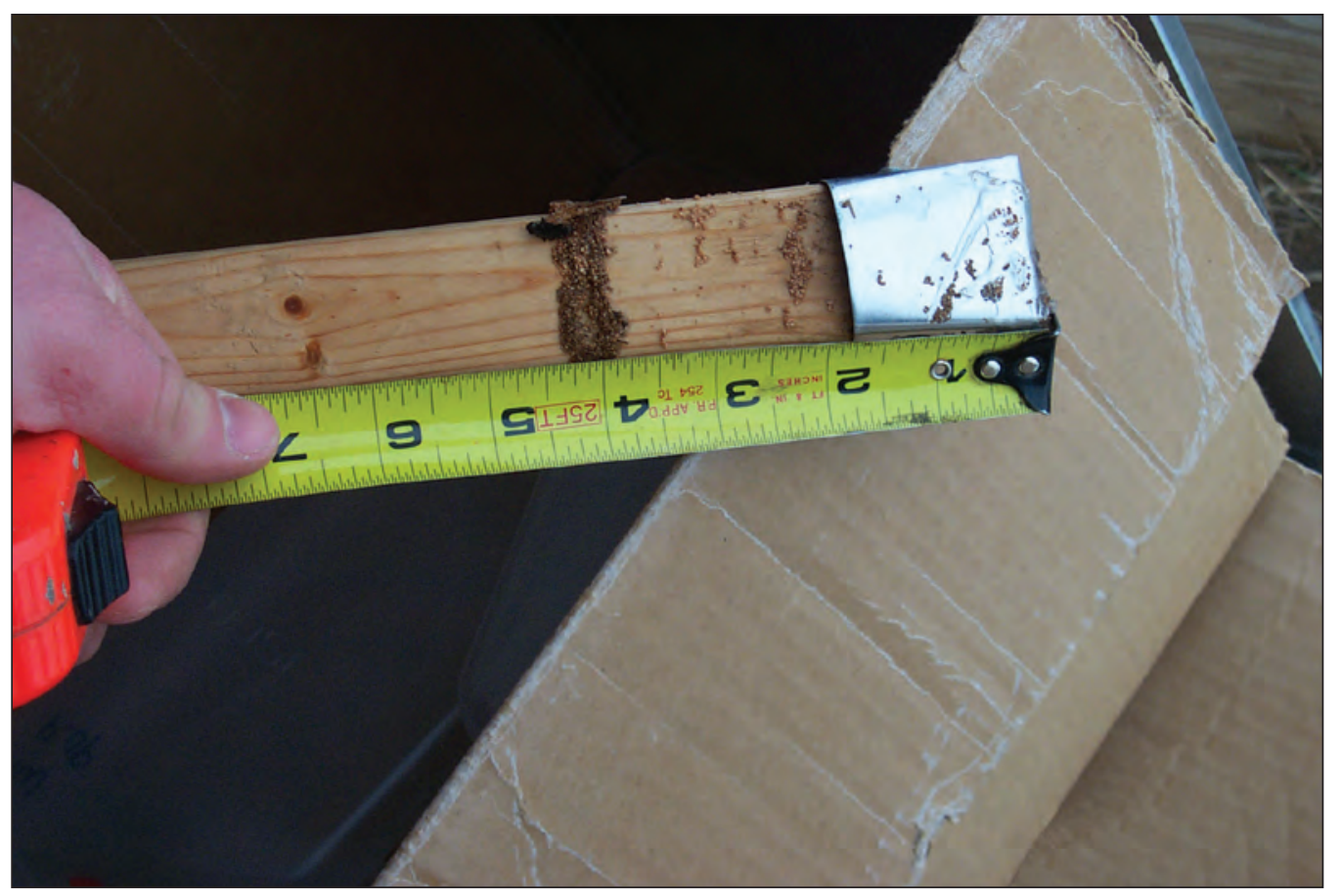

Figure 7. Measurements of the cork line on the crest-stage gages were made after a surface-water runoff event

by measuring the distance from the bottom of the piece of wood to the cork that remained stuck to the piece of wood (fig. 7). Peaks determined by the CSG were then compared to the peaks recorded by the datalogger.

Staff gages also were installed to the inside of the $\mathrm{H}$ flumes, near the location where stage was measured by the pressure transducer (figs. 4 and 8). Each time a station visit was made during a time of runoff, the staff-gage reading was recorded to the nearest thousandth of a foot. The simultaneous stage reading from the datalogger also was recorded. Stages from the staff gage and the datalogger were compared for every station visit, and adjustments were made to the data during analysis.

Heat tape (similar to that used to prevent pipes from freezing) was attached to the bottom of the $\mathrm{H}$ flumes by making a single pass near the sample-intake line and bubble tubing and out the flume exit (figs. 4 and 8). The heat tape was installed to reduce or prevent ice that formed near the bubble tubing, sample-intake line tip, and flume exit. Although the heat tape did not totally prevent ice buildup in the flumes, it was effective at reducing water freezing at the tips of the sample-intake line and bubble tubing; it also reduced water freezing in the flume exit. Generally, the flume exit was the first to freeze when ice formed; it would cause water to back up into the flume, causing more ice problems when the backed-up water eventually froze. The heat tape helped to keep the water at the flume exit from freezing and thus helped to prevent further ice problems from developing.

Determining the levelness of the floor of the $\mathrm{H}$ flumes was critical to obtain accurate records of discharge. During field testing, it was determined that, when the $\mathrm{H}$ flumes were level, measured discharge matched the rated discharge very closely. However, it was determined that a flume floor tilt from entrance to exit of just 0.02 foot in a 2.5-foot $\mathrm{H}$ flume would cause the stage to be underestimated by that same 0.02 foot. With this 0.02 -foot floor tilt and a measured stage of 0.3 feet, the resultant discharge would be underestimated by more than 10 percent compared to a level flume. Therefore, although the stagedischarge relation for an $\mathrm{H}$ flume was stable, accuracy was highly dependent on the flumes being level from front to back and from side to side. In 2006, small levels were attached to the $\mathrm{H}$ flumes as a check of levelness. Each time a station visit was made, a note was made on the sample retrieval sheet to indicate the position of the level bubble. Changes to the level readings indicated that the flume should be resurveyed and appropriate corrections applied. Using survey data, corrections were made to the data to adjust for flume tilt. 


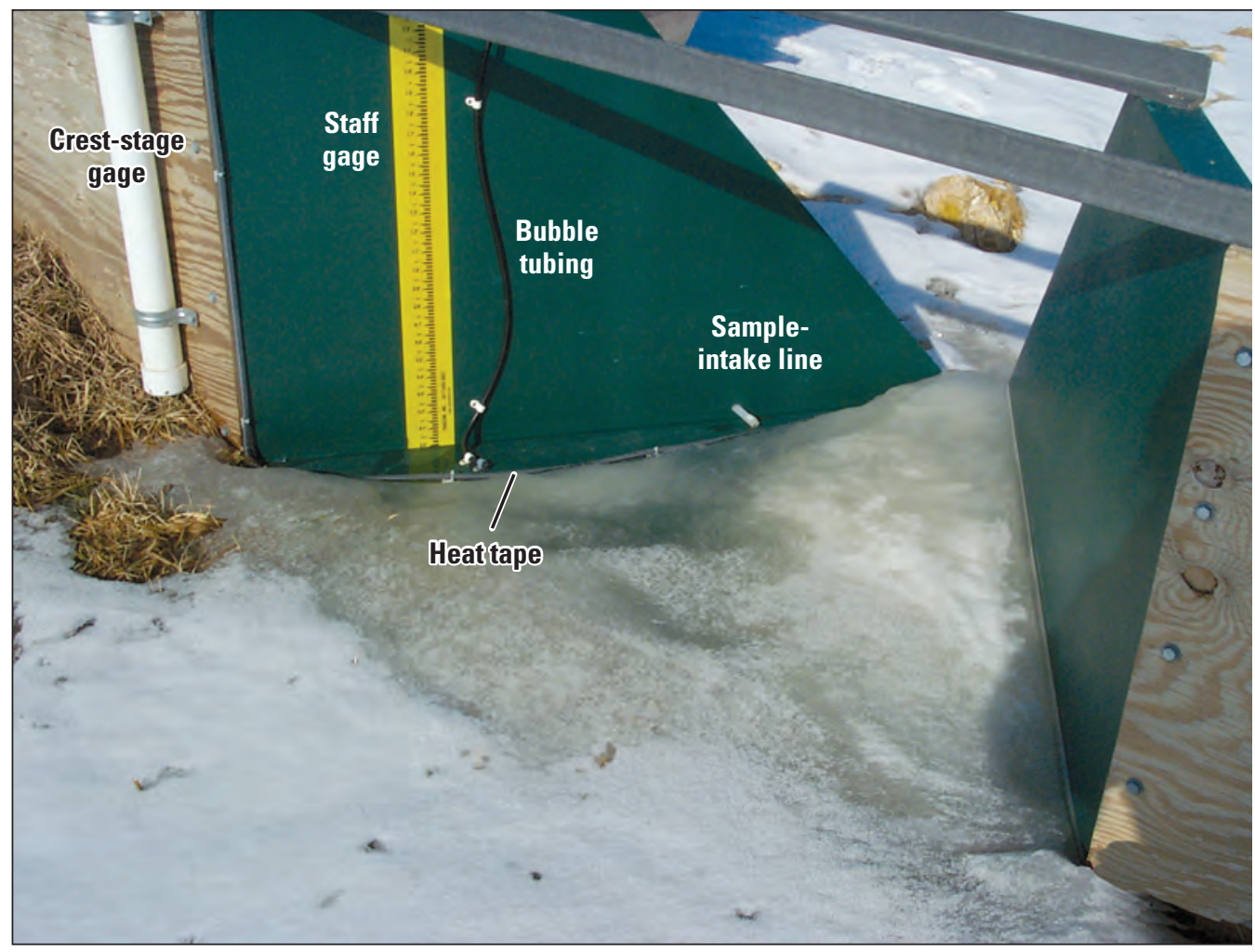

Figure 8. Ice was removed from $\mathrm{H}$ flumes before runoff events. Here, icemelt near the bubble line and sample-intake line due to the heat tape can be seen.

\section{Water-Quality Sampling Equipment}

An automated, refrigerated, 24-bottle ISCO 3700R sampler (fig. 9) was used to collect samples of surfacewater runoff. Samples were pumped from the H flumes using 3/8-inch inside by $1 / 2$-inch outside diameter Teflon-lined sample tubing (sample-intake line) into 1-liter polypropylene bottles housed in a refrigerator. Although not necessary considering the constituent list, Teflon-lined sample tubing was used to help minimize cross-contamination between samples and to provide extra strength. The sample-intake line was attached within the throat of the flume, where the runoff-water column was presumed to be mixed the best, and was connected to the flume floor to allow samples to be collected at low runoff depths (figs. 4 and 8).

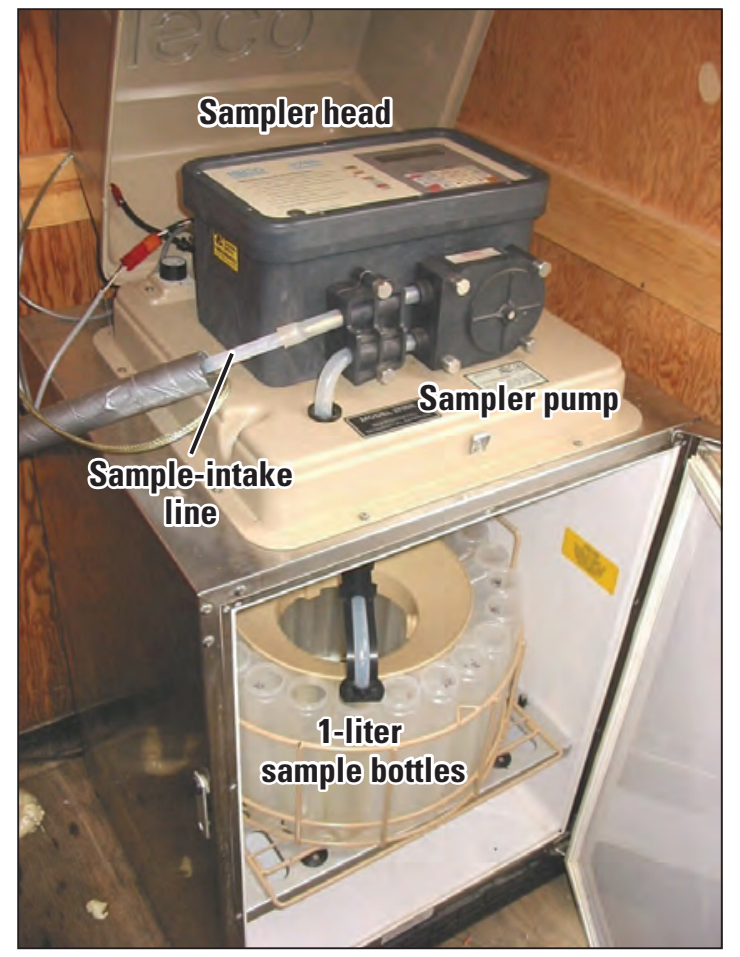

Figure 9. Automated, refrigerated samplers were used to collect samples of runoff water. 
Protecting the sample-intake line from freezing and damage was an important consideration. Care was taken to ensure that the sample-intake line sloped downgradient into the flume so that water did not collect in the line and freeze. Heat tape and foam pipe insulation were attached over the length of the sample-intake line as a further precaution to prevent freezing. Thermocouple wire was also attached beside the sample-intake line so that temperatures could be monitored. The sample-intake line, heat tape, insulation, and thermocouple wires were protected within 2-inch, flexible electrical conduit. Equipment enclosures were placed close to the point of sampling to minimize sample-intake line length. Average sample-intake line lengths for edge-of-field stations were approximately 15 feet; head heights (vertical distance between the tip of the sample-intake line on the floor of the flume and the automatic sampler head) were approximately 6 feet.

\section{Data Capture, Measurement, and Program Control}

A critical station function was to collect and store data produced by the station sensors and devices and to control when certain functions were performed (such as when data were to be stored or samples collected, or when AC power should be activated for sample refrigeration). A specialized, in-house datalogger program executed by a Campbell Scientific, Inc., CR10 or CR10X datalogger (fig. 10) was used to read, store, and control station sensors and devices. The datalogger program could easily be modified either at the station or remotely.

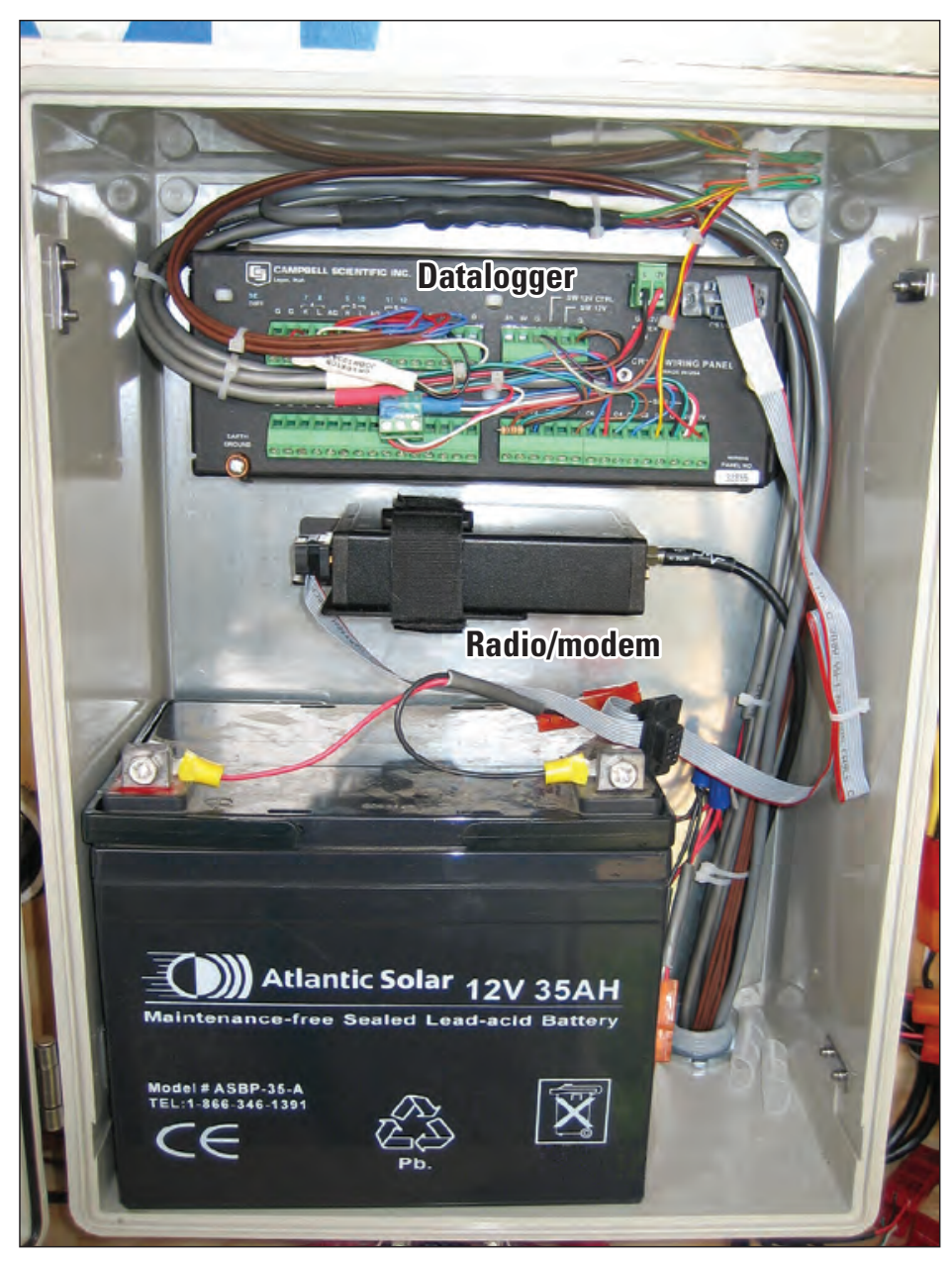

Figure 10. A Campbell Scientific, Inc., CR10X datalogger, an RF400 spread-spectrum radio/modem, and a battery were typically used for all edge-of-field, streamgaging, subsurface-tile, and meteorological stations. 


\section{Communication}

Two-way, real-time communication with stations was crucial to ensure proper equipment function, adjust sample frequency to maintain adequate sample coverage during runoff events, and allow other program changes to be made. This functionality also helped to minimize field visits and reduce the amount of lost data and unsampled runoff events.

Most of the Discovery Farms and Pioneer Farm edgeof-field stations were located where telephone lines were not available or installation was cost-prohibitive or not feasible; however, a telephone line was usually available at a central, conveniently accessible, and relatively high elevation location compared to the other stations. Where possible, a "radio base station" tower was set up at this location with a Campbell Scientific, Inc. COM 210 telephone modem, a Campbell Scientific, Inc. RF400 spreadspectrum radio/modem, and an omnidirectional antenna. Dataloggers at the edge-of-field stations were connected to RF400 radio/modems that had directional antennas aligned to target the base-station antenna. This equipment configuration allowed real-time, two-way telemetry to each datalogger from any computer with a modem and the required software. A Campbell Scientific, Inc. software program called PC208W (fig. 11) was used to dial the base-station phone number, connect with the modem, and then communicate with the remote field stations by tuning into one station after another using different RF400 radio addresses. Communication could be established and data retrieved from multiple stations with a single telephone call.

At locations where telephone lines were not available or were cost-prohibitive, AirLink Communications, Inc. Raven cellular modems were used for communication. These cellular modems allowed two-way communication to the dataloggers in the same manner in which the telephone modems operated, but data were transmitted via a wireless cellular network. Rather than using a modem to call a station, PC208W used a broadband internet connection to establish communication with the modems by way of a static Internet Protocol (IP) address.

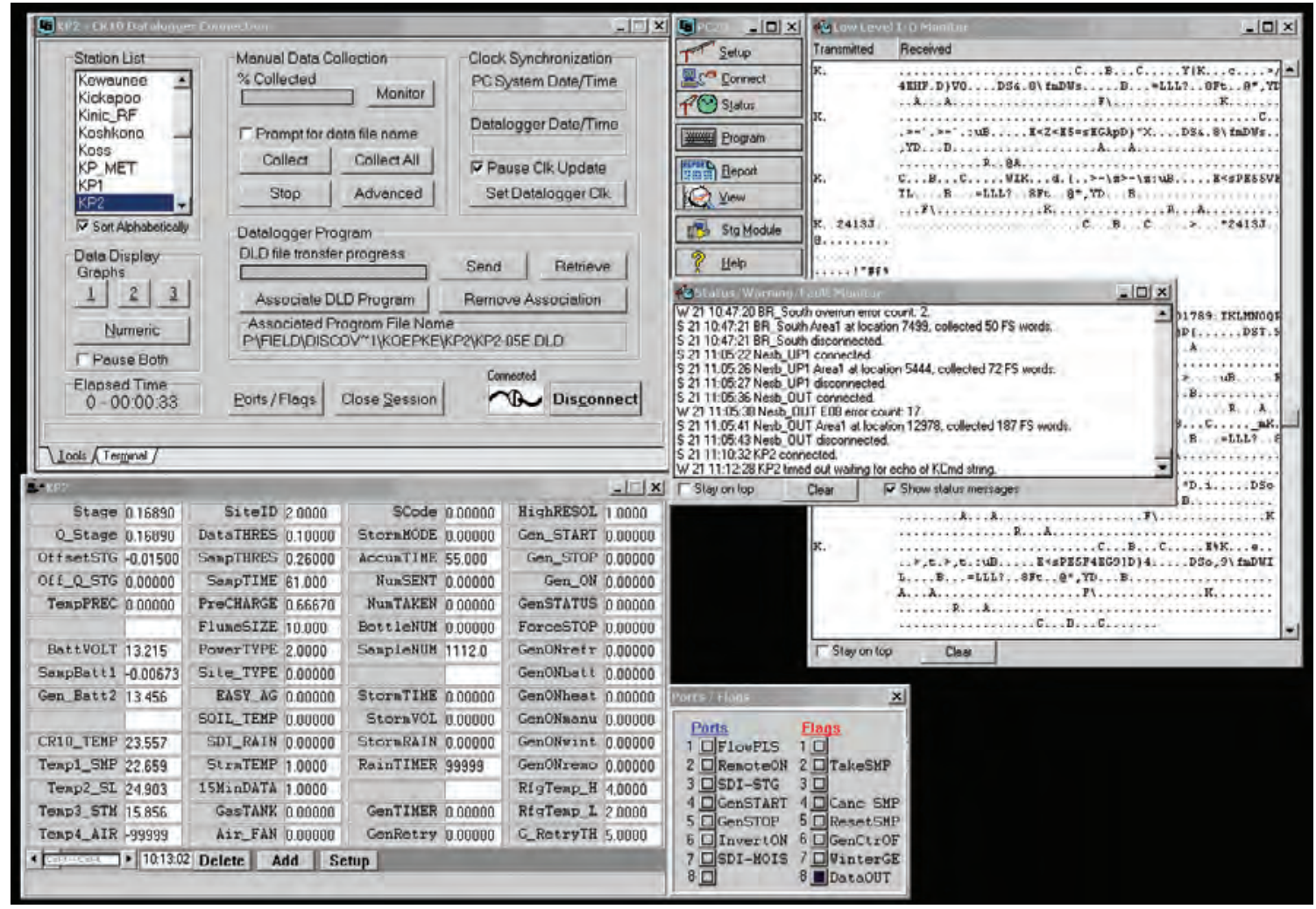

Figure 11. Campbell Scientific, Inc., PC208W datalogger communication software (sample image used with permission from Campbell Scientific, Inc.) used to communicate with stations. 


\section{Power}

Direct current (DC) and alternating current (AC) power were both required to operate equipment at the stations. The electronic equipment (including the sampler pump head) required DC power, whereas AC power was necessary for sample refrigeration and wintertime heat tapes. DC power was provided by 12 -volt batteries of various sizes (usually 8- or 26-ampere-hours) that were charged by either AC or solar power. Most Discovery Farms and Pioneer Farm stations were located where it was neither economically feasible nor practical to obtain electrical service from a power company. In these cases, recreation-vehicle (RV) remote-start generators or solarpower panels were used to provide $\mathrm{AC}$ power.

$\mathrm{RV}$ generators were located outside the equipment enclosure in a separate aluminum box (fig. 12) that was modified to allow air flow for both intake and exhaust. Landscape fabric was placed on the ground under the generator and equipment enclosure to prevent vegetative growth to reduce the potential for fires to be caused by heated generator exhaust. Five- to 25-gallon tanks were used to supply unleaded fuel to the generators. At some stations, sensors were installed within the tanks to monitor fuel levels. The generators were started and stopped by means of solid-state relays connected to the datalogger. Datalogger program logic determined when to start and stop the generators based on criteria including refrigerator temperature thresholds and wintertime deicing requirements. When operating correctly, the generators provided a steady source of power that could operate in all weather conditions; however, starting the generators remotely was sometimes difficult because of cold weather or mechanical issues. In addition, trips to the stations were sometimes necessary to maintain fuel levels to ensure proper sample refrigeration during extended periods (several days or more) of surface-water runoff.

Solar power was also used to provide AC power for sample refrigeration and to operate wintertime heat tapes for deicing at a number of Discovery Farms stations (fig. 13). Equipment generally consisted of three, 80-watt solar panels with a Morningstar Corporation Tri-Star 45-ampere charge controller that charged two 12-volt, 260-amphour batteries connected in parallel. An Exceltech, Inc. 1100-watt pure sine-wave inverter was used to convert the DC battery power to 120 volts AC power. The inverter was

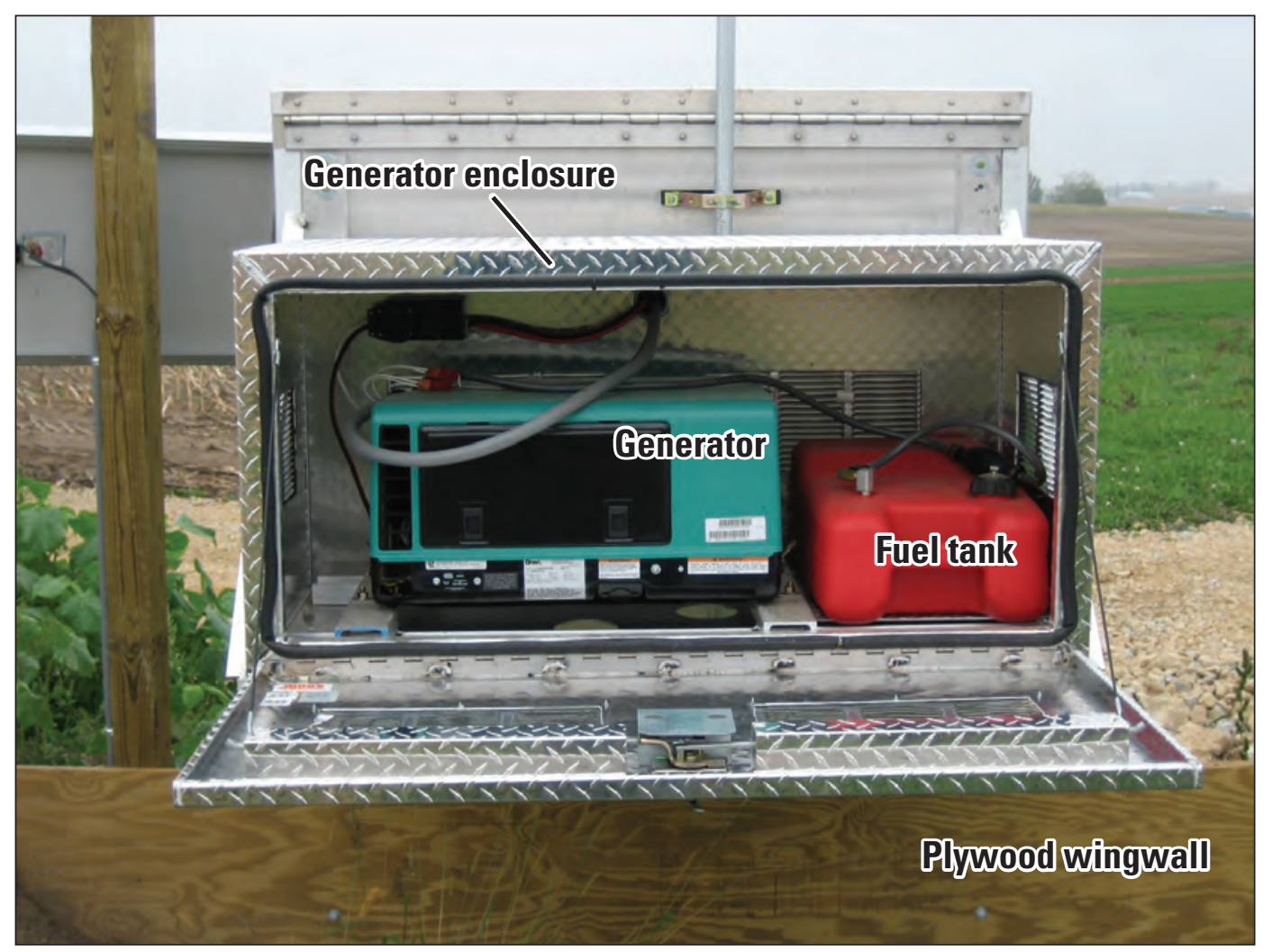

Figure 12. Remote-start generators were used to provide AC power at some stations. 
powered on and off using a solid-state relay connected to the datalogger. Datalogger program logic determined when to start and stop the generators based on criteria including refrigerator temperature thresholds and wintertime deicing requirements.

In general, the solar-powered system was able to meet the power demands of the refrigerators and heat tapes. Extended periods of surface-water runoff (several days or more) necessitating sample refrigeration or periods in which deicing was necessary for more than a day did deplete the battery reserves, especially when skies were cloudy and/or temperatures cold. Because there were no moving parts in the solar power system and no fuel tanks to keep filled, there were fewer maintenance issues with the solar power compared to generator power.

\section{Miscellaneous Equipment}

Most edge-of-field stations had time-lapse cameras installed to take a single digital photograph every day to document the field-management activities and field conditions in the monitored watersheds (fig. 13). The cameras were mounted in a fiberglass electrical enclosure with a 4-inch hole covered with a clear acrylic panel. Small DC power inverters were used to reduce the voltage to that required by the cameras. Images from the cameras were stored on flash cards, then downloaded to a laptop computer by project personnel during station visits.

\section{Runoff-Event Monitoring and Water-Quality Sample Collection}

Runoff at edge-of-field stations was dependent on many factors including type and intensity of precipitation, antecedent soil-moisture conditions, season, local terrain, soil type, crop type, and producer land-management styles. When runoff did occur, it was vital that equipment was working properly and that flexibility was programmed within the sampling scheme to handle the wide variety of runoff events that occurred. Many of the same techniques and procedures for runoff-event monitoring and sample collection were used by the Discovery Farms and Pioneer Farm programs for edge-of-field, streamgaging, and subsurface-tile stations.

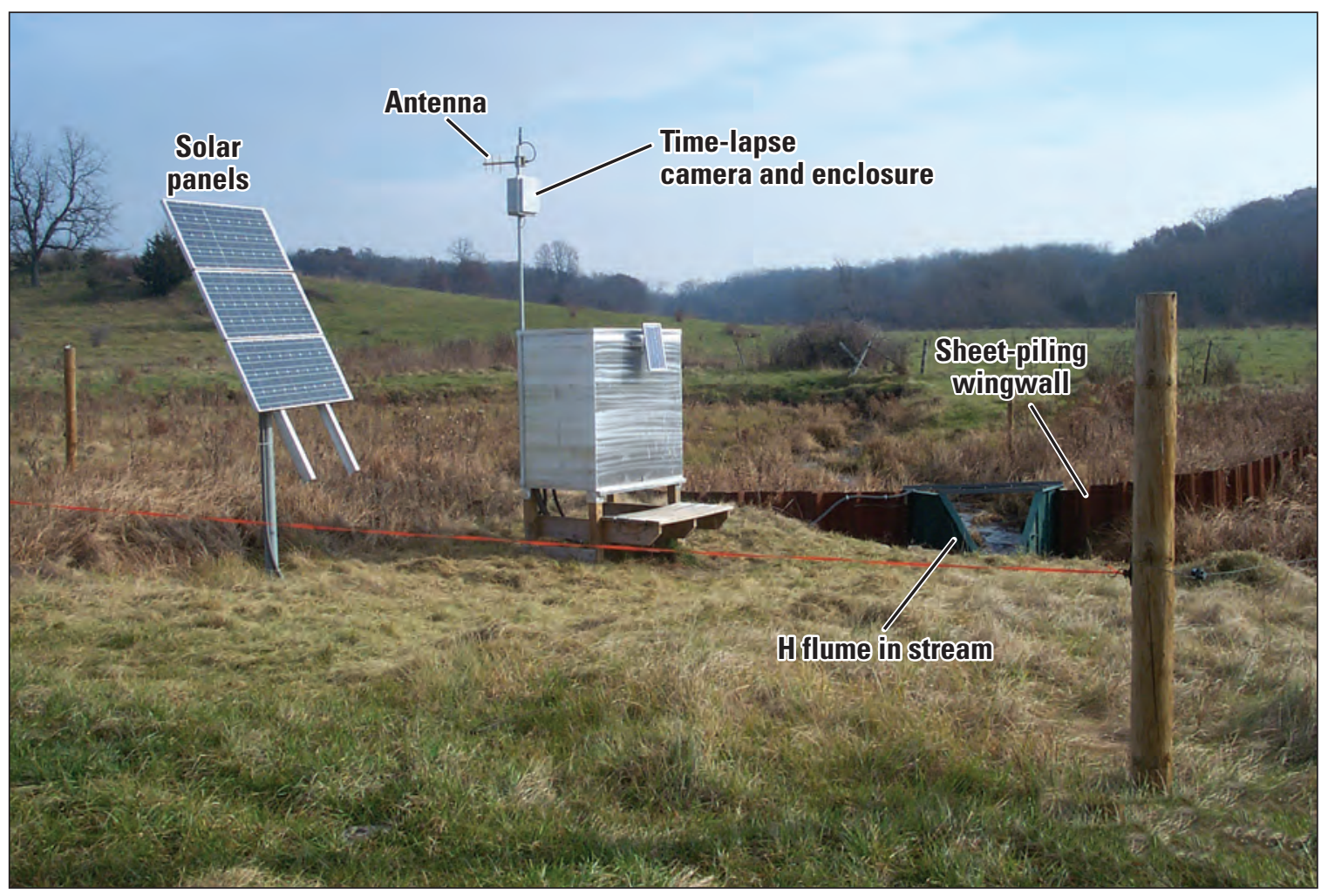

Figure 13. Streamgaging station with power provided by solar panels for sample refrigeration and wintertime deicing. 


\section{Runoff-Event Monitoring}

Precipitation, runoff, and equipment conditions were closely monitored. Sample frequency was often adjusted during runoff events to maintain adequate sample coverage without exceeding sampler capacity. Knowledge of field conditions and weather was necessary to anticipate when runoff might occur. If fields were snow covered and air temperatures were predicted to rise significantly above freezing, runoff was likely. Runoff was also likely if significant or high-intensity rainfall was predicted when soil moisture was high and vegetative growth was low. Knowledge of the typical runoff characteristics of each station was also important because it helped guide decisions regarding the appropriate sample frequency needed for adequately sampling runoff.

Data from many web-based weather stations were available online www.weather.gov, www.my-cast.com, www.intellicast.com, among others.). Each web site offered different features such as long-term forecasts, expected precipitation amounts, and severe weather alerts. Webbased Doppler radar stations with the ability to show storm motion (looping) was an invaluable tool for monitoring runoff events, because they helped determine the likeli- hood, timing, intensity, and expected duration of precipitation events. Radar web sites that also allowed the user to display station coordinates were particularly useful, because the exact location of the watershed was shown in relation to approaching precipitation.

When runoff was expected, the data-retrieval interval (set in PC208W) was reduced so that data were collected more frequently. Data were then automatically updated into Campbell Scientific, Inc., Real Time Data Monitoring Software (RTDM) that provided a custom-designed graphical representation of the values recorded by the datalogger (fig. 14). This allowed quick assessment of the data, such as the number of samples collected, sample frequency, rate of change of the hydrograph, and equipment functionality that would not be possible simply by calling the station and observing instantaneous conditions. This assessment also allowed rapid and accurate decisions to change the sampling frequency during runoff and evaluate equipment performance. If significant problems were found, such as the sampler not functioning properly or unusual stage values, personnel were immediately sent to the station to fix the problem.

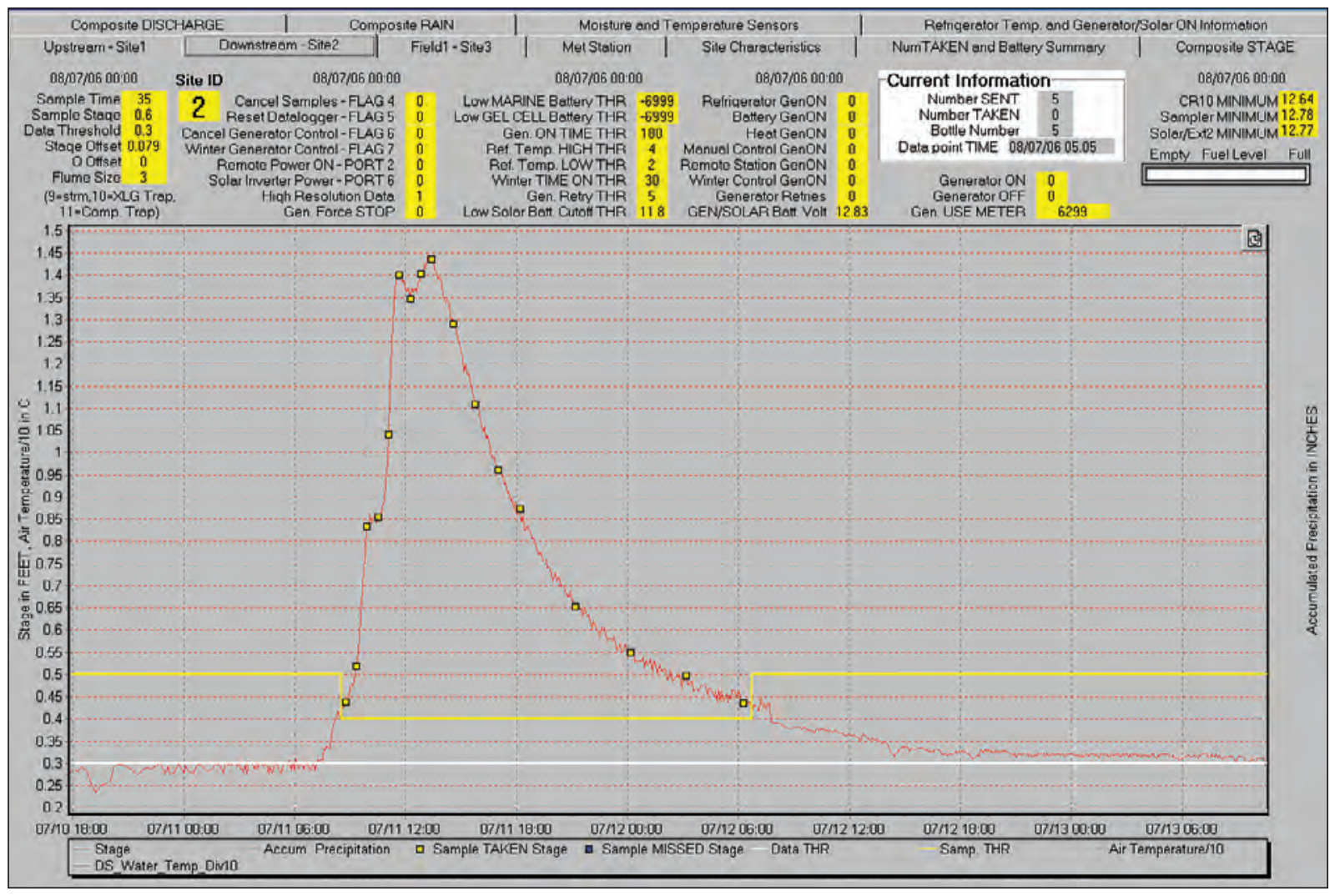

Figure 14. Real Time Data Monitoring Software (RTDM) data display allowed rapid assessment of many datalogger variables over time (sample image used with permission from Campbell Scientific, Inc.). 
Many runoff events occurred outside traditional office hours. At such times, USGS WWSC personnel used several tools to aid them in data and sample collection associated with the monitoring of runoff events. For example, Virtual Private Network (VPN) software was used to gain authenticated and secure access to office computers from any properly configured computer. Then, using Remote Desktop Connection (RDC), a software program from Microsoft Corporation, desktop computer resourcesfiles, preferences, and applications such as PC208W and RTDM - were available. Using VPN and RDC, anything that could be done from the WWSC office could also be done from offsite locations with Internet access.

\section{Sample Collection for Runoff Events}

One of the data-collection goals of the Discovery Farms and Pioneer Farm programs was to collect water samples that adequately represented the variability in constituent concentrations during periods of runoff so that accurate constituent loads and yields could be computed. Collecting samples to compute loads and yields was challenging because the duration and intensity of runoff events at edge-of-field stations were difficult to predict and varied considerably from season to season, event to event, and within events.

An edge-of-field runoff event was defined as the time from the onset of rainfall- or snowmelt-induced surfacewater runoff to the time when runoff ceased. Rainfall-runoff events at edge-of-field stations that occurred during late spring through fall were generally short in duration (minutes to hours) but high in intensity (high rate of change in discharge). Rainfall- or snowmelt-runoff events that occurred during winter and early spring were generally longer in duration (hours to days) and of lower intensity. A single runoff event could include multiple peak discharges in response to changes in the intensity of rainfall or rate of snowmelt. In winter and early spring, above-freezing temperatures during daytime sometimes caused snowmelt-runoff events wherein runoff volume subsequently decreased as temperatures dropped below freezing during the night.

\section{Time-Paced Compared to Volume-Paced Sampling}

Two basic ways that samples can be collected to characterize a runoff event using an automated sampler are time paced or volume paced. Time-paced samples are collected at predetermined time intervals during a runoff event, and volume-paced samples are collected when a predetermined volume of water passes by the station.
When sample collection is based on volume, it is necessary to roughly predict both the maximum discharge and the volume of a runoff event in order to collect the appropriate number of samples to adequately characterize the event. If the volume between samples is set too low, the sampler capacity can be exceeded before the event ends or samples can be missed because new samples can be triggered before the previous sample is pumped. Conversely, it is possible to set the volume between samples too high, resulting in too few samples to adequately represent the runoff event. Although the predetermined volume can be modified during an event to prevent these situations, these modifications complicate the sample-splitting process.

Problems with volume-paced sampling can also arise when backwater or icing conditions exist. In either case, the volume between samples is computed incorrectly in the datalogger program, resulting in samples that are not representative of the true volume of water passing by the station.

Because of the difficulty in predicting the maximum discharge and the volume of a runoff event and the issues that arise with backwater or icing conditions for volumepaced samples, time-paced samples were collected for edge-of-field stations for the Discovery Farms and Pioneer Farm programs. Proper use of this method resulted in the most reliable and most comprehensive sample coverage, ranging from small, short-duration runoff events to large, long-duration runoff events.

\section{Sampling Frequency}

Sampling frequency during a runoff event was controlled and adjusted by use of the datalogger. With remote communication, the datalogger program was modified to adjust for changing weather and runoff. The ability to adjust sampling frequency remotely was perhaps the most important technological aspect of the sampling process because it enabled adequate coverage of the wide range of discharge volumes and length of runoff events that occurred.

The need to adjust sampling frequency is illustrated in figure 14. Samples for this runoff event were initially collected at 35-minute intervals. Had that frequency been maintained for the entire runoff period, the sampler would have reached capacity before the end of the runoff event, and samples would not have been collected to represent the recession limb of the hydrograph. In this case, however, the sampling frequency was reduced to 1 hour after the peak, and then eventually to 3-hour intervals so that the sampler capacity would not be exceeded before the end of the runoff event. In addition, because only 17 samples 
were collected, there were still 7 samples in reserve in case another runoff event occurred before samples could be retrieved and the sampler reset.

\section{Program Logic and Sampler Function}

The datalogger recorded stage data at 15 - or 60minute intervals when surface-water runoff was not occurring. During runoff events, the data-recording frequency increased to 1 minute or 5 minutes when the stages in the $\mathrm{H}$ flume exceeded a threshold of 0.04 foot, which was just enough to completely submerge the bubble tubing. At this stage, known as the data threshold, a surface-water runoff event was likely occurring. Stages below this could have been anomalous spikes caused by direct precipitation into the $\mathrm{H}$ flume or by wind. The datalogger program entered sampling mode at approximately 0.08 foot-when the depth of water in the flume completely submerged the sample-intake line. Samples collected below this stage were likely to entrain air, resulting in improperly filled bottles. Once in sampling mode, the datalogger triggered samples based on a preset time until the stage fell below the sampling threshold. All thresholds were adjustable within the datalogger program through on-station or remote communication.

When a sample was triggered by the datalogger, the ISCO sampler responded by completing a rinse cycle to reduce cross contamination between samples. First, any residual water in the sample-intake line was purged. Runoff water was then pumped from flow in the flume through the sample-line tubing to the pump-head tubing and then purged back to the flume to complete one rinse cycle. The sampler then pumped the runoff water up the sample-line and pump-head tubing into the sample bottle. Finally, the sample-line tubing was purged again. No further cleaning of the sample line was done. The ISCO sampler was calibrated to deliver approximately 950 milliliters for each sample. If a sample was successfully collected, the ISCO sampler sent a high-frequency pulse back to the datalogger. The number of pulses sent was equivalent to the current bottle number. Use of these data from the sampler and datalogger was helpful to ensure proper sampler function.

\section{Sample Pickup}

Runoff samples collected by the ISCO samplers were generally retrieved within 24 hours of the end of a runoff event. At that time, sample-retrieval sheets and/or miscellaneous-note sheets were filled out (Appendixes 1 and 2), and staff-gage readings in the $\mathrm{H}$ flumes and the corresponding stages recorded by the datalogger were noted. Samples were removed from the ISCO samplers, labeled, placed in coolers with ice, and then transported to the University of Wisconsin-Stevens Point Water and Environmental Analysis Laboratory (WEAL) in Stevens Point, Wis., for analysis. Samples for edge-of-field stations were typically received by the laboratory within 3 days of a runoff event. Several trips to pick up and deliver samples were typically made for runoff periods that lasted for more than 2 days. Occasionally, some samples were not received by the laboratory for 4 days or more from the time the first sample was collected. Effects of exceeding sample holding times for constituents and physical properties listed in table 4 were not evaluated. Any data exceeding standard laboratoryrecommended holding times were flagged by the laboratory with the appropriate information.

During sample retrieval, sample-retrieval sheets (Appendix 1) and/or miscellaneous-note sheets (Appendix 2) were completed. The sample-retrieval sheets included information regarding field or runoff conditions, field observations, ISCO sampler dates and times, sample bottle labeling, nitrogen system status, bottle fill volumes, CSG readings, and selected datalogger information. If samples were retrieved during runoff, the staff-gage reading in the $\mathrm{H}$ flume and the stage output by the datalogger program also were recorded. These comparisons helped to indicate whether the pressure transducer and nitrogen system were accurately measuring actual $\mathrm{H}$-flume stage. If discrepancies were found between the two readings, the recorded field data were used to correct the datalogger stage and discharge record accordingly.

\section{Sample Collection for Quality Assurance and Quality Control}

It was essential that the data collected were of known and acceptable quality to support the data analyses planned for the project. The WWSC used a quality-assurance (QA) plan (Richards and others, 2006) that addressed waterquality data for all projects including Discovery Farms and Pioneer Farm. Using the guidelines of this plan, field blanks and cross-section coefficient samples were scheduled for collection at all Discovery Farms and Pioneer Farm stations. These samples helped determine precision and accuracy between the automatic samples as well as how representative the automated samples were of the "true" constituent concentrations in the water column. The goal was that approximately 10 percent of the total number of samples submitted would be quality-control (QC) samples. 
Field Blanks

Field blanks were used to determine whether contamination was introduced by the entire sampling process, including the autosampler equipment (sample-intake line and sample bottles) and sample-processing procedures (churn splitting, filtering, and use of laboratory-analysis bottles). The procedures used to collect field blanks were similar to those documented in the WWSC QA plan; however, type 1 reagent-grade water was not used because results to date have shown that this level of accuracy was unnecessary for the project needs. Rather, deionized water produced in the WWSC field office was used for field blanks. Samples of the deionized blank water were periodically analyzed for all constituents and properties determined for runoff samples. If field-blank constituent concentrations were consistently of the same magnitude or greater than concentrations in runoff samples, an evaluation of sampling equipment and process was done to determine the source of contamination. Field blanks were collected once per year at each station for Discovery Farms and Pioneer Farm; however, field blank collection started in 2006 at the Pioneer Farm stations.

\section{Cross-Section Coefficient Samples}

To determine whether constituent concentrations in the automatic, discrete samples (which were pumped from a single point at the tip of the sample-intake line) were representative of the constituent concentrations in the cross section of the water column, concurrent-replicate samples (also termed cross-section coefficient samples) were collected: one manually and one pumped by the automatic sampler. The WWSC QA Plan calls for collection of a manual sample by either the equal-width-increment (EWI) or equal-distance-measurement (EDI) method; however, it was usually too shallow to accurately collect a sample using these methods. Rather, a 1-liter polypropylene bottle was placed into the flow stream (grabbed) at the throat (exit) of the $\mathrm{H}$ flume as it cascaded to the ground below. This method collected water from the narrowest point of flow, so the chances of obtaining representative samples were likely the highest here. Immediately after the manual sample was collected, the automatic sampler was triggered to pump a single, discrete sample using the same rinse and purge cycle used for standard runoff-event samples. Both samples were analyzed as discrete samples, and no splitting of the samples was required. Cross-section coefficient samples were scheduled for collection at least once per year at all Discovery Farms stations.
Analytical results of QC samples were inspected immediately upon receipt to identify any problems with sample collection, handling, or analysis. If constituent concentrations in blank samples were consistently greater than or equal to runoff-event sample concentrations, or if cross-section coefficient samples were not closely comparable to each other, the reporting laboratory was contacted to check for errors in data reporting. If sample water was still available at the laboratory, reanalysis was sometimes requested. If the problem was not found at the laboratory, a systematic process was used to determine the causes of the contamination. The most common contamination was due to the technique used to collect blank samples. The technique was slightly modified over time to ensure that blank water was properly purged through all sampling equipment during the rinse cycle.

\section{Maintenance}

Maintenance was vital to accurately measure the quantity and quality of surface-water runoff from edge-offield stations. During spring, summer, and fall, stations were periodically maintained by mowing around the enclosure and along the wingwall. This was done to ensure easy access around the enclosure as well as to allow inspection of the wingwall. Flumes were surveyed at least twice per year to determine whether adjustments to the stage-discharge relation were necessary. Maintaining fuel levels for stations with generators was also a part of station maintenance.

More maintenance was needed at edge-of-field stations during winter than for the rest of the year. During winter, snow and ice could fill the $\mathrm{H}$ flume and downstream channel, causing backwater conditions if runoff had occurred. In addition, ice in the flume could cause the bubble tubing and the sample-intake line to freeze, causing erroneously high stage measurements and preventing samples from being pumped.

Frequent visits were necessary to remove ice and snow prior to anticipated surface-water runoff events. Ice was generally removed by carefully breaking it into smaller pieces with a hammer. Portable clothing steamers also were used to cut through ice that was particularly thick. In most cases, snow was removed from the $\mathrm{H}$ flume, and a trench was dug in the snow upstream and downstream from the $\mathrm{H}$ flume (fig. 15). The trench upstream from the $\mathrm{H}$ flume prevented surface-water runoff from flowing on top of the snow and cascading into the $\mathrm{H}$ flume, causing erroneous stage readings because of turbulence. The trench downstream from the $\mathrm{H}$ flume was cleared to a point where the flume would be free of backwater. 


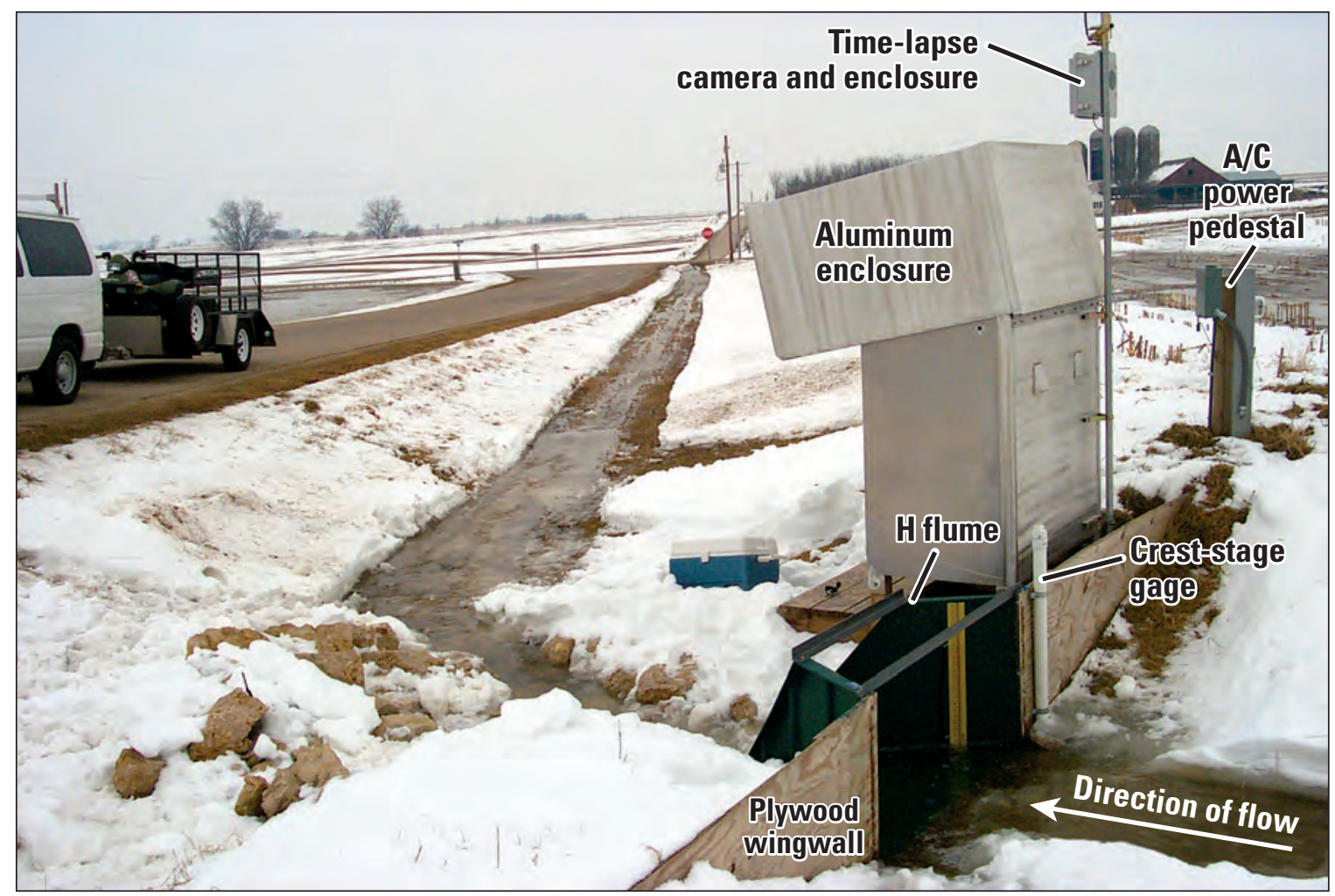

Figure 15. Snow was cleared downstream from the flume to prevent backwater conditions. Wintertime maintenance was essential to collecting accurate data.

Numerous attempts were made to reduce maintenance required by the ice formation in the $\mathrm{H}$ flumes. Most were relatively ineffective. Development of better ice-preventative systems is still being researched; however, there was no substitute for frequent station visits for proper maintenance.

The first four $\mathrm{H}$ flumes for edge-of-field stations at Pioneer Farm were ordered with a standard white finish. All newer flumes for Pioneer Farm and all Discovery Farms flumes were ordered with a dark-green finish. On sunny days, the dark color of the $\mathrm{H}$ flume helped to absorb solar energy, thus melting ice within the flume, or at least making ice less likely to attach securely to the flume, making it easier to clear the flume of ice.

Plywood and clear acrylic covers were built over the flumes to try to prevent snow buildup and to trap heat within the flume. These methods generally did not work well, because snow became trapped and accumulated in the $\mathrm{H}$ flume underneath the covers. The acrylic covers were brittle in cold weather and broke easily. Rubber flaps were added to minimize the snow buildup, but they often froze to the ground in ice that formed in front of the flume. Propane heaters were hung in the $\mathrm{H}$ flumes to prevent ice from forming. The propane heaters were difficult to keep operating because wind would blow out the pilot light.

Infrared heat lamps were also used to prevent ice formation. The lamps melted the ice directly below the lamp, but power had to remain on constantly to prevent ice from reforming. The constant power necessary was only available at AC-powered stations. Also, the heat lamp bulbs had a tendency to break in below-freezing conditions.

Tents were erected to cover the $\mathrm{H}$ flume and a short distance upstream and downstream from the flume to prevent ice formation at some Pioneer Farm stations. Directional propane heaters were used in conjunction with the tents to prevent freezing. This method was successful but required much maintenance. If ice formed within the tents, it was difficult to remove because of limited working space.

Heat tape was placed within the $\mathrm{H}$ flume at most edge-of-field stations to reduce or prevent ice that formed near the bubble tubing, sample-intake-line tip, and flume exit. The heat tape was attached to the floor of the $\mathrm{H}$ flume near the sample-intake line and bubble tubing, and exited out of the downstream side of the flume. The heat tape was 
somewhat effective, provided that it could be constantly powered. Although the heat tape did not totally prevent ice buildup in the flumes, it was effective at reducing water freezing in the tip of the sample-intake line and bubble tubing and reduced freezing of water in the exit of the flume.

\section{Streamgaging Stations}

\section{Equipment}

There were six streamgaging stations ranging in contributing basin size from 215 to 1,882 acres in the Discovery Farms and Pioneer Farm programs. Discovery Farms streamgaging stations used $\mathrm{H}$ flumes to compute discharge, whereas the streamgaging stations at Pioneer Farm used standard, measurement-based stage-discharge techniques to compute discharge. Equipment similar to that used for edge-of-field stations was used for stage measurement, sampling, data capture, measurement and control, communication, and power: Sutron Accubar nonsubmersible pressure transducers were used to monitor stage, refrigerated ISCO samplers were used to collect water samples, and Campbell Scientific, Inc. CR10 or CR10X dataloggers were used for data capture and program control. Communication was established by either telephone modem and/or wireless telemetry, and electrical power was provided by AC, generator, or solar power. The primary difference between equipment used for streamgaging stations and edge-of-field stations was that the Discovery Farms streamgaging stations used interlocking, 2-foot-wide, 8-gage steel sheet piling for wingwalls, rather than plywood. In addition, the Discovery Farms streamgaging stations used thermocouple wire to measure water temperature.

\section{Discovery Farms}

Like edge-of-field stations, streamgaging stations monitored for the Discovery Farms program used $\mathrm{H}$ flumes for the continuous determination of discharge (fig. 16). The H flumes were connected to a wingwall constructed of steel sheet piling that was driven to the point of refusal into the stream bottom and banks. The use of sheet piling helped to prevent water from undercutting the flume and provided strength to prevent failure during periods of high discharge.

The bubble tubing for stage measurements in two of the streamgaging flumes was located within 6-inch-diameter stilling wells rather than on the flume floor. Monitoring stage in stilling wells was thought to be advantageous

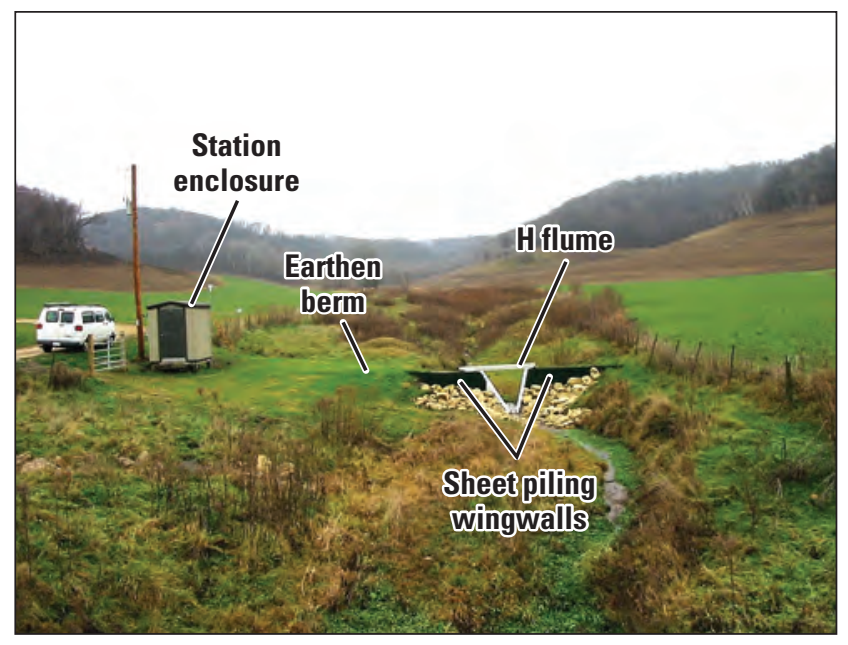

Figure 16. Sheet piling and earthen berms were used as wingwalls for the streamgaging stations at Discovery Farms.

in that stage measurements would be protected from high stream velocities that could create a drawdown effect, causing stage measurements to read erroneously low. However, sediment occasionally filled in the stilling well, causing erroneously high stage readings. In addition, numerous comparisons of staff-gage measurements to those recorded by the dataloggers showed that drawdown was insignificant in $\mathrm{H}$ flumes where the bubble tubing was attached to the flume floor-even for high discharges. Access to the bubble tubing in a stilling well for maintenance was also more difficult.

The location of the sample-intake line tubing in the streamgaging $\mathrm{H}$ flumes was similar to that for edge-offield stations - near the flume exit—but the sample tubing was approximately 1 inch above the flume floor to prevent bedload material from being pumped into the sample bottles.

\section{Pioneer Farm}

At Pioneer Farm, two streamgaging stations were located in an upstream/downstream configuration. Unlike edge-of-field stations at the farm, $\mathrm{H}$ flumes were not used to estimate discharge. Rather, continuous discharge was estimated from continuous open-channel stage measurements according to standard USGS methods after defining a stage-discharge relation within the stream channel (fig. 17; Buchanan and Somers, 1969; Rantz, 1982). Instantaneous discharge measurements for use in the rating were made approximately every 3 weeks and more frequently during high discharges. 


\section{Sample Collection}

\section{Sample Collection and Pickup for Runoff Events}

Sample collection and pickup during periods of runoff for streamgaging stations was similar to that at edge-of-field stations for Pioneer Farm and for the Iowa County Discovery Farm. Runoff-event samples collected by the ISCO samplers were generally retrieved within 24 hours of the end of a runoff event. At that time, sampleretrieval sheets and/or miscellaneous-note sheets were filled out (Appendixes 1 and 2), and staff-gage readings in the $\mathrm{H}$ flumes and the corresponding stages recorded by the datalogger were noted. Samples were removed from the ISCO samplers, labeled, placed in coolers with ice, and then transported to the WEAL for analysis. Samples for streamgaging stations were typically received by the laboratory within 3 days of a runoff event. Several trips to pick up and deliver samples were typically made for runoff periods that lasted more than 2 days. Occasionally, some samples were not received by the laboratory for 4 days or more from the time the first sample was collected.

Stage data were recorded by the datalogger at 15 - or 60-minute intervals during base-flow conditions. The datarecording frequency increased to 1 minute or 5 minutes when the stage exceeded the data threshold, which was generally within 0.1 to 0.2 foot above the pre-event baseflow stage. The sampling threshold was set equal to or slightly greater than this stage. Sampling ended when the stage receded below the sampling threshold.

Sample collection at Buffalo County farm streamgaging stations differed from that at the stations described above. This was the first farm established for the Discovery Farms program, and the samples were sent to the Wisconsin State Laboratory of Hygiene in Madison, Wis. (WSLH). The WSLH did not do any splitting of the samples to produce the single composite sample for each surface-water runoff event, so volume-paced event samples were collected by use of the ISCO sampler. Two discrete subsamples were collected per bottle, allowing a maximum of 48 samples per runoff event. The accumulated-discharge and the sample-threshold variables were adjusted for each runoff event based on anticipated precipitation amounts and intensities, antecedent moisture conditions, and season. Accumulated discharge between samples was occasionally adjusted during runoff events to maximize sample coverage without exceeding sampler capacity.

Buffalo County farm samples were usually retrieved within 24 hours of the end of sampling a runoff event. The sample bottles were labeled and placed in a cooler with ice for transportation back to the USGS WWSC for process-

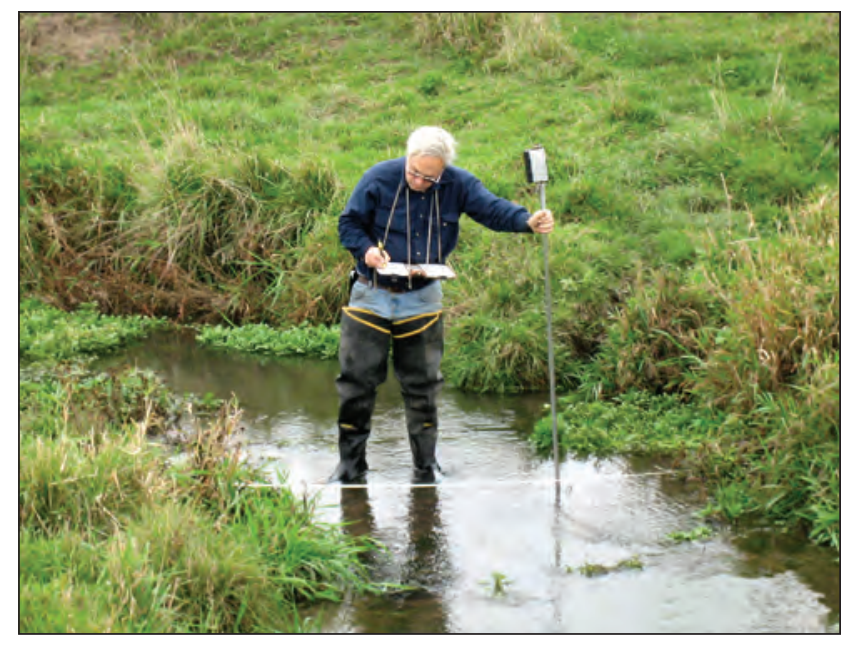

Figure 17. U.S. Geological Survey field technician making a discharge measurement at a streamgaging station at Pioneer Farm.

ing. Several trips to pick up and deliver samples were typically made for runoff events that lasted more than 2 days.

The samples were split and a single composite sample was sent to the WSLH for analysis for each runoff event.

\section{Sample Collection during Base Flow}

Base-flow samples for the Discovery Farms program were collected once per month and delivered to the WEAL (for samples from Iowa County streamgaging stations) or the WSLH (for samples from Buffalo County streamgaging stations) for analysis. Samples were collected when it was assumed that there was no overland flow component to streamflow. Each sample was assumed to represent the constituent concentrations for the base-flow component of streamflow for that month. The base-flow sample was a grab sample, collected in a 1-liter polypropylene ISCO bottle from the exit section of the flume. For the Pioneer Farm program, stream base-flow samples were collected every 2 weeks by triggering a sample with the ISCO sampler.

\section{Maintenance}

Streamgaging stations required periodic maintenance. During summer, algae growth in the flume and inside the tip of the bubble tubing occasionally caused erroneously high stage readings. Sediment was sometimes deposited in the flume during runoff events. Station visits were made to purge the tubing of algae and to clear algae and sediment from the flume. At flume locations with stilling wells, the stilling wells were periodically flushed with clean water to 
remove sediment that accumulated in the bottom. Streamgaging stations with flumes were surveyed at least twice per year to determine whether adjustments to the stagedischarge relation were necessary. Staff-gage readings in the $\mathrm{H}$ flume were also compared to stages recorded by the datalogger to check for accuracy.

During winter, ice sometimes formed in the stream channel and in the $\mathrm{H}$ flumes. During station visits, ice was removed from the flumes similarly to the methods used for edge-of-field stations. Ice in the stream channel could not be prevented and was not easily removable, so discharge measurements were made during ice-affected periods to determine the degree of backwater and to develop a stagedischarge relation to account for these conditions.

\section{Subsurface-Tile Stations}

\section{Equipment}

There were five subsurface-tile stations for the Discovery Farms program ranging in contributing basin size from 13.2 to 641 acres. Equipment similar to that used for streamgaging stations was used for stage measurement, sampling, data capture, measurement and control, communication, and power: Sutron Accubar nonsubmersible pressure transducers were used to monitor stage, refrigerated ISCO samplers were used to collect water samples, thermocouple wire was used to measure water temperature, and Campbell Scientific, Inc. CR10 or CR10X dataloggers were used for data capture and program control. Communication was established by either telephone modem and/ or wireless telemetry, and electrical power was supplied either by AC, generator, or solar power. The primary equipment difference between edge-of-field, streamgaging, and subsurface-tile stations was the type of flume used to compute discharge. Subsurface-tile stations were located both within fields and at subsurface-tile outlets.

\section{Subsurface Tiles within Fields}

Monitoring was done at three subsurface tiles within fields. The two monitored tiles in Kewaunee County (table 1, fig. 19) were made of clay and were 6 inches in diameter; the tile monitored in Manitowoc (table 1, fig. 18) was concrete and was 12 inches in diameter. All three in-field tiles were approximately 3 feet below the land surface, beneath grassed waterways.
A backhoe was used to create a 10-foot-deep hole that bisected the subsurface tile at the desired monitoring location. The hole was then backfilled with several feet of 2-inch rock, and a 10-foot-long, 5-foot-diameter round plastic culvert with cover was placed vertically on top of this rock, leaving approximately 2 feet of the culvert above ground. A 4-foot-deep trench was dug approximately 10 feet upstream and downstream from the monitoring location to break and remove sections of the existing tile. The existing tile was then replaced with a similar diameter 20-foot-long piece of polyvinyl chloride (PVC) sewer pipe that was routed through holes cut in the culvert (fig. 18). The culvert was then backfilled with 2 -inch rock to a level approximately 2 feet below the PVC pipe to allow water storage, and the remaining trench was backfilled with the excavated soil.

Either "extra-large," 60-degree, v-throat, trapezoidal flumes or 2-inch (throat width), 45-degree Washington State College trapezoidal flumes were installed in line with the PVC pipe within the vertical 5-foot-diameter culvert (fig. 19). Trapezoidal flumes were used to compute discharge in subsurface tiles at all three of these stations. These flumes were chosen because of their ability to accurately measure low discharges, and their cross-sectional shape was conducive to placement in line with subsurface tiles.

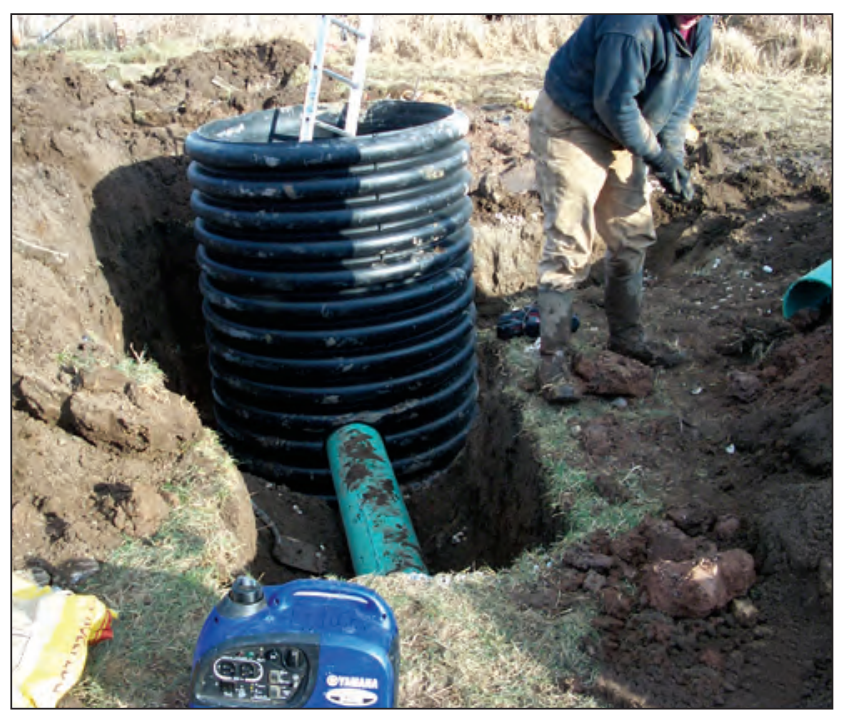

Figure 18. A 5-foot-diameter culvert was installed to allow access to in-field subsurface tiles. 


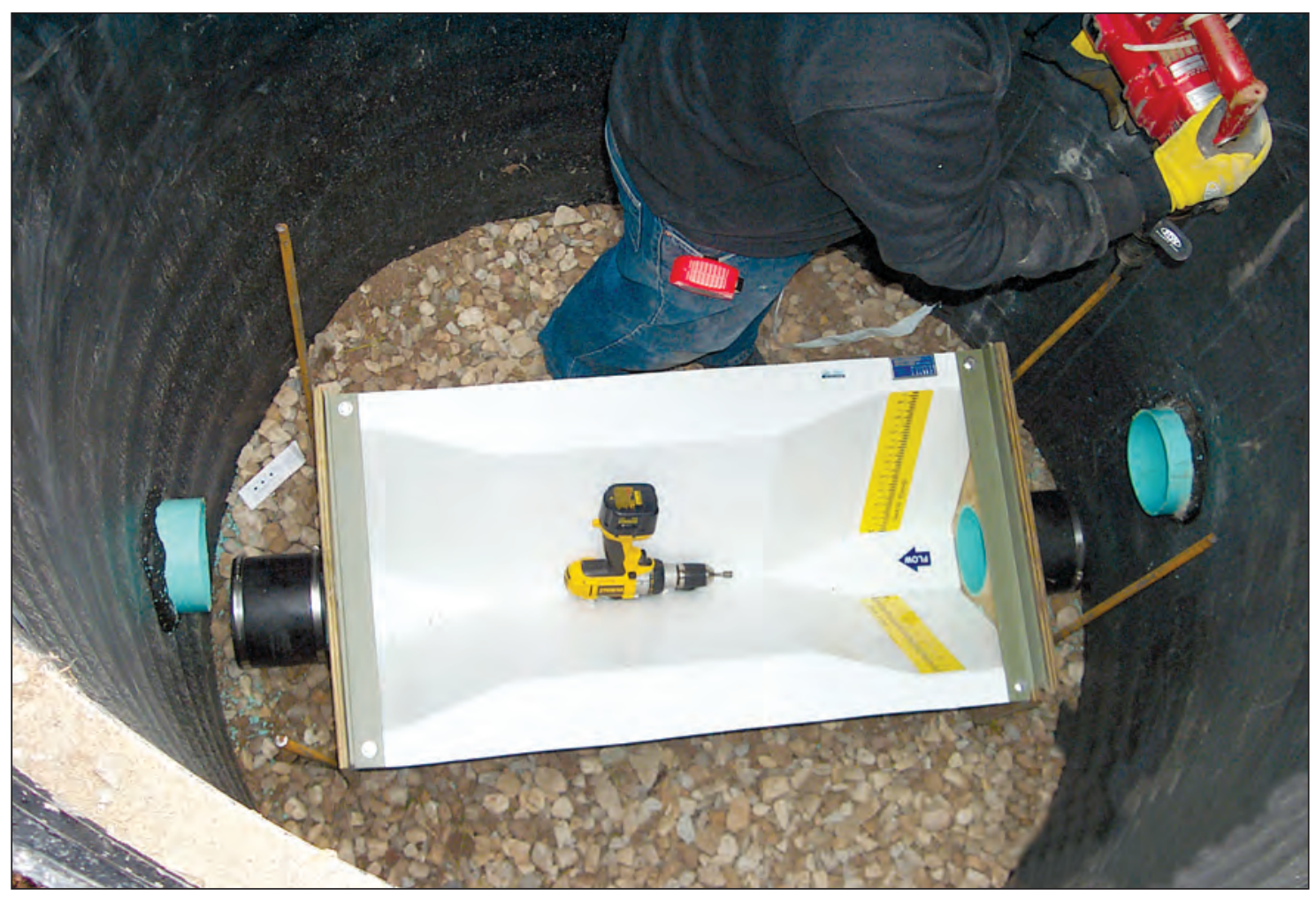

Figure 19. Extra-large, 60-degree, v-throat, trapezoidal flumes were installed inline with subsurface tiles within fields to compute discharge.

To install the flume, treated plywood was attached to both ends of the flume and a hole was cut in the plywood to receive two short pieces of the PVC pipe. The flume, plywood, and short PVC pieces were then attached to the inline PVC pipe by means of rubber gaskets. The flume was supported using pieces of rebar driven into the backfilled rock and soil. Care was taken to ensure that the flume was level from side to side and was set with a slight drop toward the downstream side (consistent with the existing tile slope). Field measurements indicated that the trapezoidal flumes were sensitive to front-to-back slope, so the slope was measured and the discharge was corrected accordingly during data analysis. Bubble tubing for measuring stage was connected to the floor of the flume near the staff gage (the upstream side). The sample-intake line was positioned approximately $1 / 4$ inch above the flume floor near the bubble tubing.

\section{Subsurface Tiles at Outlets}

Monitoring was done at the outlets of two 6-inch PVC subsurface tiles in Waukesha County. Extra-large, 60-degree, v-throat, trapezoidal flumes were used to compute discharge (fig. 20). The flumes were attached to the outlet of existing tile using the same materials as the in-field subsurface-tile stations and were supported with rebar. Treated plywood boxes with insulated covers were constructed around the flumes to prevent snow and other debris from clogging them. Bubble tubing and sampleintake lines were attached as for the in-field subsurface-tile stations.

\section{Sample Collection}

Time-paced samples were collected at in-field and subsurface-tile outlet stations. At the time of this study, changes in constituent concentrations in the monitored subsurface tiles were not well understood. Also, some of the monitored subsurface tiles were observed to flow for most of the year and, generally, stop flowing only during particularly dry periods. In order to fully characterize the dynamics of constituent concentrations found in these tiles, water was sampled at representative intervals during runoff. Increases in discharge due to precipitation or snowmelt events were sampled more frequently (minutes to hours) than were the lengthy recession periods (hours to days).

Monthly samples were adequate to describe base-flow periods in streams, because the source of water in streams (ground water) usually had relatively consistent constituent 


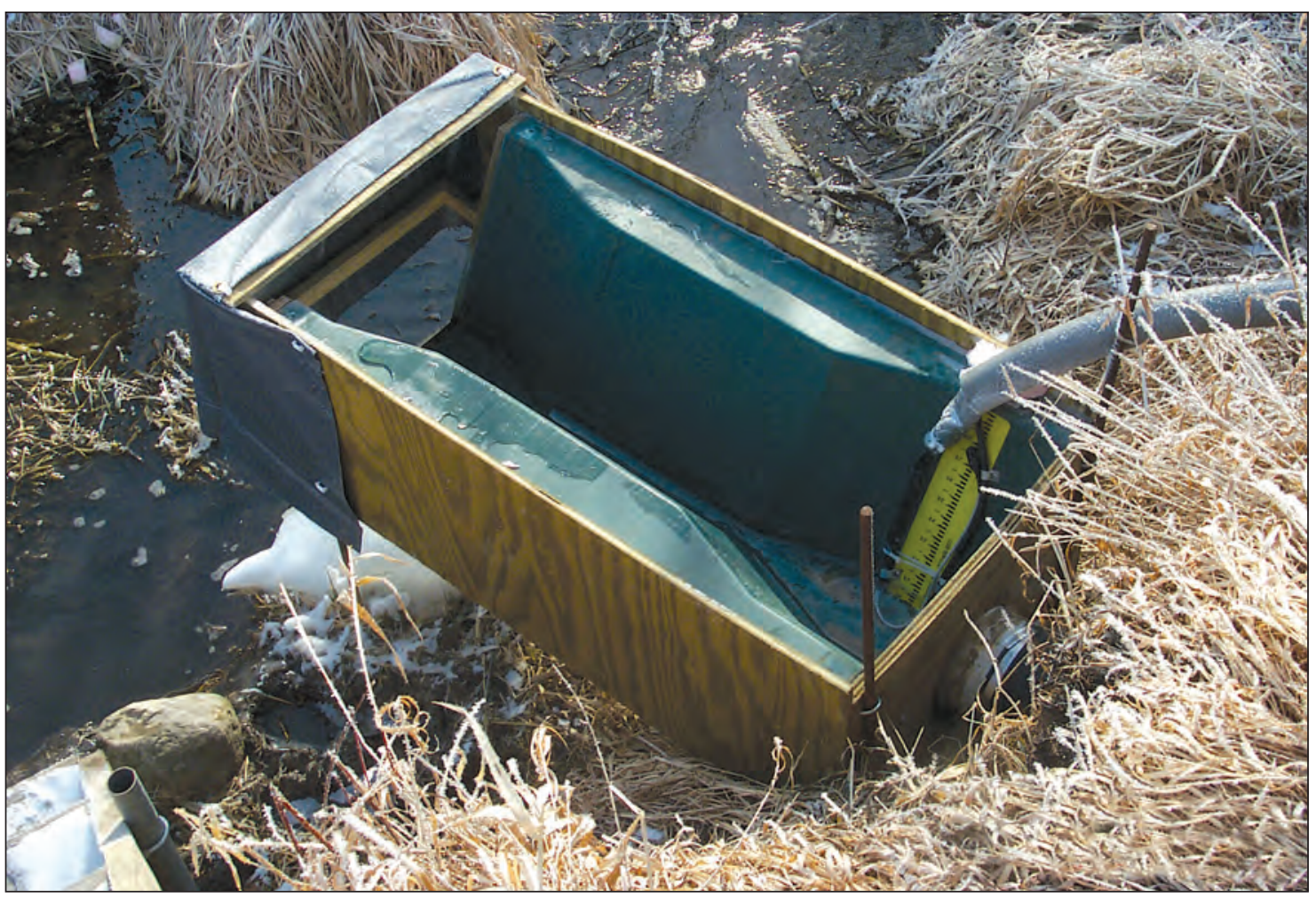

Figure 20. Extra-large, 60-degree, v-throat, trapezoidal flumes were used to compute discharge at the outlets of subsurface tiles. The insulated plywood cover was removed for this photo.

concentrations. In subsurface tiles, however, the source of water during the recession - and the associated constituent variability—was unknown, and therefore a higher sampling frequency for base-flow periods was required until the systems were better understood. If a particular subsurface-tile station was found to have consistent concentrations during base flow, a lower sampling frequency was eventually used.

Stage data were recorded by the datalogger at 15 -minute intervals during zero-flow or low-flow conditions. The data recording frequency increased to 5 minutes when the stage exceeded the data threshold, which was generally within a few hundredths of a foot above the point of zero flow. When the tile was flowing, the sample threshold was set at about 0.1 foot higher than the pre-event stage. When the tile was not flowing, the sampling threshold was usually set a few hundredths of a foot above the data threshold so that samples were collected shortly after event runoff began. Sampling ended when the stage receded below the sampling threshold.

Runoff-event samples collected by the ISCO samplers were generally retrieved within 24 hours of the end of a runoff event. At that time, sample-retrieval sheets and/ or miscellaneous-note sheets were filled out (Appendixes
1 and 2), and staff-gage readings in the $\mathrm{H}$ flumes and the corresponding stages recorded by the datalogger were noted. Samples were removed from the ISCO samplers, labeled, placed in coolers with ice, and then transported to the WEAL for analysis. Samples for subsurface-tile stations were typically received by the laboratory within 3 days of a runoff event. Several trips to pick up and deliver samples were typically made for runoff periods that lasted for more than 4 days. Occasionally, some samples were not received by the laboratory for a week or more from the time the first sample was collected.

\section{Maintenance}

Subsurface-tile stations were generally maintained much like the edge-of-field stations, with periodic mowing and inspection in summer. The in-field subsurface-tile stations did not freeze in winter, so maintenance was similar to that in other seasons. The subsurface-tile outlet stations did occasionally freeze during winter. Heat tape was placed along the sample-intake lines and bubble tubing to prevent them from freezing. 


\section{Meteorological Stations}

\section{Equipment}

Meteorological stations were installed at five of the seven Discovery Farms and at Pioneer Farm (fig. 21). Each meteorological station recorded precipitation, wind speed, wind direction, air temperature, relative humidity, solar radiation, soil temperatures (at 2, 5, 10, 20, 40, and 80 centimeters depth), and soil moisture (30-centimeter average and/or at 10, 20, 30, and 50 centimeters depth). A detailed listing of manufacturers and equipment names can be found in table 6. Each station was also equipped to allow remote communication via wireless or phone telemetry.

Wind speed and direction, air temperature and relative humidity, and solar radiation instruments were attached to a 20-foot aluminum tower at approximately 20 feet, 6 feet, and 7 feet above ground level, respectively. The tower was located on a hill and/or away from buildings and trees on the monitored farm. In some cases, a taller tower was installed to enable or improve wireless communication.

Soil temperature probes were installed by means of a strip of treated wood with small holes drilled at the appropriate depths. The probes were inserted through the holes and secured with wire ties (fig. 22). A 4- to 6-inchdiameter vertical hole was dug in the soil and the wood and probes were placed into the hole, pushed horizontally into the undisturbed soil profile; the hole was then carefully backfilled.

Two types of soil-moisture probes were usually used at each location: the Campbell Scientific, Inc. model CS616 and the Sentek EasyAg probe. The CS616 was inserted into the ground vertically and, as installed, measured the average soil moisture content of the top 30 centimeters of soil. The EasyAg was installed vertically by use of product-specific installation tools. Soil-moisture values for the EasyAg were measured at 10-, 20-, 30-, and 50-centimeter depths.

Tipping-bucket precipitation gages ( 0.01 inch per tip) were installed on either a 6 -inch round wooden post or 2-inch galvanized pipe. The post or pipe was driven 3-4 feet into the ground, and the precipitation gage was attached to the top and leveled. The top of the precipitation gage was typically 7 feet off the ground and away from overhead obstructions. The precipitation gages were used to quantify all unfrozen precipitation.

Meteorological data were recorded on a Campbell Scientific, Inc. CR10 or CR10X datalogger. A Campbell Scientific, Inc. COM 210 telephone modem and/or Campbell Scientific, Inc. RF400 radio/modem were used for remote communication. Equipment at the station was powered by a 12 volt, 8 -ampere-hour battery charged by a 10-watt solar panel. All datalogger and communication instrumentation was contained in a fiberglass enclosure mounted to the tower.

\section{Maintenance}

Maintenance was minimal at meteorological stations. During the growing season, grass was trimmed around the base of the station tower. During this time, equipment was visually inspected. The tipping-bucket precipitation gages were checked for levelness and cleaned periodically throughout the year. Calibrations were done at least once per year to ensure accuracy.

Table 6. Equipment used for collection of meteorological data.

[Any use of trade, product, or firm names is for descriptive purposes only and does not imply endorsement by the U.S. Government.]

\begin{tabular}{lll}
\hline \multicolumn{1}{c}{ Instrument type } & \multicolumn{1}{c}{ Manufacturer } & \multicolumn{1}{c}{ Instrument name } \\
\hline Wind speed and direction & Met One Instruments, Inc. & 034B windset \\
Air temperature and relative humidity & Vaisala & 50Y temperature/RH probe with solar radiation shield \\
Solar radiation & LI-COR Biosciences. Inc. & LI200x pyranometer \\
Soil temperature & Campbell Scientific Inc. & 107 temperature probe \\
Soil moisture & Sentek Sensor Technologies & EasyAg \\
Soil moisture & Campbell Scientific, Inc. & CS615, CS616 \\
Precipitation & Design Analysis Associates & H340SDI Tipping-bucket Rain Gage \\
\hline
\end{tabular}




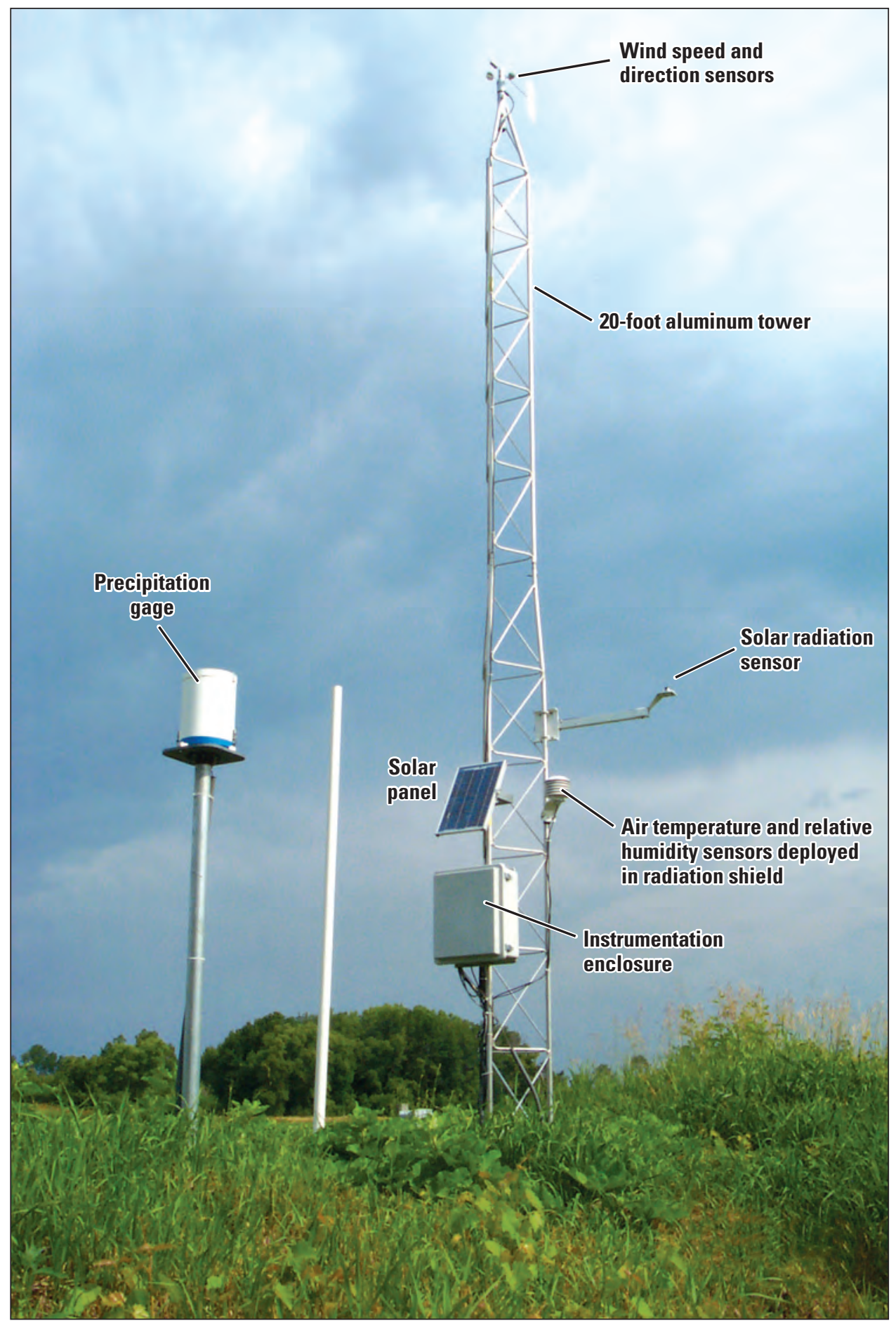

Figure 21. Meteorological station equipment typically measured precipitation, wind speed and direction, air and soil temperature (in profile), relative humidity, solar radiation, and soil moisture (in profile). 


\section{Sample Processing for Edge- of-Field, Streamgaging, and Subsurface-Tile Stations}

Water-quantity and water-quality data generated for each runoff event were subjected to a series of office and laboratory processes that required consideration of two issues: which samples were to be combined to form a composite sample, and how the samples were to be combined. Samples were processed one of two ways as described below. Both processes were designed to provide a sample for laboratory analysis that represented the water conditions for that sampled period.

\section{Sample Processing for Samples Sent to the Water and Environmental Analysis Laboratory}

Numerous time-paced, 1-liter discrete samples were collected for each runoff event. Analyzing each discrete sample was cost prohibitive and more than was needed to meet the objectives of the Discovery Farms and Pioneer Farm programs. Rather, a single, composite sample that represented the mean discharge-weighted concentration for each runoff event was produced. This composite sample was produced from discharge-weighted portions of every discrete sample collected.

Prior to sample analyses, a "splitting record" was developed for each runoff event to help prepare the composite sample (Appendix 3). The constituent concentrations from this sample were multiplied by the runoff-event volume to estimate an event load.

\section{Splitting Records}

A splitting record was a spreadsheet generated from detailed time-series data for stage, discharge, precipitation, and selected sample information for each runoff event. A portion of this splitting record, the "summary" (fig. 23), was emailed to the WEAL to provide information on how the samples were labeled during pickup, when samples were picked up, sample dates and times, which discrete samples were to be combined for a particular composite sample, the volumes of each sample that should be used to create the composite sample, and other pertinent information.

Computations within the splitting record worksheet were based on the assumption that each discrete sample

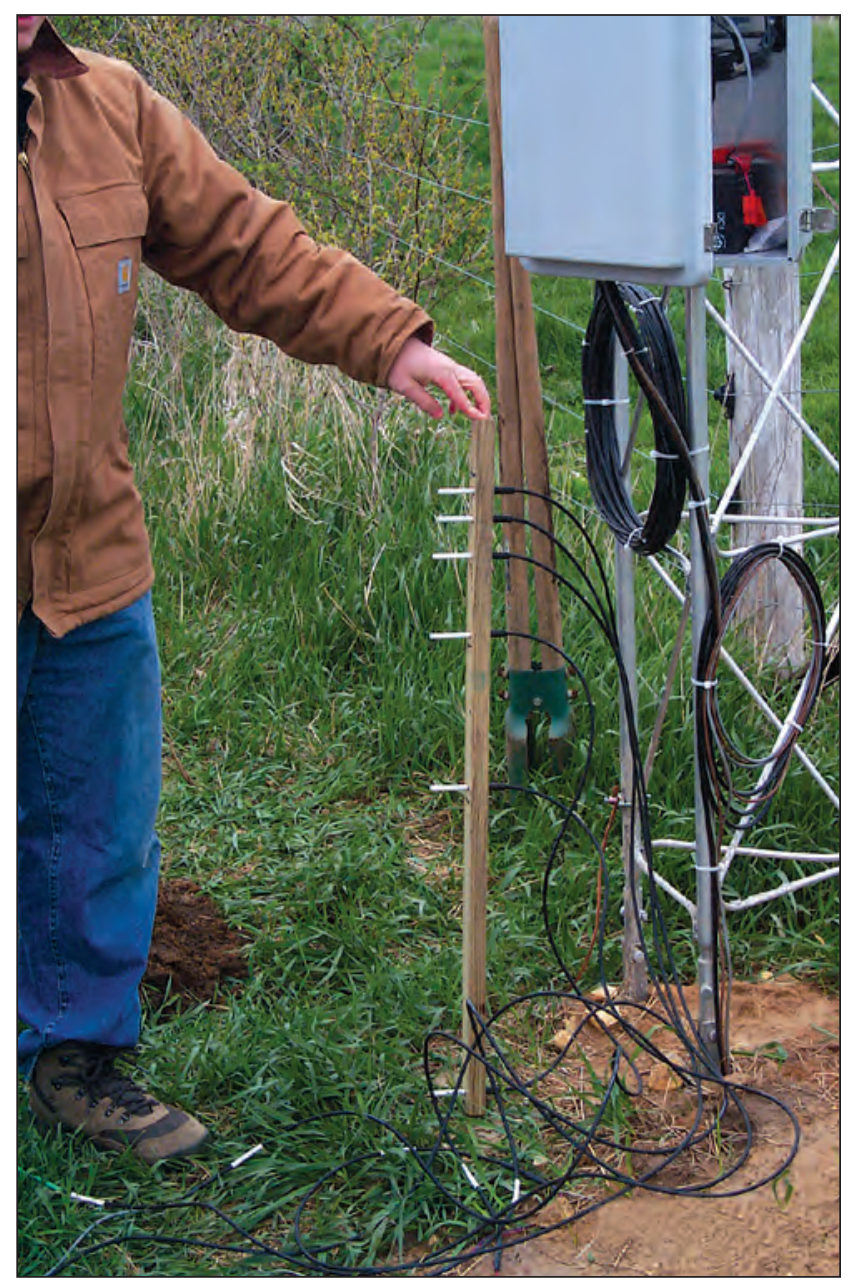

Figure 22. Soil-temperature probes ready for installation.

collected during a runoff event represented average constituent concentrations in runoff water that had passed through the flume from the time halfway between a sample and the sample before and after it. Based on this assumption, the runoff volume that each discrete sample represented was calculated by summing the time-series discharge values for the appropriate time periods. Each discrete sample-runoff volume was then multiplied by the maximum amount of water to be removed from each sample bottle and then divided by the maximum discrete sample-runoff volume (of all the discrete samples to be included in the composite sample). The maximum amount of water to be removed from each sample bottle was then adjusted so that the total volume of the composite sample did not exceed 4 liters (slightly less than the churn capacity). These calculations determined the appropriate volume of water to be removed from each discrete sample (aliquot) to be combined to create a discharge-weighted composite sample. By use of this 


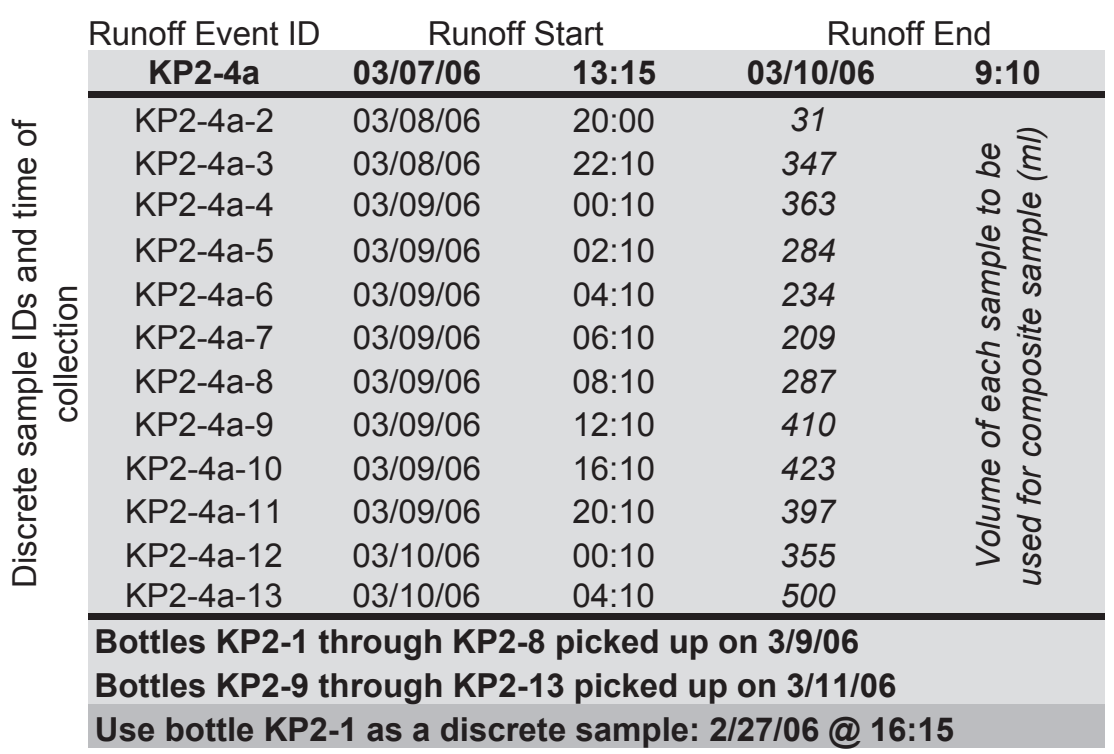

Figure 23. Example of a splitting record summary showing which samples to combine and the proper aliquot sizes to create a discharge-weighted composite sample.

technique, the discrete samples representing the highest amounts of runoff volume had the highest volume of water represented in the composite sample, whereas the discrete samples representing the smallest amounts of runoff volume had the smallest amounts of water represented in the composite sample. The result of combining discrete samples in this manner was the creation of a dischargeweighted composite sample in which constituent analyses represented the event-mean concentration for a runoff event.

\section{Edge-of-Field Stations}

Splitting records for edge-of-field stations were typically created within 1 week after the end of a runoff event and subsequent sample collection in order to expedite the preparation and preservation of samples. Consequently, "raw" stage or discharge data from the datalogger was often used to produce the splitting record. Minor corrections that may have been required were done at a later time. Major corrections that would significantly affect the runoff-event volumes (and thus the volumes of each discrete sample necessary to create the composite sample) were made before producing the splitting record.

Runoff generally did not occur between events for edge-of-field stations; therefore, start and end times were usually based on when surface-water runoff began and ended. However, determining the runoff event start and end times from the "raw" data was sometimes difficult because low stages were particularly "noisy" due to wind, ice, debris, or sedimentation. In addition, splitting records were sometimes created before water stopped flowing completely. To ensure reasonably accurate volumes during the splitting-record process, start times were assumed to occur when the flume stage increased to 0.05 foot and end times were assumed to occur when stages subsided below 0.05 foot. This stage was chosen because the volume of water passing through the flume was minimal and stages above this were usually accurate with minor corrections only occasionally necessary.

During events that had multiple distinct peaks, start and end times were based on the minimum stage between peaks. For example, snowmelt events commonly lasted several days, with daytime peaks and nighttime recessions. Occasionally, discharge would continue to decrease throughout the night and then increase again with warmer temperatures the next day. In these cases, the end time of an event was assumed to occur at the same time the next event started; when the stage just started to increase. Usually, this was at the minimum stage between peaks.

\section{Streamgaging Stations}

Unlike edge-of-field stations, the monitored streams had continuous discharge; consequently, a base-flow component of streamflow needed to be accounted for when determining the start and end times of runoff events. The event start was defined as the time when the stage or discharge hydrograph began to increase above base flow. Because the recession limb of stream-runoff events was 
generally prolonged and blended into the base flow, determination of the true end of an event was somewhat subjective. For the Discovery Farms and Pioneer Farm programs, the end of a stream-runoff event was defined as the time when there was no overland flow and a minimal bank-storage component to streamflow. Although there were several methods to determine this time (Linsley and others, 1982), a technique that yielded consistent results was a simple, graphical approach. First, the event hydrograph (stage or discharge) was plotted on paper. A line (line 1) was drawn on the right-hand end of the recession plot starting 6 hours or more after overland flow was assumed to have stopped (fig. 24). Where line 1 started to diverge from the recession plot, line 2 was drawn along the slope of the previous part of the recession. The event end was then defined as the time when line 2 started to diverge from the recession plot. After determining the event start and end, a splitting record was produced in a manner similar to that used for edge-of-field stations. Discrete samples collected after the event were discarded. Like edge-of-field stations, start and end times for multiple-peak events were based on the minimum stage between peaks.

\section{Subsurface-Tile Stations}

Event start and end times were determined for subsurface-tile stations in a manner similar to that for streamgaging stations. The event start was defined as the time when the stage or discharge hydrograph began to increase. For some subsurface-tile stations, hydrograph recessions were similar to those for streams, and the same graphical method was used to determine event-end times. At other subsurface-tile stations, hydrograph recessions were not well defined and were prolonged (days to weeks), and the graphical approach was not useful or practical. For these stations, event-end times were usually determined by visible changes in hydrograph shape. When no shape change was obvious, event-end times were determined based on when samples were collected so that holding times were minimized. Like edge-of-field and streamgaging stations, start and end times for multiple-peak events were based on the minimum stage between peaks.

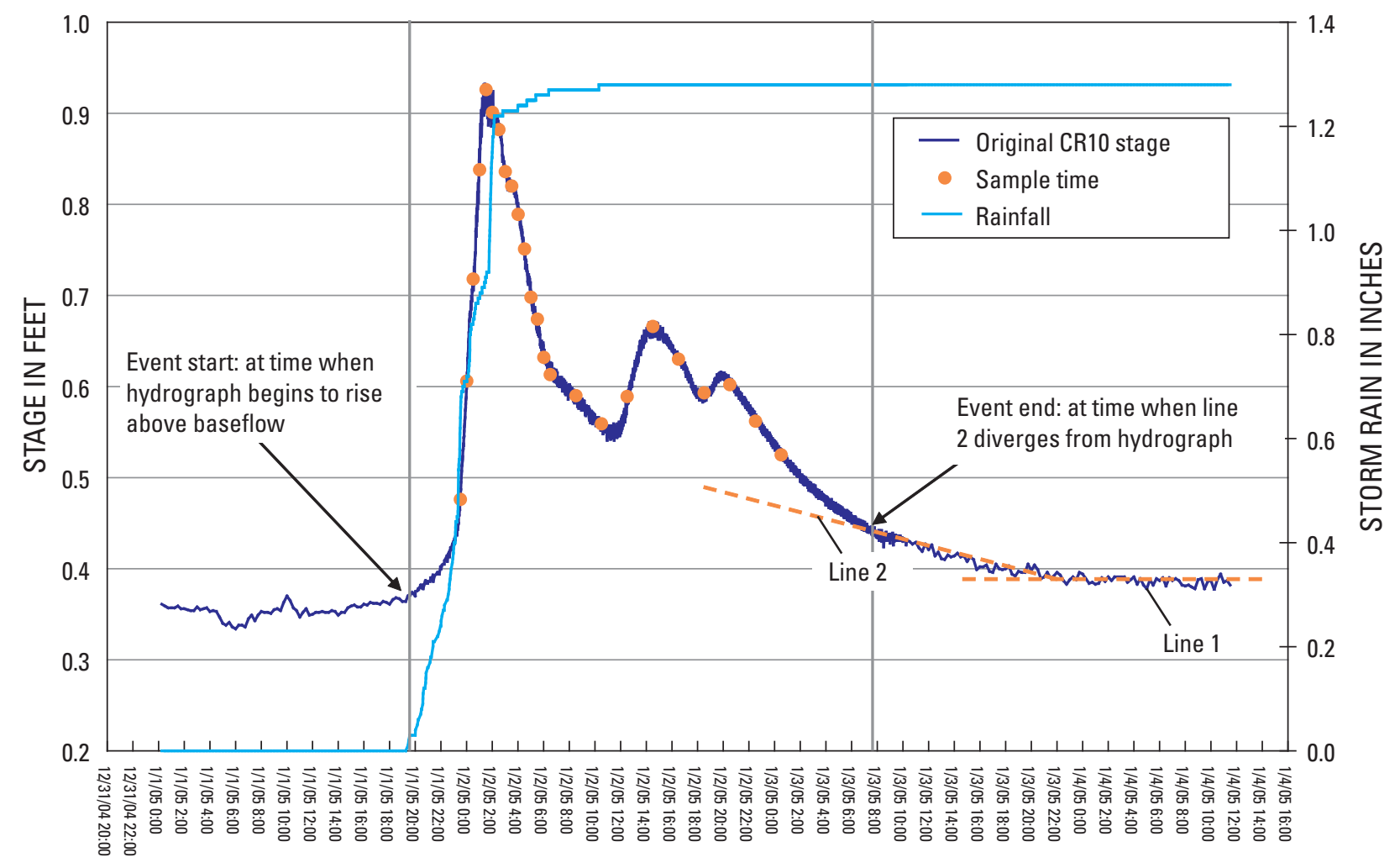

Figure 24. Example hydrograph showing the method used for determining the start and end of a runoff event at a streamgaging station. 


\section{Laboratory Procedures}

Discrete samples that arrived at the WEAL were organized by station and date and were placed in a walkin cooler at $4^{\circ} \mathrm{C}$. Once the splitting-record summary was received by the laboratory, the sample bottles were removed from the cooler and arranged in order. Each sample set was labeled with station name, event number, sample number, and sample date. The bottles were then shaken vigorously, and a photograph was taken while any suspended materials were still in suspension (fig. 25). The photograph was used as a visual reference to the runoff event to help explain variability in constituent concentrations.

\section{Splitting Procedures}

Once the discrete samples were organized, the splitting-record summary was used to combine the appropriate aliquots from each of the discrete samples to make the composite sample. Each sample bottle was shaken vigorously prior to being poured into a 4.5 -liter polyethylene churn splitter. The lid was placed on the churn and locked in place, and a pneumatic arm attached to the paddle shaft was activated to properly agitate the sample by moving the churn paddle at a rate greater than 9 vertical inches per second. The sample was agitated for at least 30 seconds before the aliquot was dispensed (according to the splitting-record summary and within $+/-10$ milliliters) into a glass graduated cylinder. The aliquot was then poured into a 1-liter polyethylene bottle. The churn and graduated cylinder were not rinsed between samples within the same set but were triple rinsed with reverse-osmosis (RO) water between samples from different stations. Aliquots from subsequent discrete samples were poured into the same 1-liter bottle until the bottle was full, then a separate 1-liter bottle was used, and so forth.

After the appropriate aliquots had been taken out of each of the discrete samples, up to 4 liters (four 1-liter bottles) of sample water was available to make the composite sample. Water from these bottle(s) was poured back into a churn where it was again agitated for at least 30 seconds before laboratory-analysis bottles were filled with the final, composite-sample water.

\section{Filtering}

Composite samples were filtered by first placing them into a clean, polyethylene transfer bottle. Samples were filtered using a filter cassette containing a 47-millimeter-diameter mixed-cellulose ester membrane with a 0.45 -micrometer pore size and a 934-AH or GD 1-micro-

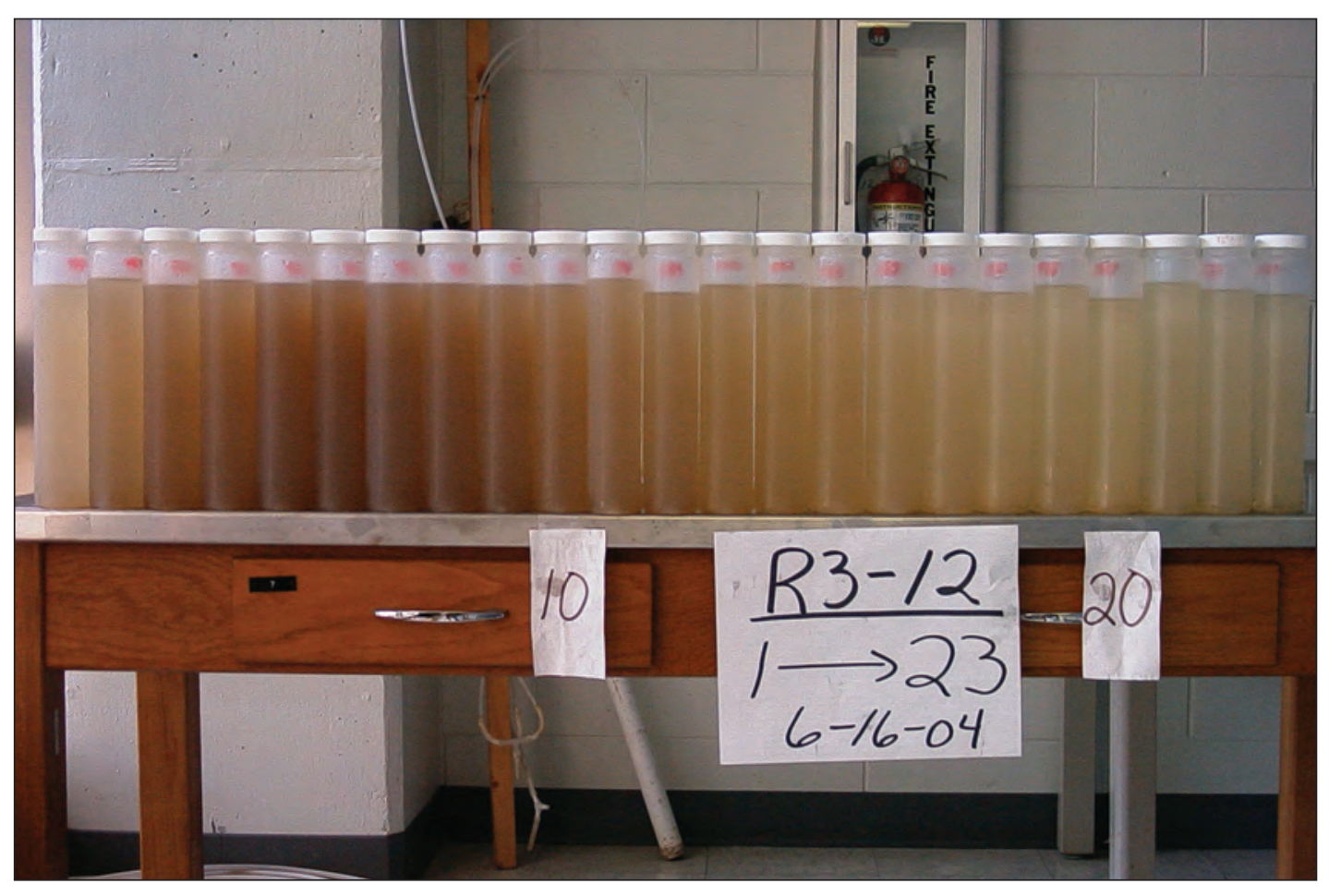

Figure 25. Photographs were taken of each set of water-quality sample bottles prior to compositing. 
meter prefilter connected to a syringe. Approximately 10 milliliters of the composite sample was poured from the transfer bottle into the syringe. The syringe was then rolled to allow the composite sample to rinse the syringe and filtering cassette until it was slowly poured out. More composite-sample water was added to the syringe, then 10 to 20 milliliters was filtered through the cassette and discarded. The remainder of the composite sample was filtered through the cassette into a laboratory-analysis bottle. For samples that contained large amounts of suspended solids or organic material, suspended particles were allowed to settle before rinsing and filtering. For these samples, a GD1 multi-grade prefilter was used instead of the 934-AH glass-fiber prefilter.

\section{Sample Processing for Samples Sent to the Wisconsin State Laboratory of Hygiene}

Different sample-processing procedures were necessary for the Buffalo County streamgaging stations because samples were analyzed at the WSLH and discrete samples were collected on a volume-paced basis. Because this technique was chosen, a splitting record was not needed. The WSLH did not prepare or split samples in a manner similar to that at the WEAL, so samples were split into the proper laboratory-analysis bottles and preserved appropriately before arrival at the WSLH.

Runoff event start and end times were determined as defined previously. Once these times were determined, the discrete sample times were examined to determine which samples should be used to create the composite sample. If sampling for a runoff event stopped before the end of the runoff event, all of the samples were kept for the composite sample. If sampling continued past the end of the runoff event, the extra samples were discarded. If the end time of the runoff event occurred between two samples that were in the same bottle (two samples were collected per 1-liter bottle at the Buffalo County streamgaging stations), then one-half of the last bottle was used for the composite sample.

\section{Splitting Procedures}

Because volume-paced samples were collected at the Buffalo County streamgaging stations, a composite sample was prepared by combining all of the discrete samples into a cleaned, polyethylene churn splitter (either 8 or 14 liters, depending on the number of discrete samples) and sample water for the individual WSLH laboratory-analysis bottles was drawn off accordingly. Sometimes, however, the preset accumulated volume between discrete samples was changed during a runoff event to increase or decrease the frequency at which samples were collected. In these cases, it was necessary to calculate how water from each discrete sample needed to be included in the composite sample.

For example, if 10 samples were collected at a certain accumulated volume, $x$, and an additional 10 samples were collected at double the accumulated volume, $2 x$ (samples were collected one-half as frequently on a volume basis), then the first 10 samples represented $10^{*} x /(10 * x+10 * 2 x)$, or one-third of the total event volume. The last 10 samples represented $10 * 2 x /(10 * x+10 * 2 x)$, or two-thirds of the total event volume. It follows that by simply combining all of the samples equally (each set of 10 bottles would represent one-half (10/20) of the total sample volume), the first 10 samples would be overrepresented and the last 10 samples would be underrepresented, thus biasing the event-mean sample concentrations.

To correct for this, the 10 bottles collected at the original accumulated volume were combined in a churn splitter and one-half of the total volume of these samples was drawn off. This water was then returned to a cleaned churn splitter and combined with the full volume of the other 10 samples. Now, the first 10 bottles of the runoff event only represented one-third of the total sample volume $(1 / 2 * 10) /$ $((1 / 2 * 10)+10)$, and the last 10 bottles represented the other two-thirds (10/15). Constituent concentrations for samples combined in this manner now correctly represented the event-mean concentrations.

Once the composite sample was combined into the churn splitter, it was agitated with a churn paddle at a rate greater than 9 vertical inches per second and dispensed into WSLH sample bottles (fig. 26). Whole-water samples and filtered samples were then collected and preserved.

\section{Filtering}

A Geotech Environmental Equipment, Inc. capsuletype Dispos-a-filter with a 0.45 -micrometer pore size was used to filter whole water from event samples for dissolved constituents. To initially flush the filter, 500 milliliters of deionized water was pumped through the filter, followed by 250 milliliters of whole water composite sample. Additional composite sample was then pumped through the filter and directed into the appropriate laboratory-analysis bottles.

Base-flow samples, which usually had much lower sediment concentrations, were filtered with a 47-millimeter-diameter, Geotech Environmental Equipment, Inc. cellulose acetate Geofilter with a 0.45 -micrometer pore size. 


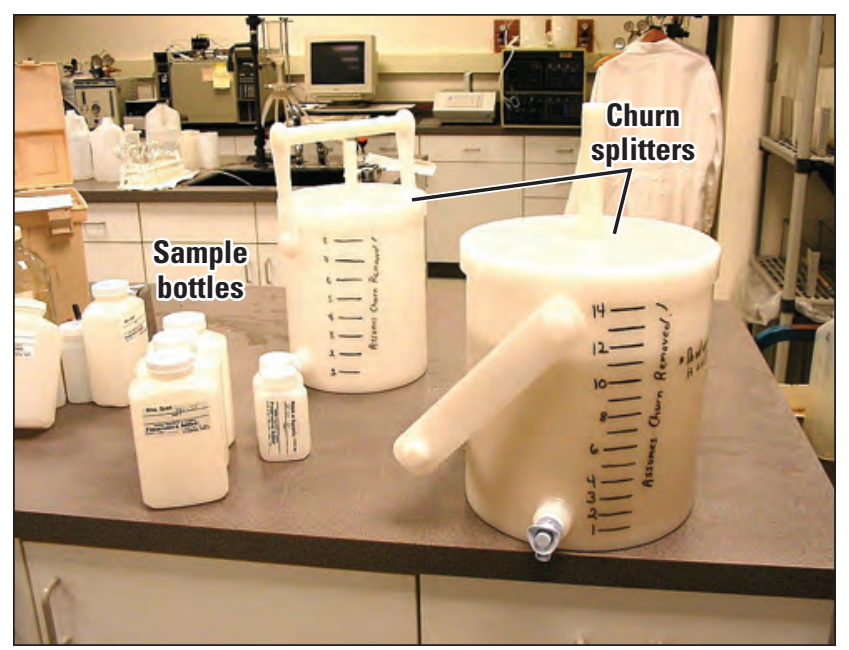

Figure 26. Churn splitters and Wisconsin State Laboratory of Hygiene (WSLH) sample bottles used for preparing samples from the Buffalo County Discovery Farm.

A variable-speed peristaltic pump was used to initially pump 250 milliliters of deionized water through the filter, followed by the composite sample.

\section{Laboratory Quality Assurance and Quality Control}

Both laboratories used for the Discovery Farms and Pioneer Farm Projects (WEAL and WSLH) were USGS accredited laboratories approved by the USGS Branch of Water Quality Systems. The analytical methods of each laboratory were therefore approved and published, standard operating procedures for these methods were documented, an internal laboratory quality-assurance plan was approved, a quality-control plan that provided data necessary to continuously track precision and accuracy of analytical data was in place, and the ability to provide the analytical services required was demonstrated. Each laboratory had a series of procedures including continuing calibration verification blanks and standards, matrix spikes, duplicates, and reference samples to ensure that constituent analyses were accurate and unbiased. Each laboratory was also reviewed periodically to ensure that documented procedures continued to be followed and that the conditions and practices in the laboratories helped them to produce analytical results of a known and documented quality.

\section{Data Analysis for Edge-of-Field, Streamgaging, Subsurface-Tile, and Meteorological Stations}

Data analysis was a process of checking, correcting, and finalizing water-quantity, water-quality, and precipitation data to ensure that it was complete and stored accurately within USGS NWIS databases. These processes were generally similar to standard USGS protocols for completing the end-of-year records for surface-water stations (Garn, 2002); however, there were some aspects of the data-analysis process that were developed specifically for the Discovery Farms and Pioneer Farm programs.

\section{Edge-of-Field Stations}

\section{Water-Quantity Data Analyses}

The first step of data analysis for edge-of-field stations was to correct the stage record. All stage corrections were applied using the Automated Data Processing System (ADAPS), an interface that allowed corrections to be applied to data within the NWIS database (U.S. Geological Survey, 2006b). Most traditional USGS surface-water streamgaging stations use multiple discharge measurements and corresponding stage readings to adjust the stage-discharge relation throughout the year. Discharge measurements were not made at edge-of-field stations; discharge was computed using precalibrated $\mathrm{H}$ flumes in which the stage-discharge relation was already predetermined. Comparisons of concurrent staff-gage readings and datalogger-stage readings were made throughout the water year to ensure that the stage record — and thus the discharge record-was accurate.

Miscellaneous-note sheets and sample-retrieval sheets (Appendixes 1 and 2) were organized for each station, and the concurrent staff-gage and datalogger-stage readings were compiled. Staff-gage readings were sometimes different from datalogger-stage readings for a variety of reasons including freezing of the bubble tubing, evaporation of water around the float (for some stations with shaft encoders), side-to-side flume tilt, and sensor drift. When differences between the staff-gage stage and datalogger stage exceeded 0.01 foot, a correction was applied to the datalogger-stage records in the NWIS database for appropriate periods.

Occasionally, there were periods when computed discharges did not reflect the actual discharge conditions at the station because of backwater conditions and/or ice 
formation in the flume. Whereas some of these periods could be estimated by applying corrections, some of them required manual data editing to produce an estimated, continuous record of discharge. These data edits were based on station-visit notes, comparisons with nearby gages, and temperature records. Figure 27 shows an example of discharge data that were edited for an event in which ice formed in the flume, causing backup of water and erroneously high computed discharges. Data edits were made in HYDRA (a graphical-analysis tool that is a subset program in ADAPS), which allowed NWIS data to be displayed and modified (U.S. Geological Survey, 2005). Data edits were usually applied shortly after a runoff event so that the conditions of the event were fresh in the mind of the hydrographer.

Peak stages recorded by the crest-stage gage (CSG) were also compared to peak stages in the datalogger record. When differences between "good" or "excellent" CSG peak stages and the peak datalogger stages exceeded 0.20 foot, a correction was applied. A larger tolerance for these differences was allowed because cork readings from the CSG were not always accurate, and stage values during runoff events were recorded every 1 or 5 minutes in the datalogger. Actual stage peaks could have occurred that were not recorded by the datalogger during these time intervals.

An offset for the datalogger stage was usually applied to the stage recorded in the datalogger at most edge-offield stations to account for the thickness of the bubble tubing or flume tilt. This offset (generally about 0.015 foot) allowed the recorded stages to match the staff-gage stages during periods of flow but resulted in nonzero stages during periods of no flow. For these periods, stages were corrected to zero; otherwise, erroneous runoff volumes would have been calculated.

Field personnel made specific notes for any maintenance that may have affected the stage record. If modifications to the stage occurred during a station visit (such as during debris or ice removal or an offset change), notes were made of the occurrence, date, and time. Corrections for these modifications were applied to the stage records for appropriate periods.

In addition to compiling notes to determine the appropriate corrections necessary for stage data, the notes also were checked to determine whether rating-shift corrections were necessary. During field testing, it was determined

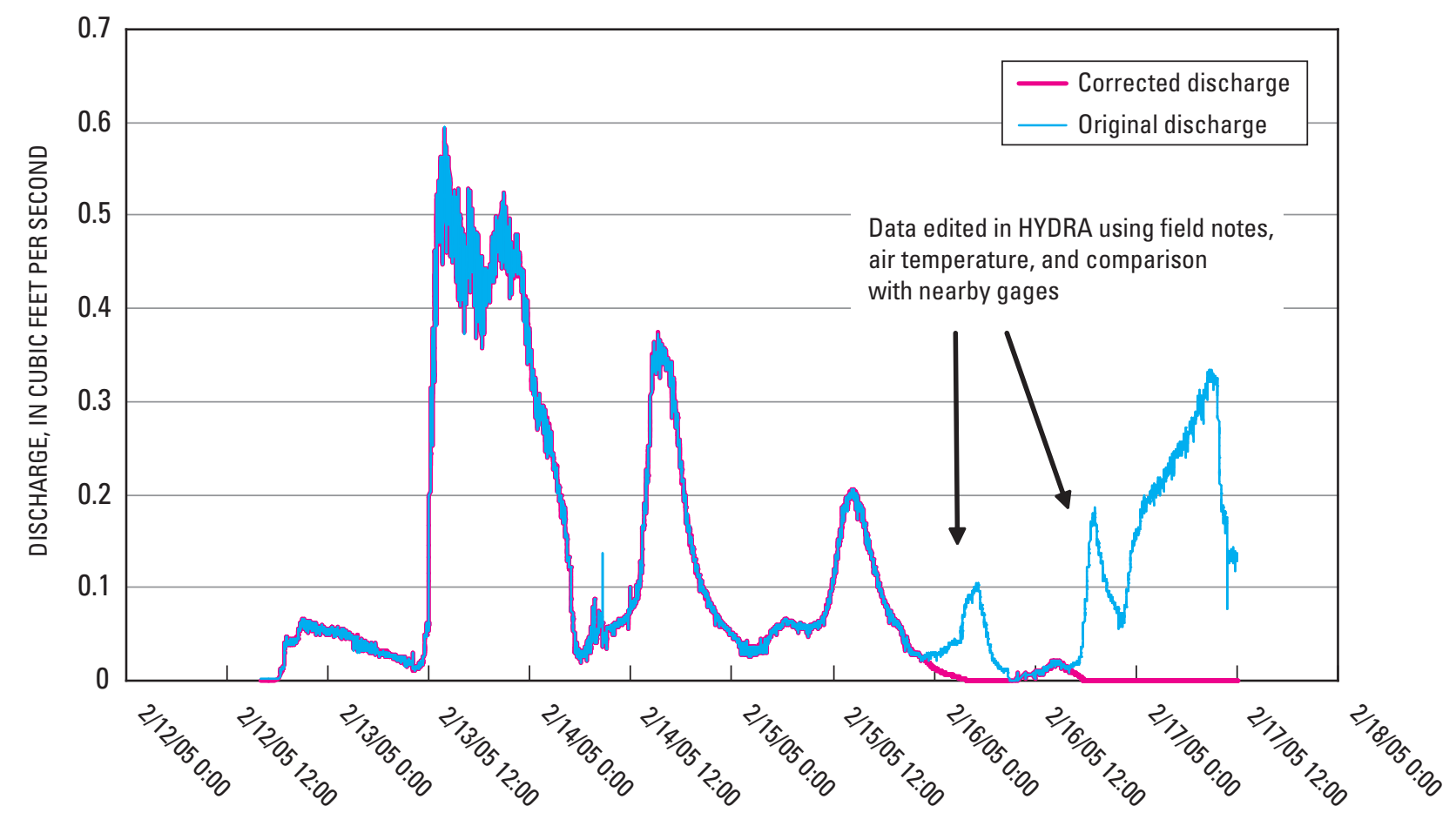

Figure 27. Example of corrections made to discharge data using HYDRA during periods that ice formed in the flume during a runoff event. HYDRA is a graphical-analysis tool that is a subset program in the Automated Data Processing System (ADAPS), which allows U.S. Geological Survey data from the National Water Information System (NWIS) to be displayed and modified. 
that, when the $\mathrm{H}$ flumes were level, measured discharge matched the rated discharge very closely. However, it was determined that a flume floor tilt from entrance to exit of just 0.02 foot in a 2.5-foot $\mathrm{H}$ flume would cause the stage to be underestimated by that same 0.02 foot. With this 0.02 -foot floor tilt and a measured stage of 0.3 feet, the resultant discharge would be underestimated by more than 10 percent compared to a level flume.

Although the stage-discharge relation for an $\mathrm{H}$ flume was stable, accuracy was highly dependent on the flumes being level from front to back and from side to side. Accurate surveys of flume tilt were done at least twice per year to determine the appropriate shift corrections. When surveys revealed that flume tilt exceeded 0.01 foot, a ratingshift correction was applied to the record for appropriate periods.

Once all corrections were applied, the stage and discharge record was recomputed and reviewed to ensure that the data and shift corrections were applied appropriately. Once reviewed, the stage and discharge records were "approved" in NWIS, a process that locks the data to prevent further modification. A station-analysis document was created to describe the flow conditions at the station during the year and to provide detail for extreme runoff events, all data and shift corrections, and any other corrections that were deemed necessary.

The next step in the data-analysis process was to determine runoff-event start and end times and volumes. Although start and end times were determined during the spitting-record process, they were usually based on raw data. This determination was based on finalized data.

HYDRA was used to visually evaluate the stage record and to determine runoff-event start and end times. For edgeof-field stations, runoff events were assumed to begin just before the time when the stage increased above zero and were assumed to end at the time when the stage returned to zero. Sometimes it was necessary to add data points to the record to estimate the beginning or end of an event because the 1- or 5-minute data output during runoff events did not begin until the stage increased above the data threshold (approximately 0.04 foot).

After determining runoff-event start and end times, the total runoff-event volume and event-peak discharge were calculated. As noted earlier, runoff-event times for edge-of-field stations began and ended at a stage of zero, whereas the sampled portions of the runoff events (using raw data) generally began and ended at a stage of approximately 0.05 foot. For this reason, the calculated sampled volumes were usually slightly less than total event volumes.
A data-summary spreadsheet was prepared for each edge-of-field station (Appendix 4). These spreadsheets included information for start and end time of runoff events, percentage of event volume sampled, number of discrete samples collected per event, peak discharge, precipitation depth and intensity, runoff-event volume, and ground conditions preceding an event (frozen soil or unfrozen soil), as well as constituent concentrations, loads, and yields. They also included constituent concentrations for QC samples taken throughout the water year. The datasummary spreadsheets were the primary form of shared data for edge-of-field stations for the Discovery Farms and Pioneer Farm programs.

\section{Water-Quality Data Analyses}

The next step of data analysis for edge-of-field stations was to organize all the water-quality constituent concentrations from the WEAL and enter them into the USGS QWDATA database (U.S. Geological Survey, 2006b).

Results were received from the WEAL via email throughout the year as they were released. When the results were received, they were matched to the appropriate sampled runoff events based on station name, event identification number, and sample start and end time. The constituent concentrations and any associated laboratory codes were then copied and pasted into the data-summary spreadsheet for each station. After the spreadsheet had been checked and finalized at the end of the water year, the water-quality data were imported into the QWDATA database.

\section{Estimating Constituent Concentrations for Unsampled Runoff Events}

Few runoff events were not sampled at the edge-offield stations. Annual sample-volume coverage for the edge-of-field stations was typically 90 percent or greater. In order to determine annual constituent loads, event-mean concentrations were estimated for runoff events that were not sampled by substituting concentrations from similar runoff events that were sampled during similar time periods. First, all sampled runoff events were evaluated to determine whether they represented a "typical" runoff event for a particular time period. Anomalous events were considered to be events influenced by on-farm activities that were not representative of the yearly farm activities, such as construction activities. Anomalous events that were sampled were included in the calculations for annual load, but they were not used to estimate concentrations for unsampled runoff events. Runoff events that had poor 
sample coverage (generally less than four discrete samples per runoff event) also were not used to estimate concentrations for unsampled runoff events.

Runoff events were compared with regard to date of runoff, total volume, peak discharge, and characteristics of precipitation that induced the surface-water runoff event (precipitation depth and intensity). Event-mean concentrations from the sampled runoff event that most represented the qualities of the unsampled event were then used as estimates for the unsampled event. The annual load was determined by summing loads for sampled and unsampled runoff events.

\section{Streamgaging Stations}

\section{Water-Quantity Data Analyses}

Data analysis for streamgaging stations was similar to data analysis at edge-of-field stations; the first step of which was to correct the stage record supplied by the dataloggers. All Discovery Farms streamgaging stations were monitored with $\mathrm{H}$ flumes in which the stage readings were converted to discharge by use of a predetermined rating. Data corrections and any other necessary data modifications were applied in the same manner as with edge-offield stations.

Flumes were not used at streamgaging stations for at Pioneer Farm. Rather, discharge was computed from a stage-discharge relation that was determined from multiple measurements of discharge (Garn, 2002). As with edge-offield stations, data corrections were made for differences between actual stream stage (measured from a known datum) and datalogger stage; however, additional steps were required to ensure that discharge data were accurate.

Discharge measurements were made every 3 weeks and during periods of high discharge. A base rating that best represented the relation between stage and discharge was constructed with these measurements. Throughout the year, discharge measurements were compared to the rating to determine whether corrections were necessary to adjust the base rating so that it was representative of the actual discharge conditions. Corrections were often necessary for ice cover in winter and vegetative growth in the stream channel during summer. Runoff events that scoured or deposited sediment in the stream channel often necessitated corrections or rating modification.

Unlike edge-of-field stations, events at streamgaging stations were assumed to begin when the stage or discharge hydrograph increased above base flow and ended when there was no overland flow component and a mini- mal bank storage component. Start- and end-time determinations were made before splitting records were prepared, so the event-sample volume was usually the same as the total-event volume for streamgaging stations.

Once the discharge record was completed, checked, and approved, an analysis for significant, unsampled runoff events greater than 0.1 percent of the total annual volume (including base flow) was done. The discharge hydrograph for each unsampled-runoff event was plotted on paper and start and end times were determined by use of the graphical method described earlier; runoff-event volumes then were calculated. These significant, unsampled runoff events were used in the analysis of water-quality data for streamgaging stations.

Data-summary spreadsheets were compiled for streamgaging stations in a similar fashion to edge-offield stations, with the start and end time of runoff events, percentage of event volume sampled, number of discrete samples per event, peak discharge, precpitation depth and intensity, constituent concentrations, and so forth. Data-summary spreadsheets for streamgaging stations were different from edge-of-field stations in that they did not include discharge data for the entire water year. Only sampled runoff events and those unsampled events deemed significant were included. Data-summary spreadsheets for streamgaging stations also contained constituent concentrations for monthly base-flow samples.

For these reasons, data-summary spreadsheets were not considered to be the primary form of shared data for streamgaging stations for the Discovery Farms and Pioneer Farm programs. Rather, additional data processes were necessary to create a supplementary document that described the entire water year for event- and base-flow components.

\section{Water-Quality Data Analyses}

Water-quality data for streamgaging stations were received from the WEAL and entered into QWDATA by the same process as for edge-of-field stations. The Buffalo County stations were an exception because analyses were done at the WSLH. For these stations, concentration data were transmitted from the WSLH database to the WWSC, and results were subsequently uploaded to the QWDATA database throughout the year. 


\section{Estimating Constituent Concentrations for Significant Unsampled Runoff Events}

In order to accurately determine annual constituent loads for streamgaging stations, it was sometimes necessary to estimate constituent concentrations for significant, unsampled runoff events. Significant runoff events were considered to be those representing greater than 0.1 percent of the annual discharge. Small (yet significant) unsampled events were those between 0.1 and 2 percent of the annual discharge, whereas large, unsampled events were those 2 percent or more of the annual discharge. Runoff events representing less than 0.1 percent of the annual discharge were considered insignificant.

Estimated concentrations for small and large unsampled runoff events were determined differently. Constituent concentrations for small, unsampled events were estimated in a manner similar to that described for edge-of-field stations. Runoff events were compared with regard to date of runoff, total volume, peak discharge, and the precipitation characteristics that caused the runoff event (precipitation amount and intensity). Event-mean concentrations from the sampled runoff event that most represented the qualities of the unsampled event were then used as estimates.

Constituent concentrations for large, unsampled events were estimated by use of regressions of multiple variables including runoff volume, precipitation amount and intensity, peak discharge, and season. Multiple years of data were usually necessary to obtain a wide range of runoff events for satisfactory regression tests. Only data for sampled-runoff events were used in the regressions.

\section{Daily and Annual Load Computation}

The next step of the data-analysis process for streamgaging stations was to determine the daily and annual constituent loads. Event-mean concentrations for sampled and unsampled events were organized by start and end time in a spreadsheet. Monthly base-flow constituent concentrations were used within the spreadsheet to represent stream conditions from the time immediately after an event ended to the time at which the next event began. The spreadsheet data were then imported into the Graphical Constituent Loading Analysis System (GCLAS) (Koltun and others, 2006), which was used to compute a daily load for each constituent. Annual loads were computed by summing all of the daily loads.

To better understand the interactions between agricultural practices and stream-water quality, it was often useful to separate streamflow into base-flow and event-flow com- ponents. On-farm practices that contributed to runoff could then be correlated to the event-flow loads, whereas baseflow loads could be used to determine the contribution by ground water and/or on-farm practices that contributed to ground water. The USGS Hydrograph Separation Program (HYSEP) (Sloto and Crouse, 1996) was used to separate daily discharges and constituent loads into base-flow and event-flow components.

Data spreadsheets with daily constituent load, daily discharge, and daily base-flow and event-flow components were compiled for each streamgaging station. These spreadsheets, in addition to the data-summary spreadsheets, were the primary forms of shared data for streamgaging stations for the Discovery Farms and Pioneer Farm programs.

\section{Subsurface-Tile Stations}

\section{Water-Quantity Data Analyses}

Data analysis for subsurface-tile stations was similar to data analysis at edge-of-field and streamgaging stations, the first step of which was to correct the stage record. All Discovery Farms subsurface-tile stations were monitored with trapezoidal flumes in which the stage readings were converted to discharge by use of a predetermined rating. Data corrections and any other necessary data modifications were applied in the same manner as with edge-offield stations.

There were occasional and brief periods where the capacity of the flume at the in-field subsurface-tile stations was exceeded (surcharging), resulting in stage data that did not accurately represent discharge. These surcharge periods were typified by an abrupt increase in stage, followed by a steep recession, and then by an abrupt transition to a period of gradual recession (fig. 28). The discharge at the transition stages was assumed to be the maximum tilecapacity discharge. This assumption was verified by periodic measurements of velocity (and thus discharge) during surcharge periods. Discharge during periods of surcharge was edited in NWIS using HYDRA.

In addition to extended periods of surcharge, variable backwater conditions were observed at the subsurface-tile station in Manitowoc County. Backwater differed from surcharge in that the discharge for a given stage was variable depending on downstream conditions. Velocity meters were installed to determine a velocity-stage-discharge relation to obtain a more accurate record of discharge.

Data-summary spreadsheets were compiled for subsurface-tile stations in a similar fashion to those for 


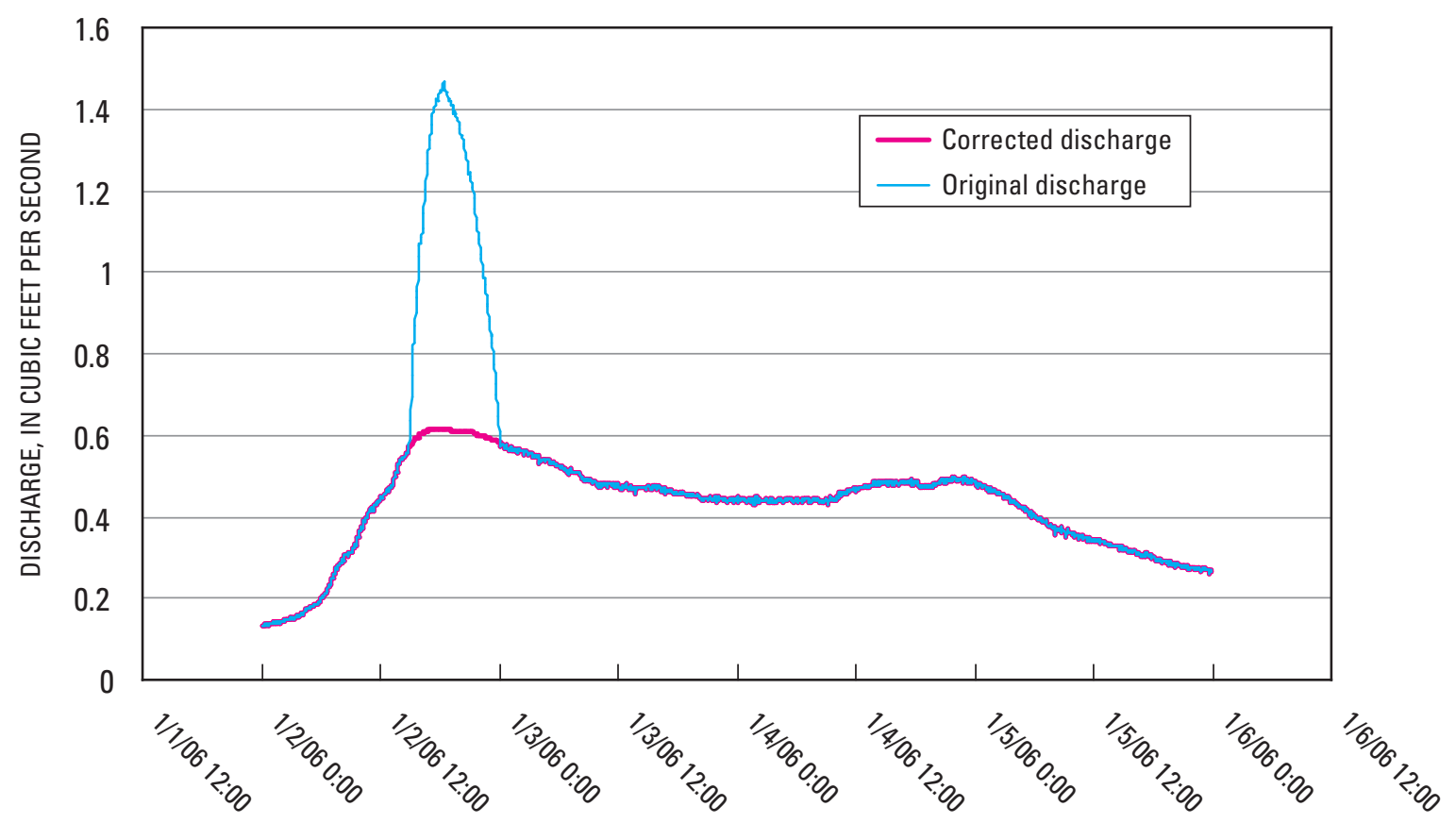

Figure 28. Example of corrections made to discharge data due to surcharge conditions in a subsurface tile.

edge-of-field stations, with the start and end time of runoff events, percentage of event volume sampled, number of discrete samples per event, peak discharge, precipitation depth and intensity, constituent concentrations, and so forth. The data-summary spreadsheets were considered to be the primary form of shared data for subsurface-tile stations for the Discovery Farms program.

\section{Water-Quality Data Analyses}

Water-quality data for subsurface-tile stations were received from the WEAL and entered into QWDATA by the same process as for edge-of-field and streamgaging stations.

\section{Estimating Constituent Concentrations for Significant Unsampled Runoff Events}

After the spreadsheet was checked and finalized at the end of the water year, constituent concentrations were loaded from the spreadsheet into the QWDATA database. Event-mean concentrations from sampled-runoff events that most represented the qualities of unsampled events were used as estimates for unsampled events. Annual sample-volume coverage for subsurface-tile stations was typically 90 percent or greater. The annual load was determined by summing loads for sampled and unsampled runoff events.

\section{Meteorological Data}

Data analysis for meteorological stations primarily involved correcting and checking the precipitation record. The tipping-bucket precipitation gages were not heated, so data interpreted to be frozen precipitation melting in the precipitation-gage funnel were removed from the record. HYDRA was used to determine these periods by plotting precipitation data with air temperature, relative humidity, solar radiation, and discharge data. Spurious data created by field personnel during station visits also were removed from the record at this time.

Additional corrections made to the precipitation data were based on calibrations that were done at least once per year. A calibration was done by putting a known amount of water into the precipitation-gage funnel at an equivalent rate of approximately 2 inches per hour. If the amount of water measured by the precipitation gage was greater than 5 percent different from the expected value, a correction was applied in ADAPS for this difference. The correction was usually prorated from the previous calibration, unless 
observations indicated that the correction should have been applied at a different date.

Occasionally, a precipitation gage did not operate properly due to clogging or other operational issues. Data from a precipitation gage at a water-quality station located within several miles (although usually much closer, less than half a mile) of the precipitation gage in question were substituted for the period of missing or inaccurate record. The substitution of precipitation-gage data from one station to another was documented and only done when runoff characteristics between the gages were similar, indicating similar precipitation. Incidents where precipitation data were substituted between precipitation gages were marked as estimated.

Once corrected and checked, the daily sum precipitation data were approved in NWIS. A station-analysis document was then created to describe the conditions at the station during the year and to detail extreme events, all data corrections, and any other corrections that were deemed necessary.

In addition to the NWIS-published daily precipitation amounts, computations were made for individual precipitation events. Precipitation amount, maximum 5-, 10-, 15-, 30-, and 60-minute precipitation intensity, and the Universal Soil Loss Equation erosivity index also were computed for all individual precipitation events throughout the water year. The precipitation amount and erosivity index values were used to populate the data-summary spreadsheets for water-quality stations. All other meteorological data were stored in NWIS, but not published.

\section{Summary and Conclusions}

The University of Wisconsin-Madison Discovery Farms and University of Wisconsin-Platteville Pioneer Farm programs were created in 2000 to help Wisconsin farmers meet environmental and economic challenges. As a partner with each program, and in cooperation with the Wisconsin Department of Natural Resources and the Sand County Foundation, the U.S. Geological Survey (USGS) Wisconsin Water Science Center (WWSC) installed, maintained, and operated equipment to collect water-quantity and water-quality data from 25 edge-of-field, 6 streamgaging, and 5 subsurface-tile stations at 7 Discovery Farms and Pioneer Farm. The farms are located in the southern half of Wisconsin and represent a variety of landscape settings and crop- and animal-production enterprises common to Wisconsin agriculture. Meteorological stations were established at most farms to measure precipitation, wind speed and direction, air and soil temperature (in profile), relative humidity, solar radiation, and soil moisture (in profile). Data collection began in September 2001 and is continuing through the present (2008).

This report describes methods used by USGS WWSC personnel to collect, process, and analyze water-quantity, water-quality, and meteorological data for edge-of-field, streamgaging, subsurface-tile, and meteorological stations at Discovery Farms and Pioneer Farm from September 2001 through October 2007. Information presented includes equipment used; event-monitoring and samplecollection procedures; station maintenance; sample handling and processing procedures; water-quantity, waterquality, and precipitation data analyses; and procedures for determining estimated constituent concentrations for unsampled runoff events.

Edge-of-field, streamgaging, and subsurface-tile stations typically used similar equipment to monitor and collect water-quantity and water-quality data throughout the year. Aluminum, clam-style equipment enclosures were placed at each monitoring location to contain equipment. Nonsubmersible pressure transducers coupled with a nitrogen bubbling system were used to monitor stages in $\mathrm{H}$ flumes, trapezoidal flumes, or open stream channels. Discharges were computed from the stage-discharge relations determined for each flume or from periodic measurements of open-channel flow. Flume levels were routinely recorded to ensure rating accuracy.

Automated, refrigerated, 24-bottle ISCO 3700R samplers were used to collect discrete, time-paced and volumepaced water samples during runoff events. A specialized datalogger program executed by Campbell Scientific, Inc. CR10 and CR10X dataloggers was used to read, store, and control sensors and devices at each station. A combination of land telephone lines, Campbell Scientific, Inc. RF400 spread-spectrum radio/modems, and Air-Link Communications, Inc. Raven cellular modems was used to allow two-way datalogger communication. Two-way telemetry, coupled with Campbell Scientific, Inc. PC208W and Real Time Data Monitor (RTDM) retrieval and data-display software, greatly enhanced ability to determine runoff conditions, change sample frequency, and determine equipment functionality. Virtual Private Network (VPN) and Remote Desktop Connection (RDC) software were used to gain authenticated and secure access to real-time datalogger data from any properly configured computer having Internet access or a connected phone modem.

Discrete water samples collected by the ISCO automated samplers were generally retrieved within 24 hours of the end of a runoff event. Prior to sample analyses, a 
"splitting record" was developed for each runoff event that contained time-series data for stage, discharge, precipitation, and selected sample information. On the basis of the splitting record, appropriate aliquots from each discrete sample were combined to create a single, composite sample. This sample was then analyzed for sediment, nutrients, and other selected constituents - the concentrations of which represented the average or event-mean concentration of the runoff event. Constituent concentrations from this composite sample were multiplied by the runoff-event volume to compute runoff-event loads and yields.

Field blanks and cross-section coefficient samples were collected to determine whether contamination was introduced by the entire sampling process or whether constituent concentrations in the automatic, discrete samples (which were pumped from a single point at the tip of the sample-intake line) were representative of the constituent concentrations in the cross section of the water column.

Data analysis was done in a similar fashion for each monitoring station. In all cases, the gage-height record was corrected for a variety of reasons including sensor drift, freezing, and algal growth. The discharge was computed from the stage-discharge relation determined for each flume size and type. A station-analysis document was created to describe the discharge conditions at the station during the year and to provide detail for extreme runoff events, all data and shift corrections, and any other corrections that were deemed necessary. Data analysis for meteorological stations primarily involved correcting and checking the precipitation record. Precipitation gages were calibrated at least once per year.

Water-quality data were received from the laboratory and entered into the USGS QWDATA database, and spreadsheets were populated for each monitored station. These spreadsheets contained the start and end time of runoff events, percentage of event volume sampled, number of discrete samples per event, peak discharge, precipitation depth and intensity, constituent concentrations, and event and annual loads and yields. To compute annual loads for each station, sampled and unsampled runoff events needed to be summed. For all station types, unsampled runoff events typically represented less than 10 percent of the annual load. Event-mean concentrations for small unsampled events were estimated by substituting concentrations from similar, sampled runoff events that occurred during similar time periods. Constituent concentrations for large, unsampled runoff events were estimated by use of regressions of multiple variables including runoff volume, precipitation amount and intensity, peak discharge, and season. Data from multiple years were usually necessary to obtain a range of runoff events to perform satisfactory regression analyses. Only data for sampled runoff events were used in the regressions.

Additional steps were taken to complete the data analysis for streamgaging stations. Discharge and constituent-load data were separated into base-flow and event-flow components for these stations. On-farm practices that contributed to overland flow could be used to correlate to the runoff-event loads, whereas base-flow loads could be used to determine the contribution from ground water and/or on-farm practices that contributed to ground water. Spreadsheets with daily constituent load and discharge (and the base-flow and event-flow components) were compiled for each streamgaging station.

\section{Acknowledgments}

The authors would like to thank the following participants for building the programs for which the methods were applied: Dennis Frame (Discovery Farms Co-Director), Frederick Madison (Discovery Farms Co-Director), and Thomas Hunt (formerly the Director of Research and Outreach at Pioneer Farm).

\section{References}

Buchanan, T.J., and Somers, W.P., 1969, Discharge measurements at gaging stations: U.S. Geological Survey Techniques of Water-Resources Investigations, book 3, chap. A8, 65 p.

Garn, H.S., 2002, Surface-water quality-assurance plan for the Wisconsin District of the U.S. Geological Survey, Water Resources Division: U.S. Geological Survey Open-File Report 02-30, 52 p.

Groetsch, K.J., and Coleman, J., 2001, Tribal monitoring of stream flow in Swamp Creek, Forest County, Wisconsin: QAPP prepared by the Great Lakes Indian Fish and Wildlife Commission under grant X-995574-01.

Koltun, G.F.; Eberle, Michael; Gray, J.R.; and Glysson, G.D., 2006, User's manual for the Graphical Constituent Loading Analysis System (GCLAS): U.S. Geological Survey Techniques and Methods 4-C1, $51 \mathrm{p}$.

Linsley, R.K., Jr., Kohler, M.A., and Paulhus, J.L.H., 1982, Hydrology for engineers ( $3 \mathrm{~d}$ ed.): New York, McGrawHill, 508 p. 
Mathey, S.B., ed., 1998, National Water Information System (NWIS): U.S. Geological Survey Fact Sheet FS-027-98, 2 p.

Moran, J.M., and Hopkins, E.J., 2002, Wisconsin's weather and climate: Madison, Wis., University of Wisconsin Press, $321 \mathrm{p}$.

Porterfield, George, 1972, Computation of fluvial-sediment discharge: U.S. Geological Survey Techniques of Water-Resources Investigations, book 3, chap. C3, 66 p.

Rantz, S.E., and others, 1982, Measurement and computation of streamflow; Volume 1, Measurement of stage and discharge: U.S. Geological Survey Water-Supply Paper 2175, 313 p.

Richards, K.D., Elder, J.F., and Corsi, S.R., 2006, Qualityassurance plan for water-quality activities in the Wisconsin Water Science Center: Unpublished document on file at the U.S. Geological Survey Wisconsin Water Science Center, Middleton, Wis.

Sloto, R.A., and Crouse, M.Y., 1996, HYSEP-A computer program for streamflow hydrograph separation and analysis: U.S. Geological Survey Water-Resources Investigations Report 96-4040, 46 p.

U.S. Geological Survey, Wisconsin District, Data Archiving and Management Process Action Team, 2000, Policy recommendations for issues regarding the archival and management of hydrologic information, and plan and guidance for the management and archiving of hydrologic data in the Wisconsin District: Unpublished document on file at the U.S. Geological Survey Wisconsin Water Science Center, Middleton, Wis., 28 p.

U.S. Geological Survey, 2005, Use of the program HYDRA to estimate or modify unit values in ADAPS: Office of Surface Water Technical Memorandum 2005.07, accessed August 7, 2007 at http://water.usgs. gov/admin/memo/SW/sw05.07.html

U.S. Geological Survey, 2002, NWISWeb-New site for the Nation's water data: U.S. Geological Survey Fact Sheet $128-02,2$ p.

U.S. Geological Survey, 2006a, User's manual for the National Water Information System of the U.S. Geological Survey: Water-quality system: U.S. Geological Survey Open-File Report, version 4.6, 400 p.

U.S. Geological Survey, 2006b, User's manual for the National Water Information System of the U.S. Geological Survey: Automated Data Processing System (ADAPS): U.S. Geological Survey Open-File Report, version 4.6, $427 \mathrm{p}$.
Wisconsin Legislative Fiscal Bureau, 2001, Agricultural Stewardship Initiative (UW System): Wisconsin Joint Committee on Finance Paper \#955, LFB 2001-03, Budget Summary: Page 687, \#15, accessed March 14, 2007 , at http://www.legis.state.wi.us/lfb/2001-03budget/200103budgetpapers/955.pdf 


\section{Appendixes}


Appendix 1. Example of a sample-retrieval sheet.

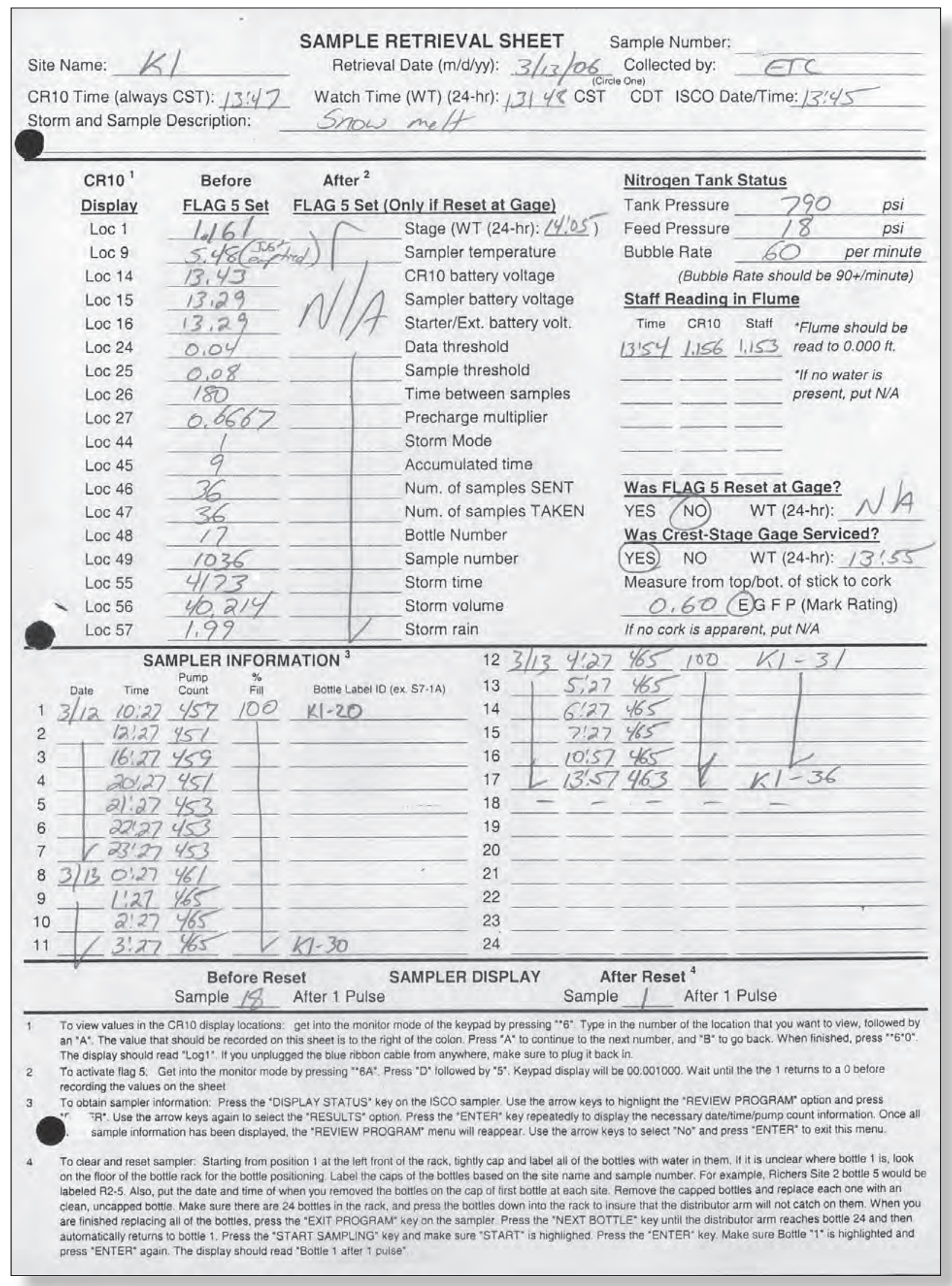


Appendix 2. Example of a miscellaneous-note sheet.

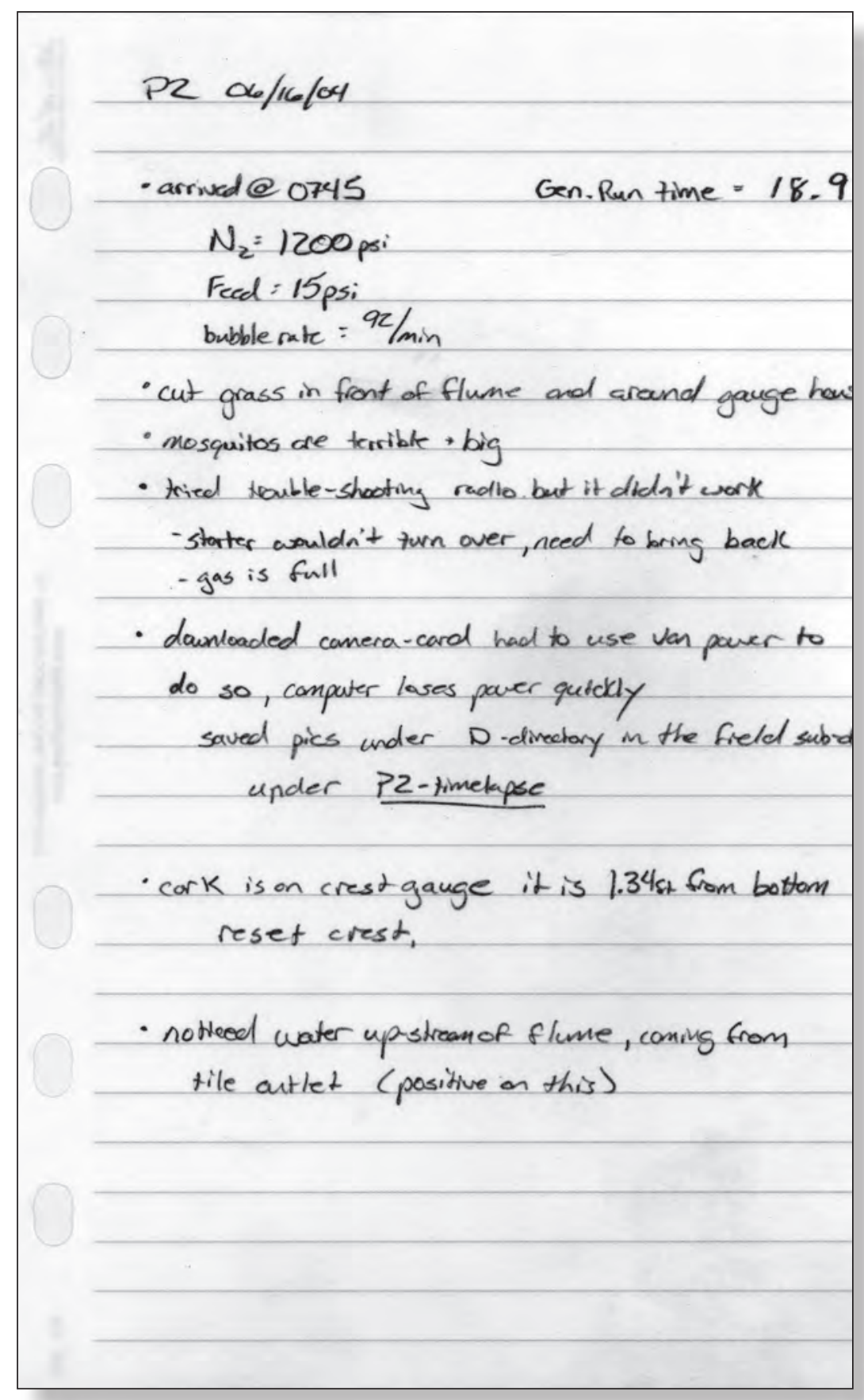




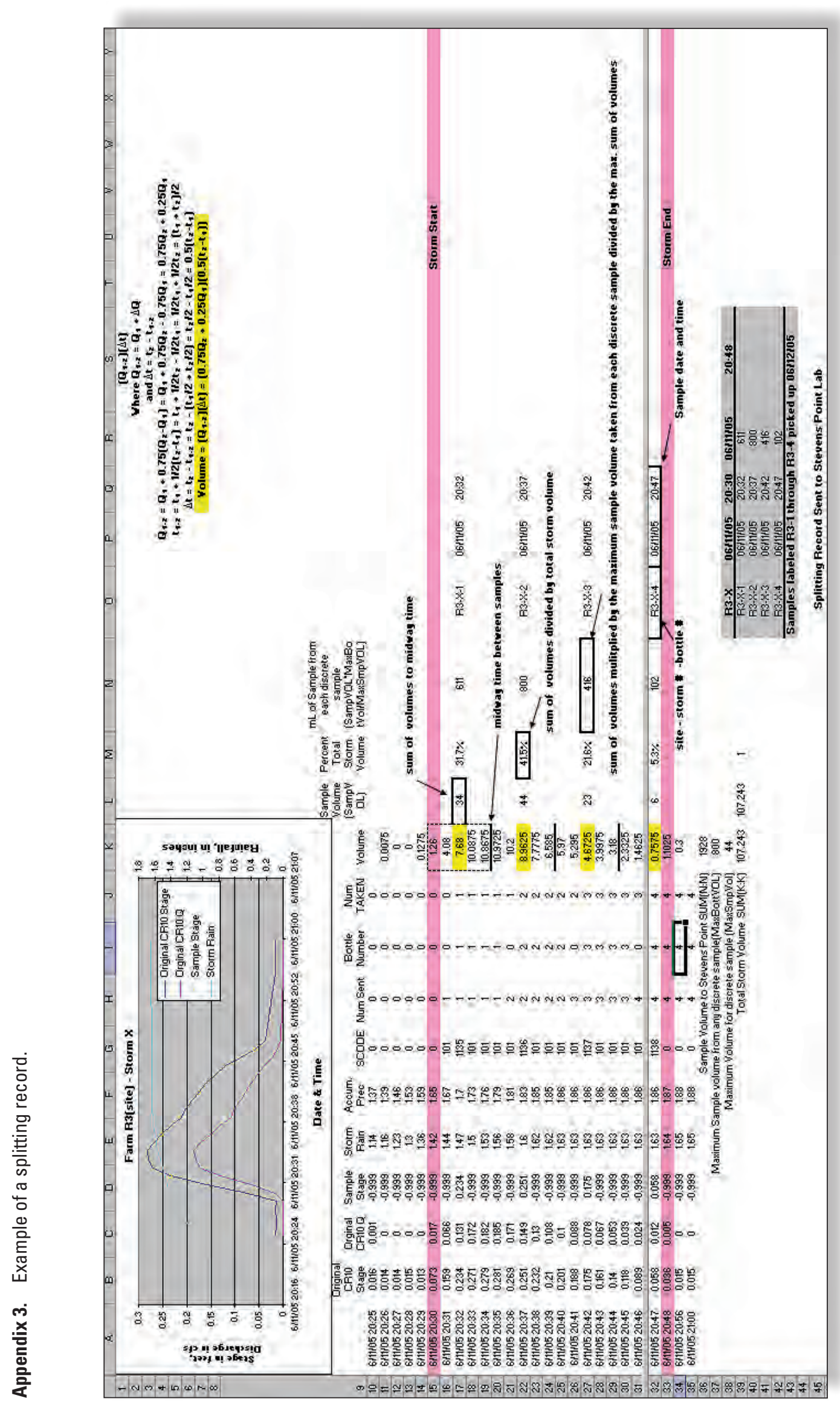


Appendix 4. Example portion of a data-summary spreadsheet.

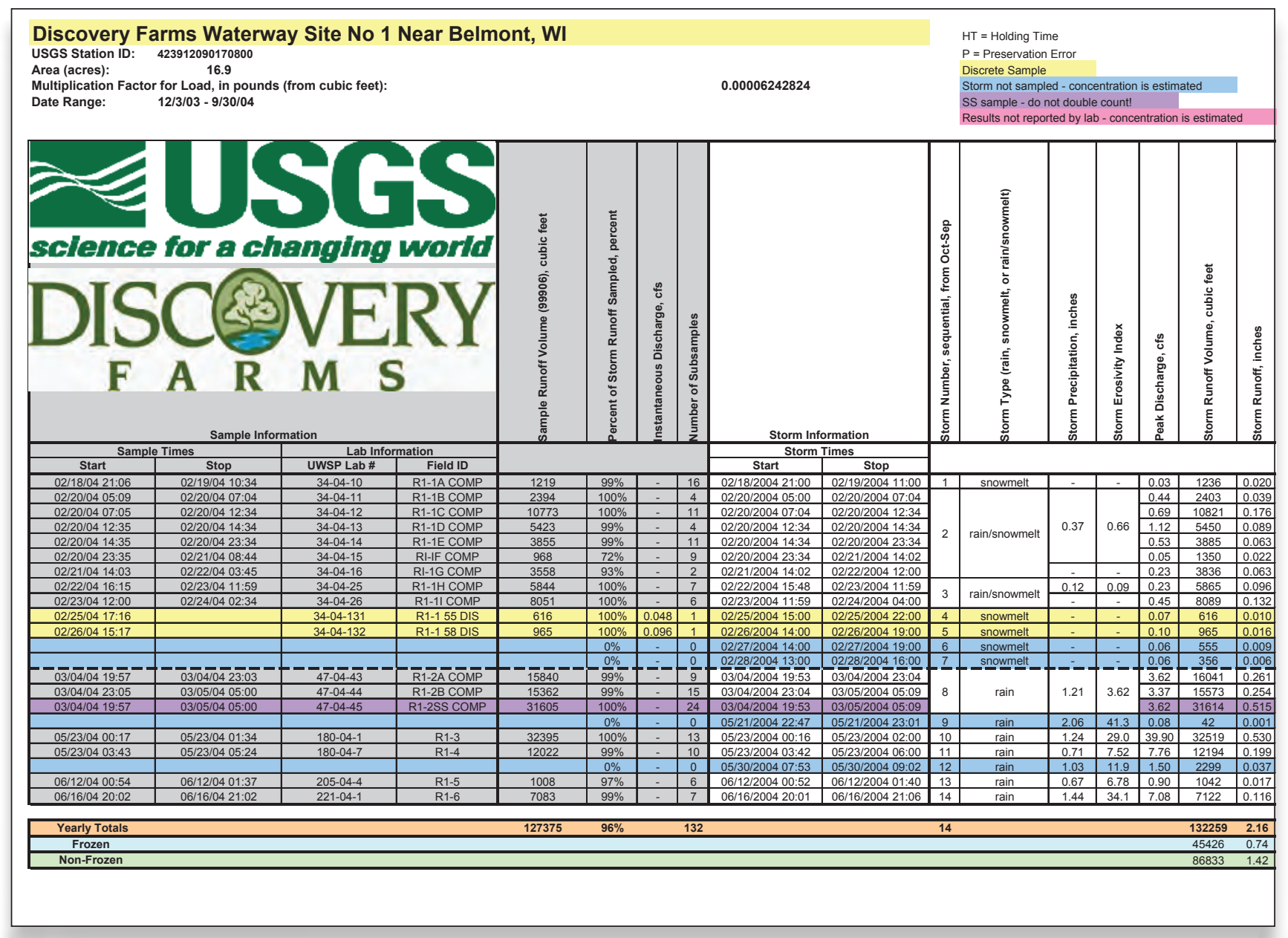


Appendix 4. Example portion of a data-summary spreadsheet—Continued.

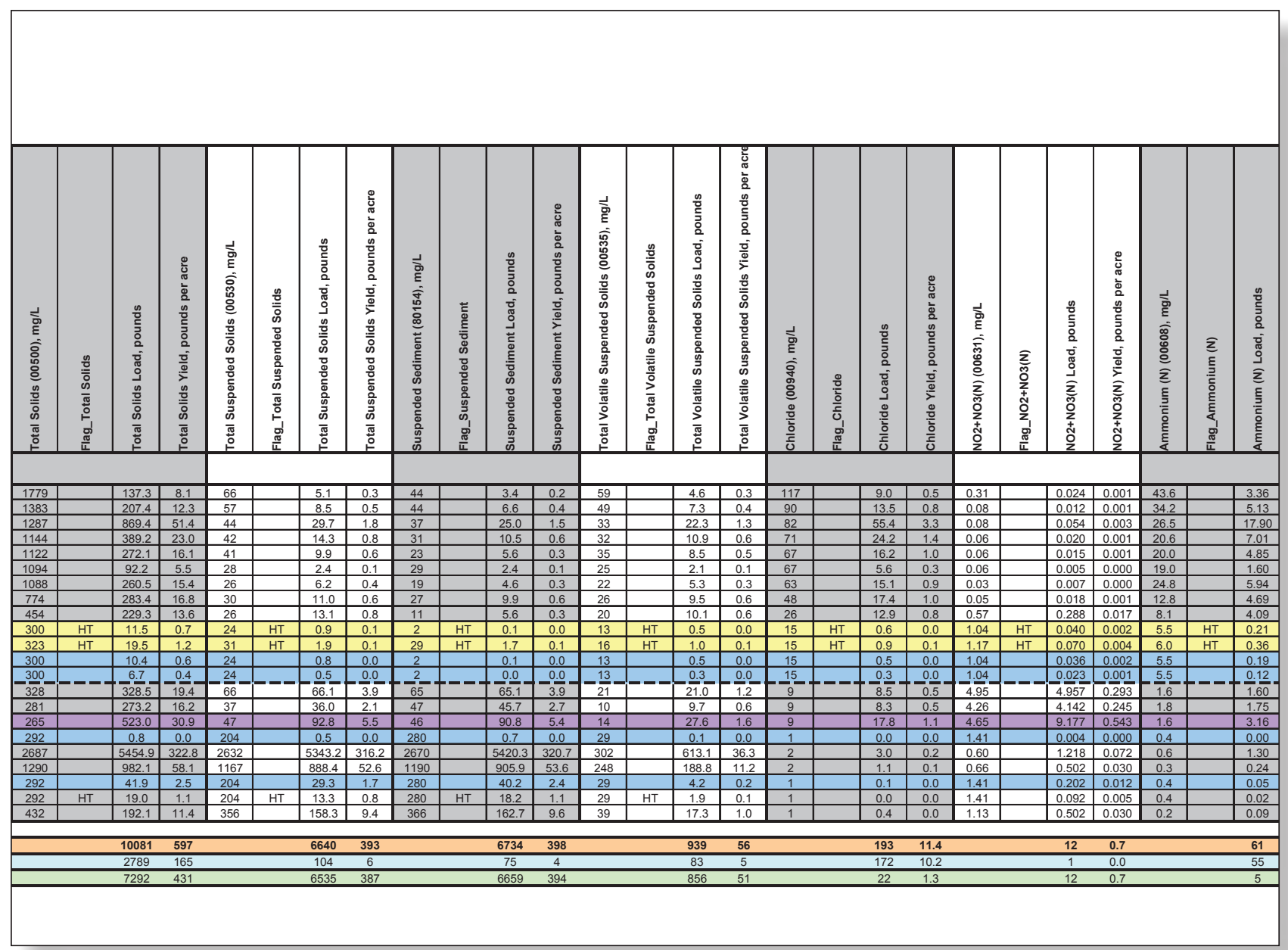


Prepared by the Wisconsin Water Science Center:

U.S. Geological Survey

Wisconsin Water Science Center

8505 Research Way

Middleton, WI 53562

tel: (608) 828-9901

fax: (608) 821-3817

This publication is available online at URL:

http://pubs.water.usgs.gov/ofr2008-1015

Information regarding the Wisconsin Water Science Center is available at URL:

http://wi.water.usgs.gov 